TALITHA NICOLETTI

ESTUDO DA RESISTÊNCIA SÉRIE DE FONTE E DRENO DE TRANSISTORES SOI FinFETS DE PORTA TRIPLA E COM CANAL TENSIONADO

São Paulo 2009 


\title{
TALITHA NICOLETTI
}

ESTUDO DA RESISTÊNCIA SÉRIE DE FONTE E DRENO DE TRANSISTORES SOI FinFETS DE PORTA TRIPLA E COM CANAL TENSIONADO

\author{
Dissertação apresentada à Escola \\ Politécnica da Universidade de São \\ Paulo para obtenção do título de \\ Mestre em Engenharia \\ Área de concentração: Microeletrônica \\ Orientador: Prof. Dr. \\ João Antonio Martino
}

São Paulo 


\section{FICHA CATALOGRÁFICA}

\section{Nicoletti, Talitha}

Estudo da resistência série de fonte e dreno de transistores SOI FinFETs de porta tripla e com canal tensionado / T. Nicoletti.

-- São Paulo, 2009. $134 \mathrm{p}$.

Dissertação (Mestrado) - Escola Politécnica da Universidade de São Paulo. Departamento de Engenharia de Sistemas Eletrônicos.

1. Transistores 2. Circuitos integrados MOS 3. Microeletrô nica I. Universidade de São Paulo. Escola Politécnica. Departamento de Engenharia de Sistemas Eletrônicos II. t. 


\section{DEDICATÓRIA}

Dedico este trabalho aos meus pais que muito amo e aos quais muito devo. 
Ser um campeão incansável onde a linha de chegada é o ponto de partida para o próximo desafio. (autor desconhecido) 


\section{AGRADECIMENTOS}

Ao professor e orientador João Antonio Martino pela amizade construída, orientação cuidadosa, seu incentivo e confiança depositada.

Ao professor Salvador Pinillos Gimenez pela fraterna amizade e admiração que se iniciou na graduação e segue no caminhar desta estrada acadêmica.

Às amigas veteranas do grupo, Carolina, Milene, Michele, Michelly e Paula em quem me inspirei quando entrei neste grupo, por suas realizações acadêmicas e profissionais.

Às amigas Sara e Glória pelos bons momentos de alegria, carinho e valiosa amizade.

Ao Laboratório de Sistemas Integráveis da Escola Politécnica da Universidade de São Paulo pela disponibilidade da infra-estrutura necessária para essa atividade de pesquisa.

Aos meus pais, pelo exemplo de vida e por tudo que me ensinaram.

À minha irmã Daphne, por sua determinação e amizade.

Ao meu noivo Daniel, por todo o incentivo e por estar comigo em todos os momentos.

A tantas outras pessoas, que de alguma forma colaboraram para a realização desse trabalho e que, de forma involuntária foram aqui omitidos. 


\section{RESUMO}

Este trabalho apresenta o estudo do comportamento da resistência série de fonte e dreno em transistores SOI FinFET de porta tripla e com canal tensionado. Nos dispositivos SOI FinFETs há um aumento da resistência série de fonte e dreno devido ao estreitamento dessas regiões, sendo esse parâmetro considerado como uma das limitações quanto à introdução desses dispositivos em tecnologias futuras. O uso de tensão mecânica no canal dos dispositivos surge como alternativa para aumentar a condução de corrente através do aumento da mobilidade dos portadores do canal, reduzindo assim, a resistência total dos transistores e, conseqüentemente, a resistência série de fonte e dreno. Inicialmente, foi feito o estudo de alguns métodos de extração da resistência série de fonte e dreno existentes na literatura, com o objetivo de se obter o mais adequado para aplicação e análise posterior. Esse trabalho foi realizado baseado em resultados experimentais e em simulações numéricas que possibilitaram o entendimento físico do fenômeno estudado. A resistência série de fonte e dreno foi explorada em diferentes tecnologias, como transistores SOI FinFETs de porta tripla convencionais e sob influência de tensionamento uniaxial e biaxial. O uso do crescimento seletivo epitaxial (SEG) nas regiões de fonte e dreno altamente dopadas das diferentes tecnologias também foi analisado, pois com essa técnica, a resistência série de fonte e dreno é reduzida substancialmente não comprometendo a condução de corrente e a transcondutância. Os resultados obtidos das diferentes tecnologias com e sem o uso de SEG foram analisados e comparados mostrando que em transistores SOI FinFETs de porta tripla, com crescimento seletivo epitaxial, apresentam o menor valor da resistência série de fonte e dreno mesmo para aqueles sem tensão mecânica na região do canal.

Palavras-chave: Tecnologia SOI. FinFETs. Resistência Série de Fonte e Dreno. Crescimento Seletivo Epitaxial. Transistores com canal tensionado. 
This work presents the study of the source and drain series resistance behavior in standard and strained SOI FinFETs triple gate transistors. In SOI FinFETs transistors there is an increase of the source and drain series resistance due to the narrow of these regions, being this parameter a key limiting factor to the next generations. The use of strained transistors is one of the potential technologies to the next generation high performance because it increase the drive current through an enhance in the carrier mobility, decreasing the transistor's total resistance and, therefore, the source and drain series resistance. Initially, a study of some series resistance extraction methods, present in the literature was done, in order to obtain the most appropriate for applications and analysis subsequent. This work was done based on experimental results and numerical simulations, enabling the physical understanding of the phenomenon studied. The series resistance was explored in different technologies, as standard SOI FinFETs triple gates and with uniaxial and biaxial strain. The use of selective epitaxial growth (SEG) in the source and drain regions, with high doping levels, was also studied in the different technologies, because with the use of this technique, the series resistance decreases substantially without compromising the drive current and transconductance. The obtained results from the different technologies with and without the use of SEG were analyzed and compared showing that, SOI FinFETs triple gate transistors with SEG present the lower values of series resistance even for standard devices if compared with strained ones without the use of SEG.

Key-words: SOI technology, FinFETs. Source and drain series resistance. Selective Epitaxial Growth. Strained transistors. 


\section{LISTA DE FIGURAS}

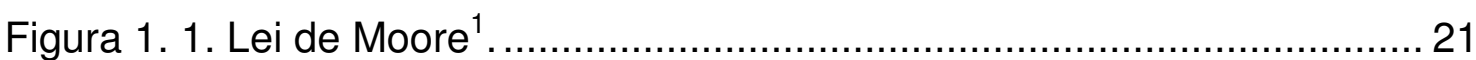

Figura 1. 2. Estrutura de FinFETs com múltiplos fins (IMEC, Bélgica)............. 22

Figura 2. 1. Perfil transversal de um transistor SOI nMOSFET........................ 25

Figura 2. 2. Diagrama de faixas de energia para transistores nMOSFETs (a) com tecnologia MOSFET convencional, (b) com tecnologia SOI parcialmente depletado e (c) com tecnologia SOI totalmente depletado............................. 28 Figura 2. 3. Distribuição das regiões de depleção em transistores (a) MOSFETs convencionais e (b) SOI totalmente depletados............................................ 33 Figura 2. 4. Tensão de limiar em função do comprimento de porta de um dispositivo MOSFET convencional e de um SOI MOSFET canal $\mathrm{n}$ totalmente

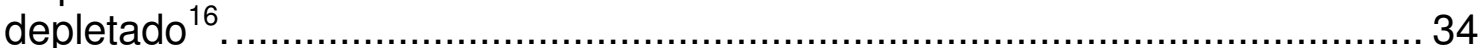

Figura 2. 5. Evolução dos transistores SOI MOSFETs. ................................. 38

Figura 2. 6. Exemplos de estruturas de porta dupla e tripla SOI MOSFETs (a) Transistor XMOS, (b) DELTA MOSFET.................................................. 39 Figura 2. 6. Exemplos de estruturas de porta dupla, (c) FinFET e (d) GAA MOSFET. .................................................................................... 40

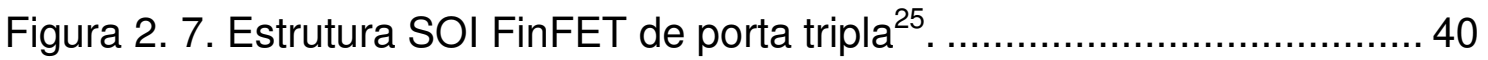

Figura 2. 8. Seção transversal das estruturas de Porta $\Omega$, onde r_sup é diferente de $r$ inf (a); e Porta $\Pi$, onde $r \_s u p$ é igual a $r$ inf (b) . ......................4 41 Figura 2. 9. Seção transversais de transistores FinFET's de Porta $\Pi$ e Porta $\Omega$. 42

Figura 2. 10. Distribuição de potencial em transistores FinFETs de Porta tripla

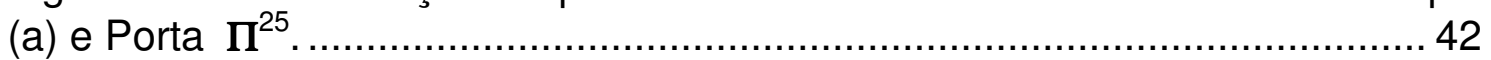
Figura 2. 11. Diferentes configurações de Porta de transistores SOI MOSFETs.

Figura 2. 12. Estrutura de múltiplos "dedos" (multi-fins)................................. 44 Figura 2. 13. Definição do sistema de coordenadas de um dispositivo de múltiplas portas ${ }^{16}$ 45

Figura 2. 14. Derivada da curva de gm em função da tensão aplicada na porta para FinFETs de porta tripla+ com diferentes concentrações de dopantes e com raio de curvatura $\quad r_{-}$sup $=r_{-} \boldsymbol{i n f}=\mathbf{1} \mathbf{m m} 1616^{16} \ldots \ldots \ldots \ldots \ldots \ldots \ldots \ldots . . . \ldots \ldots$ Figura 3. 1. Principais componentes da resistência série de fonte e dreno de um transistor SOI nMOSFET. 51

Figura 3. 2. Seção transversal de um transistor de múltiplas portas mostrando as componentes da resistência série de fonte e dreno. .................................5 54 Figura 3. 3. Resistências da região do canal de um dispositivo MOSFET....... 55 Figura 3. 4. Resistência total da região do canal em função do comprimento de máscara para diferentes tensões aplicadas na porta ${ }^{50}$. 57

Figura 3. 5. Obtenção da resistência extrínseca $R_{0}$ e do termo $\Delta L$ diretamente

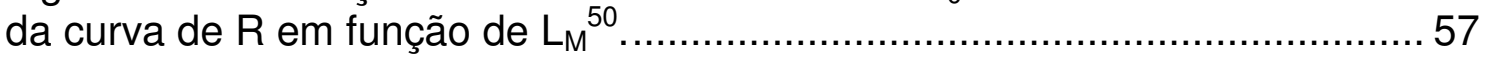
Figura 3. 6. RTOTAL em função de $L_{M}$ para duas polarizações de porta de valores aproximados ${ }^{47}$.... 59 Figura 3. 7. Componentes da $\mathrm{R}_{\mathrm{SD}}$ como conectadas no modelo analítico. Os índices adicionais '1' e '2' em $R_{\mathrm{sp} 1}$ e $\mathrm{R}_{\mathrm{sp} 2}$ são usados com intuito de representar essas componentes nas duas metades do dispositivo. $R_{\text {ext }}$ representa as 
resistências externas às regiões de fonte e dreno. Somente as resistências inscritas na área quadriculada foram modeladas por Dixit, A. et al..................61 Figura 3. 8. $R_{\text {TOTAL }}$ em função de $V_{G F}$. A resistência de fonte e dreno foi extraída dessas curvas para $\mathrm{V}_{\mathrm{GF}}$ igual a $5 \mathrm{~V}$. Os símbolos de quadrado e círculo mostram as curvas obtidas dos dispositivos com W Fin de 18 e $120 \mathrm{~nm}$, respectivamente. As linhas cheias e tracejadas foram ajustadas às medidas dos dispositivos de $\mathrm{W}_{\mathrm{FIN}}$ de 18 e $120 \mathrm{~nm}$, respectivamente ${ }^{49}$. 62 Figura 3. 9. $R_{\mathrm{SD}}$ em função de $\mathrm{W}_{\mathrm{FIN}}$ onde o modelo analítico foi comparado com a simulação tridimensional do dispositivo usando o simulador ISE-DESSIS ${ }^{49,}$.

Figura 4. 1. Perfil transversal de um transistor com camada de Nitreto de Silício (CESL). As setas indicam as componentes do stress dominante na região do canal $^{36}$. A. 66

Figura 4. 2. Perfil transversal de um transistor com região de dreno mais longa mostrando a influência das dimensões das regiões de fonte e dreno na

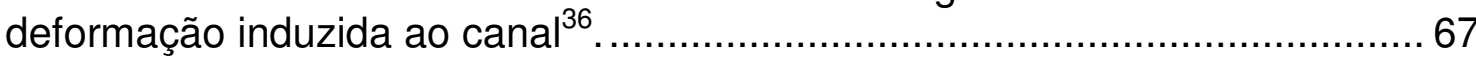

Figura 4. 3. Sequência do processo de fabricação de uma lâmina sSOI. a) Substrato de $\mathrm{Si}$ tensionado é implantado $\mathrm{com} \mathrm{H}_{2}$. b) A lâmina de $\mathrm{Si}$ tensionado é colada em uma lâmina reserva. c) Transferência do processo para lâmina reserva. d) A camada remanescente de SiGe é seletivamente corroída da camada de Si tensionado sobre o óxido ${ }^{36}$. 69

Figura 4. 4. Alteração da rede cristalina do silício após sua deposição sobre a

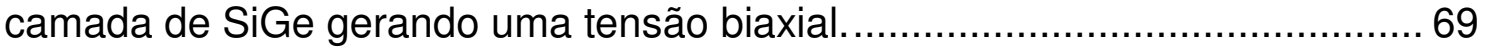
Figura 4. 5. Visão tridimensional de um FinFET de porta tripla com elevação das regiões de fonte e dreno para demonstração do SEG. ............................ 71 Figura 5.1. Pastilha contendo todos os dispositivos (a); Posição das regiões de fonte e dreno (b); Perfil transversal do FinFET de porta tripla identificando os materiais de suas regiões (c). ................................................................. 73 Figura 5. 1. Pastilha contendo todos os dispositivos (a); Posição das regiões de fonte e dreno (b); Perfil transversal do FinFET de porta tripla identificando os

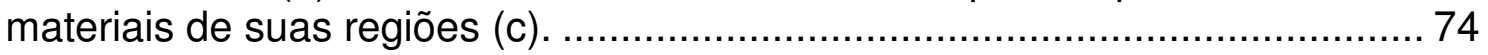

Tabela 5. 1. Características da cascata de dispositivos medidos. .................. 75 Figura 5. 2. Resultados obtidos por caracterização elétrica da corrente de dreno (ID) em função da tensão aplicada na porta $\left(V_{G F}\right)$ para os FinFETs de porta tripla com $V_{D}=50 \mathrm{mV}, \mathrm{H}_{\mathrm{FIN}}=60 \mathrm{~nm} ; \mathrm{W}_{\mathrm{FIN}}=20 \mathrm{~nm}$ para diferentes comprimentos

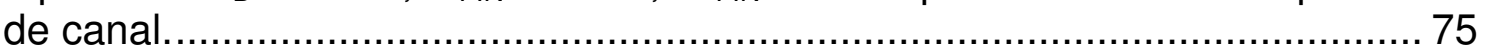
Figura 5. 3. Resultados obtidos por caracterização elétrica da tensão de limiar em função do comprimento de canal (a) e da inclinação de sublimiar em função do comprimento de canal (b)............................................................. 76 Figura 5. 4. Resultados obtidos através da caracterização elétrica da resistência total em função da tensão aplicada na porta para $W_{\mathrm{FIN}}$ de $20 \mathrm{~nm}$,

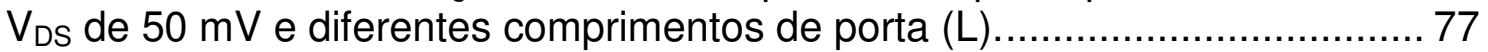
Figura 5. 5. Resistência Série de fonte e dreno em função do comprimento de canal com $V_{D}$ igual a $50 \mathrm{mV}$ com $W_{F I N}$ igual a $20 \mathrm{~nm}$, extraída pelo método da extrapolação exponencial de primeira ordem.............................................. 78 Figura 5. 6. Resistência total em função do comprimento de porta para diferentes tensões aplicadas na porta..................................................... 79 Figura 5. 7. Figura SEM de um dispositivo de múltiplos dedos...................... 80 Figura 5. 8. Layout de um dispositivo MOSFET planar de porta única (a) e layout de um dispositivo de múltiplos fins $(b)^{36}$.............................................. 80 
Figura 5. 9. Resultados obtidos por caracterização elétrica da resistência total em função da tensão aplicada na porta para dispositivos com as mesmas dimensões e número de fins diferentes. 81

Figura 5. 10. Corrente de dreno $\left(I_{D}\right)$ em função da tensão aplicada na porta $\left(\mathrm{V}_{\mathrm{GF}}\right)$ para dispositivos de referência e sob influência de canal tensionado uniaxial e biaxial com comprimento de canal de $60 \mathrm{~nm}$............................... 83 Figura 5.11. Curva da transcondutância (gm) em função da tensão aplicada na porta $\left(\mathrm{V}_{\mathrm{GF}}\right)$ para diferentes tipos de dispositivos com comprimento de canal de

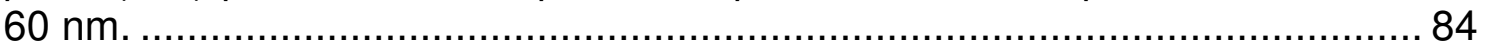
Figura 5.12. Corrente de dreno (ID) em função da tensão aplicada na porta $\left(V_{\mathrm{GF}}\right)$ para dispositivos de referência e sob influência de canal tensionado com comprimento de canal de $920 \mathrm{~nm}$. 85 Figura 5. 11. Curva da transcondutância (gm) em função da tensão aplicada na porta $\left(\mathrm{V}_{\mathrm{GF}}\right)$ para diferentes tipos de dispositivos com comprimento de canal de $920 \mathrm{~nm}$. 86

Figura 5. 12. Curva da transcondutância em função da tensão aplicada à porta para dispositivos com e sem deformação com comprimento de canal de a) 100, b) 170 e c) $420 \mathrm{~nm}$. 87

Figura 5. 13. Resistência Total em função do comprimento de porta para dispositivos com e sem o uso de deformação............................................... 89 Figura 5. 14. Curvas da RTOTAL em função dos comprimentos de canal para estimar a $R_{S D}$ através da regressão linear dessas curvas para as três tecnologias usadas.............................................................................. 90

Figura 5. 15. Análise da resistência total em função da largura do fin para comprimento de porta de $100 \mathrm{~nm}$ (a), curvas da condução de corrente (b) e transcondutância (c) para dispositivos com e sem deformação com $\mathrm{W}_{\text {FIN }}$ de 25 e $55 \mathrm{~nm}$.

Figura 5. 16. Análise da resistência total em função da largura do fin para comprimento de porta de $920 \mathrm{~nm}$.

Figura 5. 17. Curvas características da corrente de dreno em função da tensão aplicada na porta para dispositivos com e sem deformação e com e sem SEG com comprimento de canal de $100 \mathrm{~nm}$ e largura do fin de $25 \mathrm{~nm}$. 93

Figura 5. 18. Curvas da transcondutância em função da tensão aplicada à porta para dispositivos com e sem deformação e com e sem SEG com comprimento de canal de $100 \mathrm{~nm}$.............................................................................. 94 Figura 5. 19. Curvas características da corrente de dreno em função da tensão aplicada na porta para dispositivos com sem deformação e SEG com comprimentos de canal de $920 \mathrm{~nm}$ e largura do fin de $25 \mathrm{~nm}$........................ 95 Figura 5. 20. Curvas da transcondutância em função da tensão aplicada à porta para dispositivos com e sem deformação e com e sem SEG com comprimento de canal de $920 \mathrm{~nm}$. 96

Figura 5. 21. Curvas da RTOTAL em função dos comprimentos de porta para dispositivos de referência e sob influência de deformação com e sem o uso de

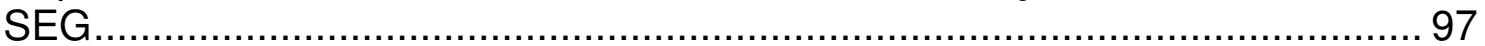
Figura 5. 22. Resistência total em função da largura do fin com comprimento de canal de $100 \mathrm{~nm}$ para as três diferentes tecnologias de dispositivos com e sem o uso de SEG e com polarização de porta de $50 \mathrm{mV}$.................................... 99 Figura 5. 23. Resistência total em função da largura do fin com comprimento de canal de $920 \mathrm{~nm}$ para as três diferentes tecnologias de dispositivos com e sem o uso de SEG e com polarização de porta de $50 \mathrm{mV}$. 100 
Figura 5. 24. Tensão de limiar em função da largura do fin para as três diferentes tecnologias de dispositivos com e sem SEG para comprimento de canal de $100 \mathrm{~nm}$ com $\mathrm{V}$ de $50 \mathrm{mV}$. 101

Figura 6. 1. Estrutura de um FinFET de porta tripla construída no DevEdit3d, em função dos eixos $x(a)$ e $y(b)$. 106

Figura 6. 2. Estrutura de um FinFET de porta tripla gerada no TonyPlot3D. . 107 Figura 6. 3. Curvas características da corrente de dreno $\left(I_{D}\right)$ em função da tensão aplicada na porta $\left(\mathrm{V}_{\mathrm{GF}}\right)$ para os FinFETs de porta tripla com $\mathrm{V}_{\mathrm{DS}}=10 \mathrm{mV}$ para $W_{\text {FIN }}$ de (a) $60 \mathrm{~nm}$, (b) $120 \mathrm{~nm}$ e (c) $500 \mathrm{~nm}$.

Figura 6. 4. Curvas da (a) tensão de limiar $V_{T}$ e (b) inclinação de sublimiar (S) em função do comprimento de canal com $V_{D S}=10 \mathrm{mV}$ para dispositivos com diferentes larguras de fins $\left(\mathrm{W}_{\mathrm{FIN}}\right)$.... 109

Figura 6. 5. Resistência Total (RTOTAL) em função da tensão aplicada na porta $\left(V_{\mathrm{GF}}\right)$ para (a) $W_{\mathrm{FIN}}=60 \mathrm{~nm}$, (b) $W_{\mathrm{FIN}}=120 \mathrm{~nm}$ e (c) $W_{\mathrm{FIN}}=500 \mathrm{~nm}$ para diferentes comprimentos de canal $(\mathrm{L})$, com $\mathrm{V}_{\mathrm{DS}}=10 \mathrm{mV}$.

Figura 6. 6. Resistência Série de fonte e dreno em função do comprimento de canal com $\mathrm{V}_{\mathrm{DS}}$ de $10 \mathrm{mV}$ para diferentes larguras de fin $\left(\mathrm{W}_{\mathrm{FIN}}\right)$. 113 Tabela 6. 1. Valores obtidos por simulação da extração da $R_{S D}$ para $V_{G F}$ de $5 \mathrm{~V}$, com $V_{D}=10 \mathrm{mV}$ para diferentes larguras de fins $\left(\mathrm{W}_{\mathrm{FIN}}\right)$ e comprimento de canal (L). 113

Figura 6. 7. Resistência série de fonte e dreno extraída para $\mathrm{V}_{\mathrm{GF}}$ igual a $5 \mathrm{~V}$ em função da largura do fin. 114

Figura 6. 8. Resistência Série de fonte e dreno em função do comprimento de canal com $V_{D}$ de $10 \mathrm{mV}$ para diferentes larguras de fin $\left(\mathrm{W}_{\mathrm{FIN}}\right)$, com

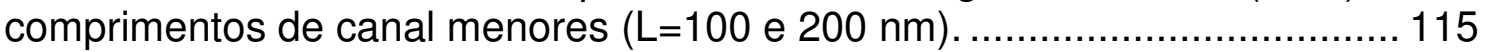
Figura 6. 9. Resistência Total em função do comprimento do canal para diferentes polarizações de porta obtidas por simulações numéricas para (a)

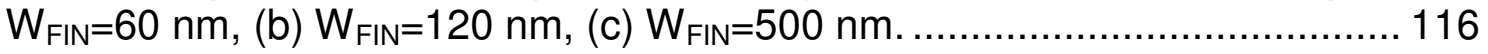
Tabela 6. 2. Valores obtidos por simulação da extração da $R_{S D}$ por extrapolação linear, com para diferentes larguras de fin $\left(\mathrm{W}_{\mathrm{FIN}}\right)$ e comprimento de canal (L). 117

Figura 6. 10. Resistência Total em função de comprimento de canal para dispositivos com comprimento de canal maiores para diferentes polarizações de porta. 117

Figura 6. 11. Curvas características $\mathrm{I}_{\mathrm{D}} \mathrm{XV} \mathrm{V}_{\mathrm{GF}}$ obtidas através de simulações tridimensionais, ajustadas às curvas experimentais, para os dispositivos de (a) referência e com comprimentos de canal de 170, 420 e $920 \mathrm{~nm}$ para largura de fin de $25 \mathrm{~nm}$.... 120 Figura 6. 12. Curvas características $\mathrm{I}_{\mathrm{D}} \mathrm{x} \mathrm{V}_{\mathrm{GF}}$ obtidas através de simulações tridimensionais, ajustadas às curvas experimentais, para os dispositivos sob a técnica uniaxial com comprimentos de canal de 100, 420 e $920 \mathrm{~nm}$ para largura de fin de $25 \mathrm{~nm}$. 121

Figura 6. 13. Curvas da transcondutância em função da tensão aplicada na porta obtidas através de medidas experimentais e simulações dos dispositivos de referência (a) e sob influência da deformação uniaxial (b) com comprimentos de canal de 100, 170, 420 e $920 \mathrm{~nm}$, largura do fin de $25 \mathrm{~nm}$ e $V_{D s}$ igual a 50 $\mathrm{mV}$.

Figura 6. 14. Curvas características $\mathrm{I}_{\mathrm{D}} \mathrm{XV} \mathrm{V}_{\mathrm{GF}}$ obtidas por simulação dos dispositivos de referência e sob influência da deformação uniaxial com comprimentos de canal de 100, 170, 420, 920 e largura do fin de $25 \mathrm{~nm}$..... 123 
Figura 6. 15. Curvas da transcondutância em função da tensão aplicada na porta obtidas através de simulação para os dispositivos de referência e com tensão uniaxial local com comprimentos de canal de 100, 170, 420 e $920 \mathrm{~nm}$ e largura de fin de $25 \mathrm{~nm}$. 124

Figura 6. 16. Curvas da $R_{\text {TOTAL }}$ em função dos comprimentos de canal para estimar a $R_{S D}$ através da regressão linear dessas curvas para os dispositivos de referência e sob influência da técnica de deformação uniaxial. 125 


\section{LISTA DE TABELAS}

Tabela 5. 1. Características da cascata de dispositivos medidos.

Tabela 5. 2. Fator de degradação da Mobilidade efetiva [V-1] para $L=920 \mathrm{~nm} 88$

Tabela 5. 3. $R_{\mathrm{SD}}[\Omega]$ estimadas para as tecnologias estudadas obtidas através da regressão linear das curvas $R_{\text {TOTAL }} X$

90

Tabela 5. 4. Fator de degradação da Mobilidade efetiva [V-1] para $L=920 \mathrm{~nm} 97$

Tabela 5. 5. $R_{\mathrm{SD}}[\Omega]$ estimadas para as tecnologias estudadas obtidas através da regressão linear das curvas $\mathrm{R}_{\text {TOTAL }} \mathrm{xL}$

98

Tabela 5. 6. Tensão de limiar para as três tecnologias estudadas com e sem o uso de SEG para comprimento de canal de $920 \mathrm{~nm}$. 102 


\section{LISTA DE SÍMBOLOS}

$C_{D} \quad$ Capacitância da região depleção por unidade de área $\left[\mathrm{F} / \mathrm{cm}^{2}\right]$

$\mathrm{C}_{\text {it }} \quad$ Capacitância de armadilhas de interface por unidade de área $\left[\mathrm{F} / \mathrm{cm}^{2}\right]$

Cox Capacitância do óxido de porta por unidade de área $\left[\mathrm{F} / \mathrm{cm}^{2}\right]$

$\mathrm{C}_{\mathrm{Si}} \quad$ Capacitância da camada de silício por unidade de área $\left[\mathrm{F} / \mathrm{cm}^{2}\right]$

d Distância de parte do comprimento de canal do transistor [ $\mu \mathrm{m}]$

$\mathrm{E}_{\mathrm{C}} \quad$ Nível energético da faixa de condução

$\mathrm{E}_{\mathrm{F}} \quad$ Nível de Fermi

Ev Nível energético da faixa de valência

ID $\quad$ Corrente entre dreno e fonte de dispositivos FinFETs [A]

IDo Corrente de um dispositivo planar de porta única, por unidade de largura $[\mathrm{A} / \mathrm{cm}]$

IDS Corrente entre dreno e fonte de dispositivos MOSFETs [A]

k Constante de Boltzmann $\left[1,38066 \times 10^{-23} \mathrm{~J} / \mathrm{K}\right]$

$\mathrm{L} \quad$ Comprimento de canal do transistor [ $\mu \mathrm{m}]$

$L_{\text {eff }} \quad$ Comprimento de canal efeitivo [nm]

$L_{M} \quad$ Comprimento de canal de máscara [nm]

$\mathrm{m}^{*} \quad$ Massa efetiva

$\mathrm{N}_{\mathrm{A}} \quad$ Concentração de impurezas aceitadoras do substrato [ $\left[\mathrm{cm}^{-3}\right]$

$\mathrm{N}_{\mathrm{af}} \quad$ Concentração de dopantes na região ativa do transistor $\mathrm{SOI}\left[\mathrm{cm}^{-3}\right]$

$\mathrm{n}_{\mathrm{i}} \quad$ Concentração intrínseca de portadores $\left[\mathrm{cm}^{-3}\right]$

$\mathrm{N}_{\mathrm{it}} \quad$ Densidade de armadilhas de interface

$P \quad$ Espaçamento entre "dedos", fins [nm]

q Carga elementar do elétron $\left[1,6 \times 10^{-19} \mathrm{C}\right]$

$Q_{D} \quad$ Carga total de depleção na camada de silício por unidade de área nos transistores SOI [C/cm $\left.{ }^{2}\right]$

$Q_{\text {dep1 }} \quad$ Densidade de carga de depleção na camada de silício do transistor SOI $\left[\mathrm{C} / \mathrm{cm}^{2}\right]$

$Q_{\text {depl }} \quad$ Densidade de carga de depleção na camada de silício do transistor MOSFET convencional [C/cm $\left.{ }^{2}\right]$

$Q_{\text {inv1 }} \quad$ Densidade de carga de inversão na primeira interface $\left[\mathrm{C} / \mathrm{cm}^{2}\right]$ 


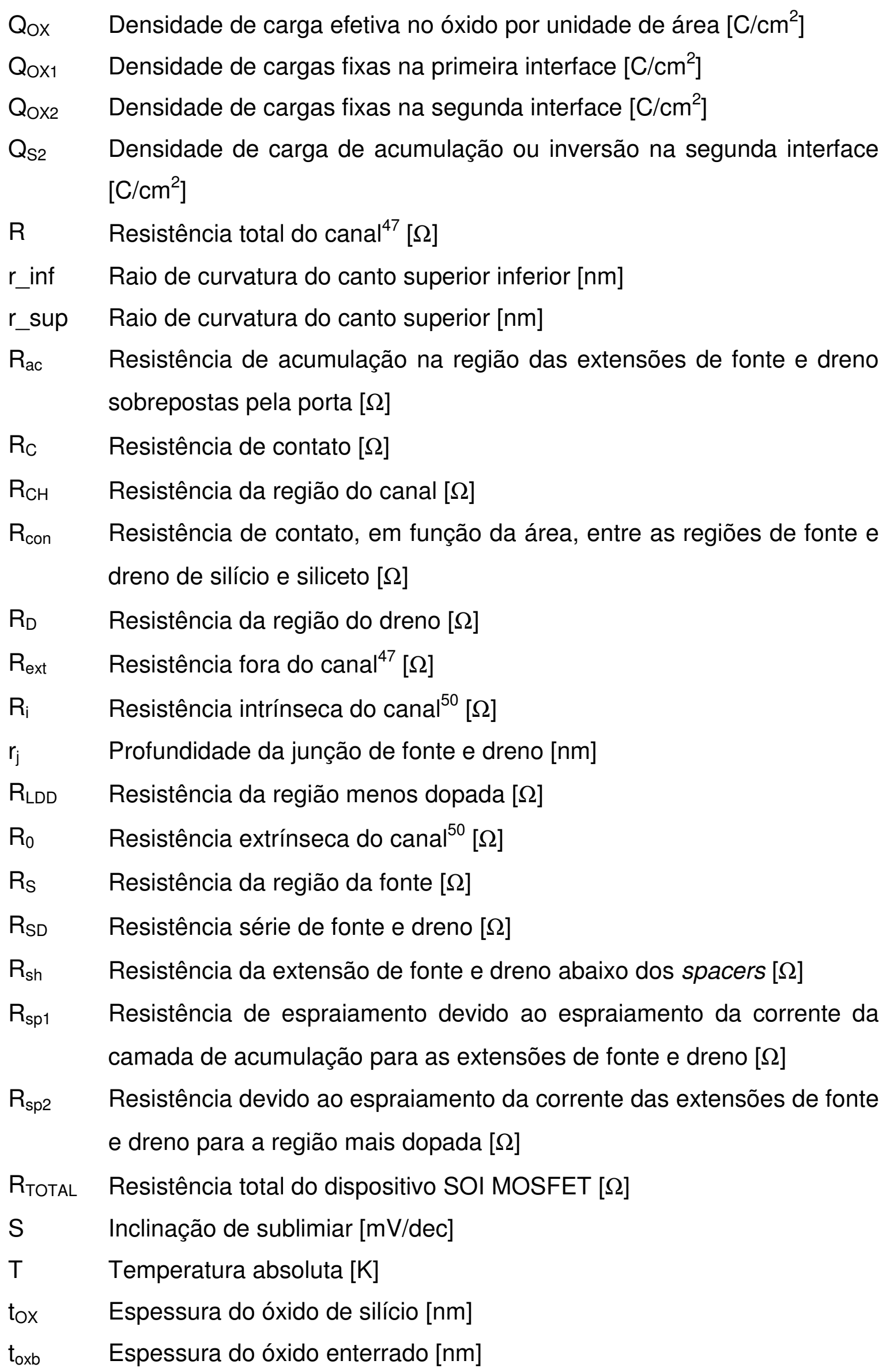




\begin{tabular}{|c|c|}
\hline$t_{\text {oxf }}$ & Espessura do óxido de porta do transistor SOI [nm] \\
\hline$t_{\mathrm{Si}}$ & Espessura da camada de silício [nm] \\
\hline$V_{D S}$ & Tensão aplicada ao dreno do transistor [V] \\
\hline $\mathrm{V}_{\mathrm{FB}}$ & Tensão de faixa plana [V] \\
\hline $\mathrm{V}_{\mathrm{GB}}$ & Tensão aplicada ao substrato do transistor SOI [V] \\
\hline $\mathrm{V}_{\mathrm{GB}, \mathrm{acc} 2}$ & Tensão aplicada ao substrato com a segunda interface acumulada [V] \\
\hline $\mathrm{V}_{\mathrm{GF}}$ & Tensão aplicada à porta do transistor SOI [V] \\
\hline $\mathrm{V}_{\mathrm{GS}}$ & Tensão entre porta e fonte do transistor MOSFET [V] \\
\hline $\mathrm{V}_{\mathrm{GX}}$ & Sobretensão de condução [V] \\
\hline $\mathrm{V}_{\mathrm{S}}$ & Tensão aplicada na fonte do transistor [V] \\
\hline $\mathrm{V}_{\text {th1, acc2 }}$ & Tensão de limiar de porta com a segunda interface acumulada [V] \\
\hline$V_{\text {th1,depl2 }}$ & Tensão de limiar de porta com a segunda interface depletada [V] \\
\hline $\mathrm{V}_{\text {th1,inv2 }}$ & Tensão de limiar de porta com a segunda interface invertida [V] \\
\hline $\mathrm{V}_{\mathrm{thF}}$ & Tensão de limiar da porta do transistor SOI [V] \\
\hline $\mathrm{W}_{\text {eff }}$ & Largura efetiva do canal do transistor SOI MOSFET [nm] \\
\hline $\mathrm{W}_{\mathrm{FIN}}$ & Largura do fin do transistor de múltiplas portas [nm] \\
\hline Xdmáx & Profundidade máxima da região de depleção [nm] \\
\hline$\alpha$ & Coeficiente que relaciona as capacitâncias de um transistor \\
\hline$\delta$ & Parâmetro resultante da associação da capacitância \\
\hline Eox & Permissividade do óxido de silício $\left[3,45 \times 10^{-13} \mathrm{~F} / \mathrm{cm}\right]$ \\
\hline$\varepsilon_{\mathrm{Si}}$ & Permissividade do silício $\left[1,06 \times 10^{-12} \mathrm{~F} / \mathrm{cm}\right]$ \\
\hline$\phi_{\mathrm{F}}$ & Potencial de Fermi da camada de silício [V] \\
\hline$\phi_{\mathrm{MS}}$ & Diferença de função trabalho entre metal e semicondutor [V] \\
\hline$\phi_{\mathrm{MS} 1}$ & $\begin{array}{l}\text { Diferença da função trabalho entre metal de porta e semicondutor no } \\
\text { transistor SOI [V] }\end{array}$ \\
\hline$\phi_{\mathrm{MS} 2}$ & $\begin{array}{l}\text { Diferença da função trabalho entre o substrato e a camada de silício no } \\
\text { transistor SOI [V] }\end{array}$ \\
\hline$\phi_{\mathrm{S} 1}$ & Potencial de superfície da primeira interface [V] \\
\hline$\phi_{\mathrm{S} 2}$ & Potencial de superfície da segunda interface [V] \\
\hline$\lambda_{1}$ & Comprimento natural para transistor de porta única \\
\hline$\lambda_{2}$ & Comprimento natural para transistor de porta dupla \\
\hline$\lambda_{3}$ & Comprimento natural para transistor de porta tripla \\
\hline$u_{\text {of }}$ & Mobilidade efetiva dos portadores do canal $\left[\mathrm{cm}^{2} / \mathrm{N} . \mathrm{s}\right]$ \\
\hline
\end{tabular}


$\mu_{\text {LAT }} \quad$ Mobilidade das Interfaces Laterais $\left[\mathrm{cm}^{2} / \mathrm{N} . \mathrm{s}\right.$ ]

$\mu_{\text {TOPO }} \quad$ Mobilidade da Interface Superior $\left[\mathrm{cm}^{2} / \mathrm{V} . \mathrm{s}\right.$ ]

$\theta \quad$ Ângulo de inclinação do fin no transistor FinFET [graus] 


\section{LISTA DE ABREVIATURAS E SIGLAS}

CMOS

CESL

DELTA

DIBL

FinFET

GAA

IMEC

LDD

MOSFET

MuGFET

SCE

SEG

$\mathrm{Si}$

$\mathrm{SiO}_{2}$

$\mathrm{SOI}$

SOS

sSOI

VLSI
Complementary Metal-Oxide-Semiconductor

Contact Etch Stop Layer

Fully Depleted Lean-Channel Transistor

Drain-Induced-Barrier-Lowering

Fin Field Effect Transistor

Gate-all-around

Interuniversity Microelectronic Center

Lightly Doped Drain

Metal-Oxide-Semiconductor Field Effect Transistor

Multi-Gate Field Effect Transistor

Short Channel Effect

Selective Epitaxial Growth

Silício

Óxido de Silício

Silicon-On-Insulator

Silicon-On-Sapphire

Strained Silicon

Very-Large-Scale Integration 


\section{SUMÁRIO}

1 INTRODUÇÃO

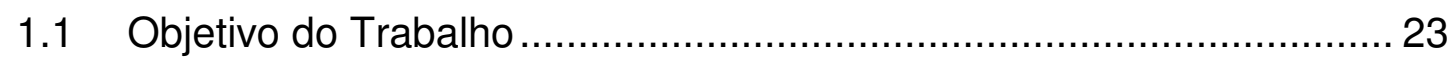

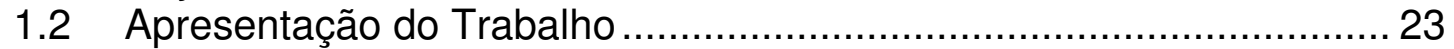

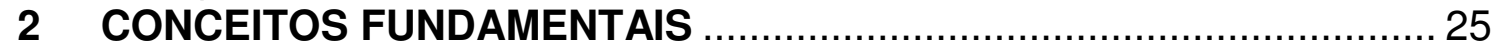

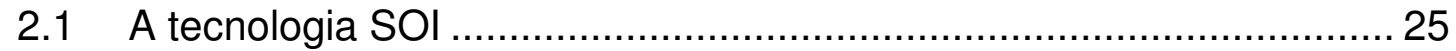

2.1.1 Tipos de Transistores SOI MOSFETs. ................................. 26

2.1.2 Principais parâmetros elétricos dos transistores SOI MOSFETs.. 29

2.1.2.1 Tensão de Limiar ................................................................. 29

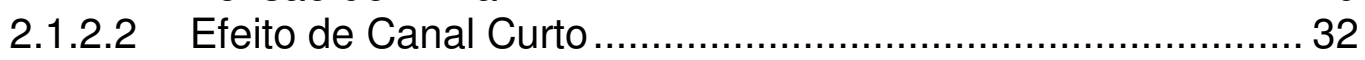

2.1.2.3 Inclinação de Sublimiar ........................................................ 34

2.2 A tecnologia SOI de Múltiplas Portas .............................................. 37

2.2.1 Dispositivos SOI MOSFETs de porta dupla ............................... 38

2.2.2 Dispositivos FinFETs de porta tripla e porta tripla + ................... 40

2.3 Características elétricas dos transistores de múltiplas portas ............. 43

2.3.1 Corrente de Dreno ............................................................... 43

2.3.2 Efeito de Canal Curto .......................................................... 44

2.3.3 Tensão de Limiar ............................................................. 47

3 ESTUDO DA RESISTÊNCIA SÉRIE DE FONTE E DRENO E MÉTODOS

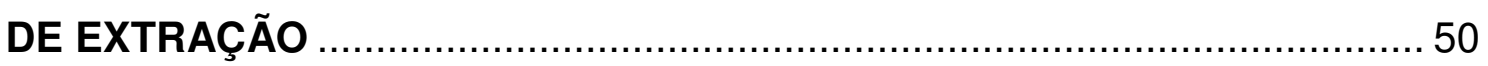

3.1 Definição da Resistência série de fonte e dreno ................................50

3.1.1 Dispositivos SOI MOSFETs.................................................. 51

3.1.2 Dispositivos SOI MOSFETs de Múltiplas Portas .......................... 53

3.2 Métodos de Extração da Resistência Série de Fonte e Dreno............. 54

3.2.1 Método de Terada e Muta ....................................................... 54

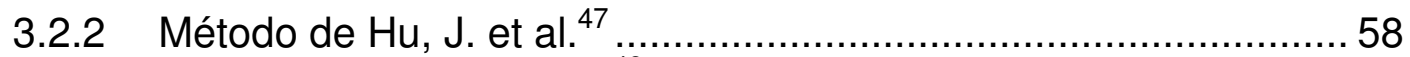

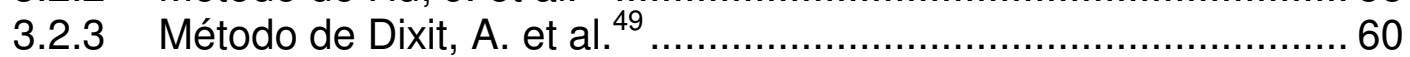

4 A TECNOLOGIA DE CANAL TENSIONADO E O CRESCIMENTO

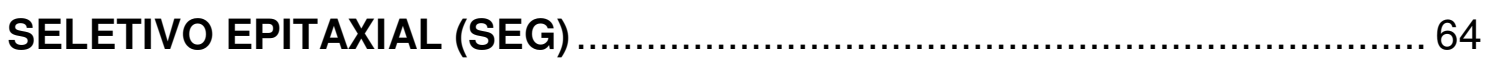

4.1 A Tecnologia de Canal Tensionado (Strained Silicon) ........................ 64

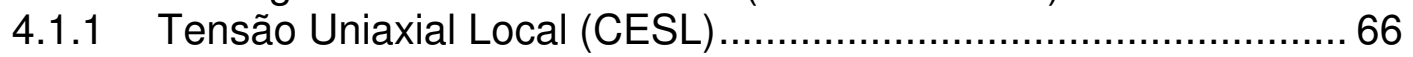

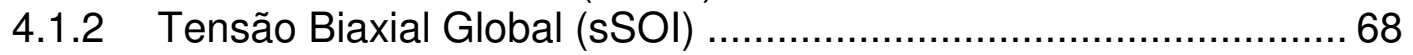

4.2 O Crescimento Seletivo Epitaxial (SEG) ……............................... 70

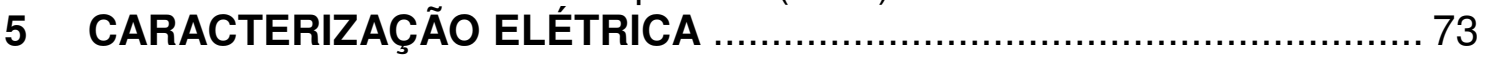

5.1 Estudo da Resistência Série de Fonte e Dreno ................................ 73

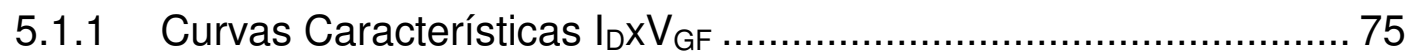

5.1.2 Extração da Resistência Série de Fonte e Dreno ......................... 77

5.1.3 Comparação da Influência do Número de Fins na $R_{\mathrm{SD}} \ldots \ldots \ldots \ldots \ldots \ldots . . . . . .79$

5.2 Análise da Resistência Total em Dispositivos FinFETs de Porta Tripla com e sem deformação e com e sem SEG ............................................ 82

5.2.1 Características dos Dispositivos Medidos ................................. 82

5.2.2 Resultados Experimentais sem SEG ...................................... 83

5.2.3 Resultados Experimentais com SEG ..................................... 93

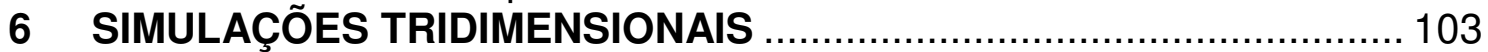




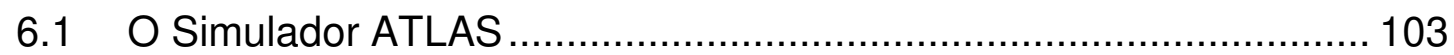

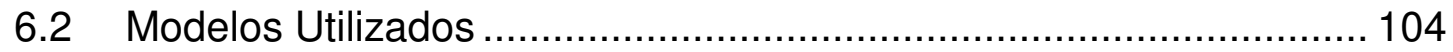

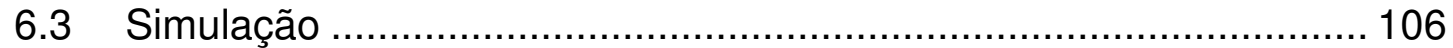

6.4 Resultados e Discussões da Simulação ........................................ 108

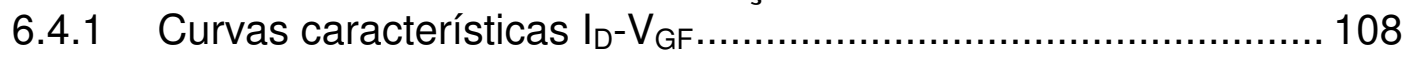

6.4.2 Extração da Resistência Série de Fonte e Dreno ........................ 111

6.4.2.1 Método de Dixit, A. et al. ${ }^{49}$................................................... 111

6.4.2.2 Métodos de Terada e Muta ${ }^{50}$ e de J. Hu, et al. ${ }^{47}$................... 115

6.5 Resultados e Discussões da Simulação com deformação................. 118

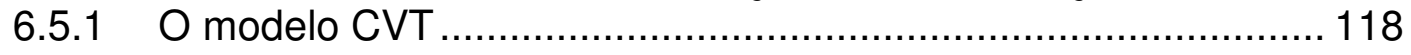

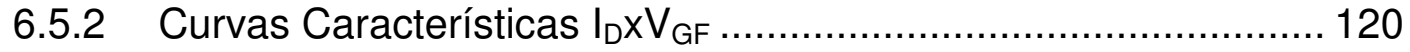

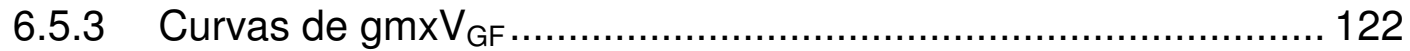

6.5.4 Comparação das curvas características dos dispositivos simulados 123

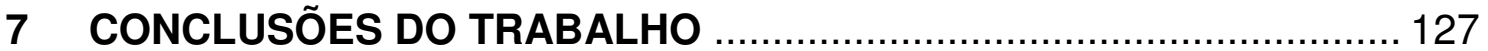

8 PUBLICAÇÕES GERADAS DURANTE O PERÍODO DE MESTRADO 129

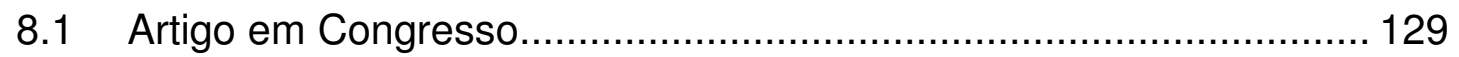

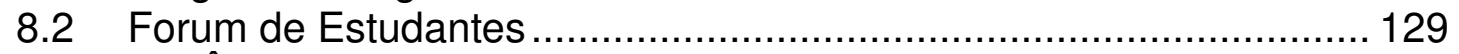

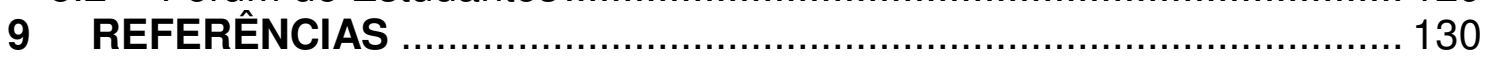




\section{INTRODUÇÃO}

A Indústria de circuitos integrados tem se desenvolvido de forma agressiva para seguir a famosa Lei de Moore (figura 1.1) ${ }^{1}$, onde o número de transistores em um circuito integrado dobra aproximadamente a cada dois anos. Esse crescimento da indústria de circuitos integrados está diretamente relacionado à sua capacidade de reduzir o tamanho dos transistores dentro de um único circuito integrado. Para que essa evolução continue acontecendo de acordo com a Lei de Moore, o desenvolvimento de transistores MOSFETs de dimensões em escalas nanométricas deve ser realizado.

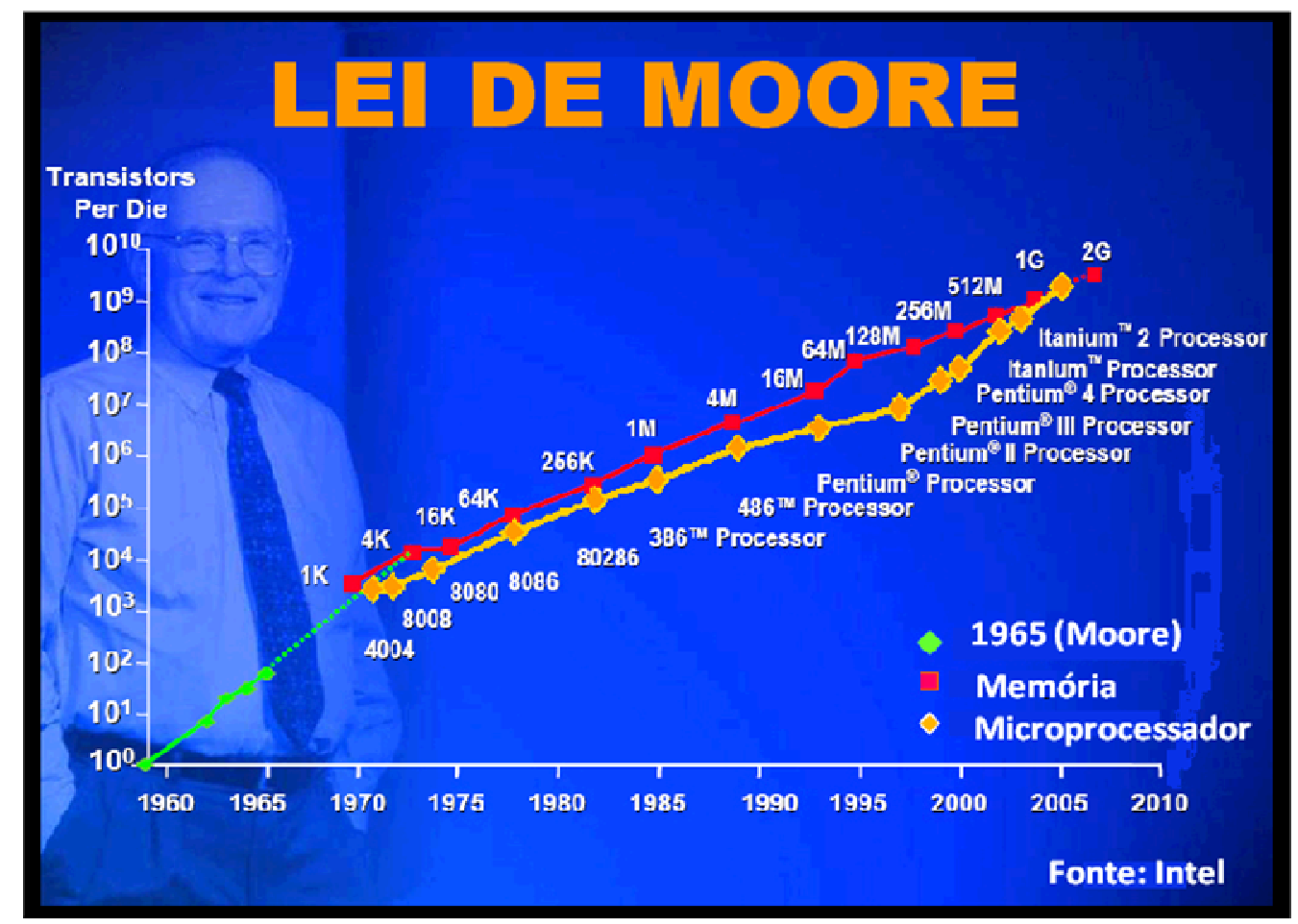

Figura 1. 1. Lei de Moore'.

Em escalas nanométricas, porém, os efeitos parasitários indesejáveis, chamados de efeito de canal curto $^{2}$ se agravam. Um exemplo desses efeitos é o compartilhamento de cargas do canal do transistor, que acontece quando as regiões de depleção associadas à fonte/dreno e canal tornam-se significativas se comparada com a gerada pela porta e canal, resultando na diminuição indesejável da tensão de limiar. 
Uma das alternativas mais promissoras para se reduzir esses efeitos é a utilização de transistores com múltiplas portas, sendo esses alvos de pesquisa intensa.

O primeiro transistor de porta dupla, chamado de $\mathrm{XMOS}^{3}$, mostrou significativa redução dos efeitos de canal curto devido ao uso de eletrodos de porta acima e abaixo da região do canal, melhorando assim o controle do potencial elétrico da camada de silício. Com o uso dessa configuração, obtevese um melhor controle da região de depleção do canal do XMOS, se comparado com o SOI MOSFET planar, minimizando a influência das regiões de depleção de fonte e dreno.

O primeiro transistor de porta dupla com canal vertical fabricado foi o DELTA ${ }^{4}$. Posteriormente, outras implementações de canal vertical foram realizadas, entre as quais os FinFET ${ }^{5}$ de porta dupla e tripla ${ }^{6}$.

A figura 1.2 mostra a imagem de um FinFET de porta tripla com múltiplos dedos (fins). Esse tipo de estrutura corresponde a vários FinFETs associados em paralelo, cujo objetivo é promover uma maior capacidade de corrente entre fonte e dreno.

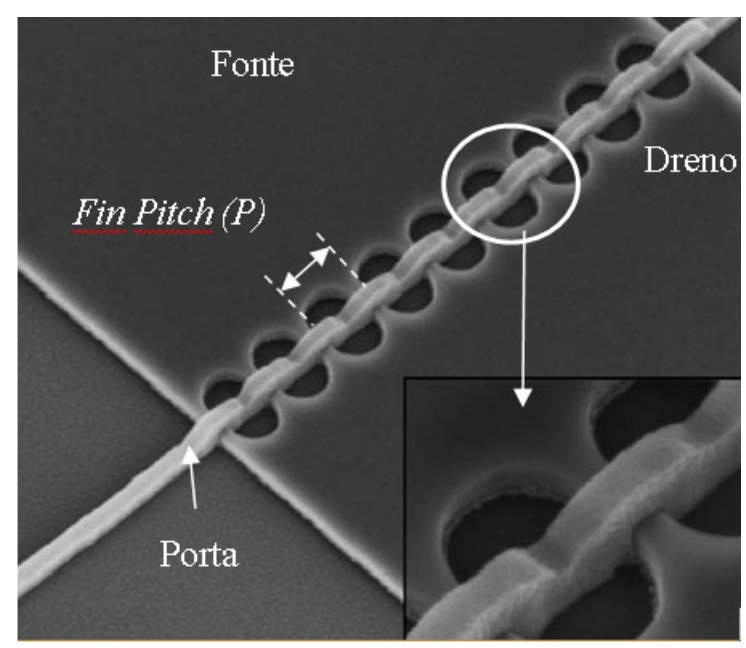

Figura 1. 2. Estrutura de FinFETs com múltiplos fins (IMEC, Bélgica).

Como o processo de fabricação é compatível ao processo SOI MOSFET convencional, algumas vantagens adicionais do SOI FinFET podem ser 
citadas, por exemplo, um melhor controle das cargas na região do canal pode ser alcançado, devido à proximidade de suas portas; aumento da mobilidade devido a região do canal ser geralmente menos dopada ${ }^{7}$; redução dos efeitos de canal curto e também das correntes de fuga; inclinação de sublimiar perto do ideal $(60 \mathrm{mV} / \mathrm{dec})^{5}$, dentre outros.

Por apresentarem dimensões muito estreitas de fonte e dreno, uma das desvantagens desses dispositivos é o fato de apresentarem altos valores na resistência série de fonte e dreno. Uma das formas de se reduzir essa resistência é a do crescimento seletivo epitaxial (SEG) nessas regiões

\subsection{Objetivo do Trabalho}

O objetivo desse trabalho de mestrado é realizar o estudo e a caracterização elétrica dos principais parâmetros do FinFET de porta tripla, através de medidas experimentais e simulações numéricas tridimensionais. Os dispositivos que foram utilizados nesse trabalho foram fabricados no Centro de pesquisas IMEC (Interuniversity Microelectronic Center) localizado na Universidade Católica de Leuven, na Bélgica. Particular atenção será dada ao estudo da resistência série de fonte e dreno e à resistência total em FinFETs de porta tripla com e sem o uso da tecnologia de canal tensionado, assim como o uso de crescimento seletivo epitaxial nesses dispositivos, com o intuito de reduzir a resistência série, sendo esse um dos principais desafios para a viabilização desse tipo de transistor para uso industrial.

\subsection{Apresentação do Trabalho}

Esse trabalho será apresentado em sete capítulos, sendo seus conteúdos principais:

Capítulo 1: Nesse capítulo é apresentado uma breve introdução da tecnologia SOI, os objetivos e forma de apresentação desse trabalho. 
Capítulo 2: Nesse capítulo, uma revisão bibliográfica sobre a tecnologia SOI é apresentada, assim como os conceitos principais; as estruturas; os parâmetros elétricos dos dispositivos SOI MOSFETs planares, evidenciando seus modos de operação decorrentes da espessura do filme de silício e da polarização aplicada e; os dispositivos SOI MOSFETs de Múltiplas Portas.

Capítulo 3: Nesse capítulo são apresentados os conceitos de resistência série de fonte e dreno em dispositivos SOI MOSFETs planares e de múltiplas portas, assim como alguns métodos de extração desse parâmetro existentes na literatura.

Capítulo 4: Nesse capítulo são apresentados os conceitos da tecnologia de canal tensionado, assim como as técnicas para sua obtenção, e o conceito do uso do crescimento seletivo epitaixal (SEG) nos dispositivos para redução da resistência série de fonte e dreno, melhorando o desempenho.

Capítulo 5: Esse capítulo apresenta as curvas características dos dispositivos FinFETs de porta tripla obtidas por caracterização elétrica, para validação dos métodos estudados, assim como as curvas características dos dispositivos sob influência da tecnologia de canal tensionado com e sem o uso do crescimento seletivo epitaxial.

Capítulo 6: Esse capítulo apresenta o Simulador numérico tridimensional ATLAS, suas características, assim como os dispositivos que este é capaz de simular, seus modelos e as características elétricas dos FinFETs de porta tripla que serão utilizados. Apresenta também as discussões dos resultados obtidos através das simulações para as diferentes tecnologias.

Capítulo 7: Finalmente, nesse capítulo, são apresentadas as conclusões desse trabalho, assim como sugestões para trabalhos futuros que podem ampliar a análise realizada durante o período de mestrado. 


\section{CONCEITOS FUNDAMENTAIS}

Nesse capítulo é apresentada uma revisão bibliográfica sobre a tecnologia SOI, assim como os conceitos, as estruturas e os principais parâmetros elétricos dos dispositivos SOI MOSFETs planares e dos dispositivos SOI MOSFETs de Múltiplas Portas.

\subsection{A tecnologia SOI}

A tecnologia SOI utiliza a própria lâmina, onde uma fina camada de silício é separada do restante da lâmina por uma camada de isolante, como por exemplo, o dióxido de silício. A presença desse óxido tem como objetivo reduzir ou eliminar os efeitos parasitários indesejáveis.

Essa tecnologia vem sendo intensamente estudada devido às suas vantagens sobre a tecnologia MOSFET convencional tais como, a completa eliminação do efeito tiristor parasitário (latch up), menor capacitância e corrente de fuga, melhor inclinação de sublimiar, maior transcondutância, menor efeito de canal curto, maior resistência à radiação ${ }^{8,9}$, e baixa sensibilidade à variação de temperatura ${ }^{10}$.

Na Figura 2.1 é apresentado o perfil transversal de um transistor SOI nMOSFET, sendo indicados os eletrodos de porta $\left(V_{G F}\right)$, substrato $\left(V_{G B}\right)$, dreno $\left(V_{D}\right)$ e fonte $\left(V_{S}\right)$, as espessuras do óxido de porta $\left(t_{\text {oxf }}\right)$, da camada de silício $\left(t_{\mathrm{si}}\right)$ e do óxido enterrado $\left(\mathrm{t}_{\mathrm{oxb}}\right)$, assim como a representação de três das interfaces $\mathrm{Si}-\mathrm{SiO}_{2}$ da estrutura.

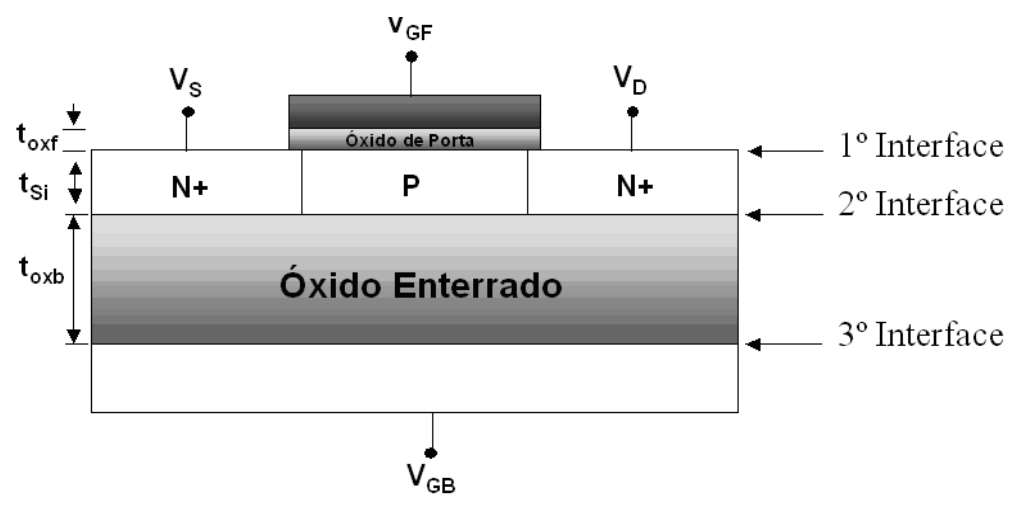

Figura 2. 1. Perfil transversal de um transistor SOI nMOSFET. 


\subsubsection{Tipos de Transistores SOI MOSFETs.}

O modo de funcionamento do transistor SOI depende da espessura da camada de silício $\left(t_{s i}\right)$, da concentração de dopantes na região ativa $\left(\mathrm{N}_{\mathrm{af}}\right)$ e da temperatura. Dependendo da espessura da camada de silício e de sua depleção máxima, o transistor pode operar totalmente depletado ou parcialmente depletado.

Nos dispositivos fabricados com a tecnologia MOSFET convencional, a região de depleção máxima $\left(x_{\text {dmáx }}\right)$ é determinada pela equação (2.1) e o potencial de Fermi, em função do tipo de dopantes do substrato, é determinado pela equação (2.2) ${ }^{11}$. A região de depleção máxima estende-se a partir da interface $\mathrm{Si}-\mathrm{SiO}_{2}$ até $\mathrm{x}_{\mathrm{dmáx}}$.

$$
\begin{gathered}
x_{\text {dmáx }}=\sqrt{\frac{4 \varepsilon_{S i} \phi_{F}}{q N_{B}}} \\
\phi_{F}=\frac{k T}{q} \ln \left(\frac{N_{B}}{n_{i}}\right)
\end{gathered}
$$

Nas equações acima, $\varepsilon_{S i}$ é a permissividade do silício; q é a carga elementar do elétron; $N_{B}$ é a concentração de impurezas do substrato; $k$ é a constante de Boltzmann; $T$ é a temperatura absoluta e $n_{i}$ é a concentração intrínseca de portadores.

Em dispositivos SOI totalmente depletados (FD SOI - "fully depleted"), a espessura da camada de silício $\left(\mathrm{t}_{\mathrm{si}}\right)$ é menor que a profundidade da depleção máxima ( $x_{\text {dmáx }}$ ), ou seja, $t_{s i}<x_{d m a ́ x}$. Nesse caso, o canal 
permanecerá depletado quando a tensão de limiar for aplicada, independente da tensão aplicada ao substrato.

Esses dispositivos apresentam as melhores características elétricas entre os dispositivos SOI, tais como, menor efeito de canal curto ${ }^{12}$, características quase ideais de inclinação de sublimiar $^{13}$, maior mobilidade ${ }^{14}$, maior corrente de saturação, menor campo elétrico no silício, maior transcondutância e menor variação da tensão de limiar com a temperatura ${ }^{15}$, se comparado aos transistores MOSFETs convencionais e parcialmente depletados.

Em dispositivos SOI parcialmente depletados (PD SOI - "partially depleted'), a espessura da camada de silício ( $\mathrm{t}_{\mathrm{si}}$ ) é maior do que duas vezes a profundidade da depleção máxima, ou seja, $t_{s i}>2 x_{d m a ́ x}$, Nesse caso, nunca haverá interação entre as regiões de depleção provenientes da primeira e segunda interfaces. Haverá sempre uma região neutra entre as regiões de depleção que se ligada por um contato de corpo, faz com que o dispositivo tenha um comportamento idêntico ao dos transistores MOSFETs convencionais.

Caso essa região esteja eletricamente flutuando, aparecerão efeitos parasitários indesejáveis como o efeito de elevação abrupta de corrente (kink effect).

A figura 2.2 apresenta os diagramas das faixas de energia dos dispositivos fabricados segundo a tecnologia MOSFET convencional, SOI parcialmente depletado e SOI totalmente depletado, onde $E_{C}, E_{F}$ e $E_{V}$ são os níveis de energia de condução, Fermi e valência, respectivamente. 
(A)

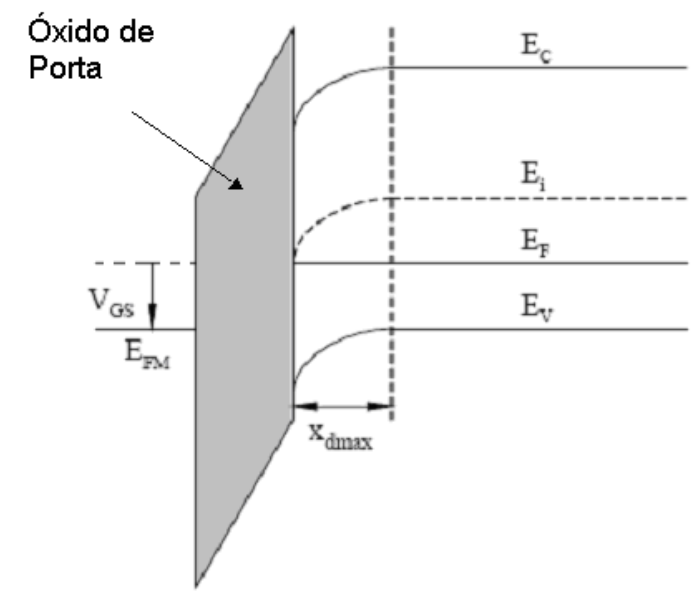

(B)

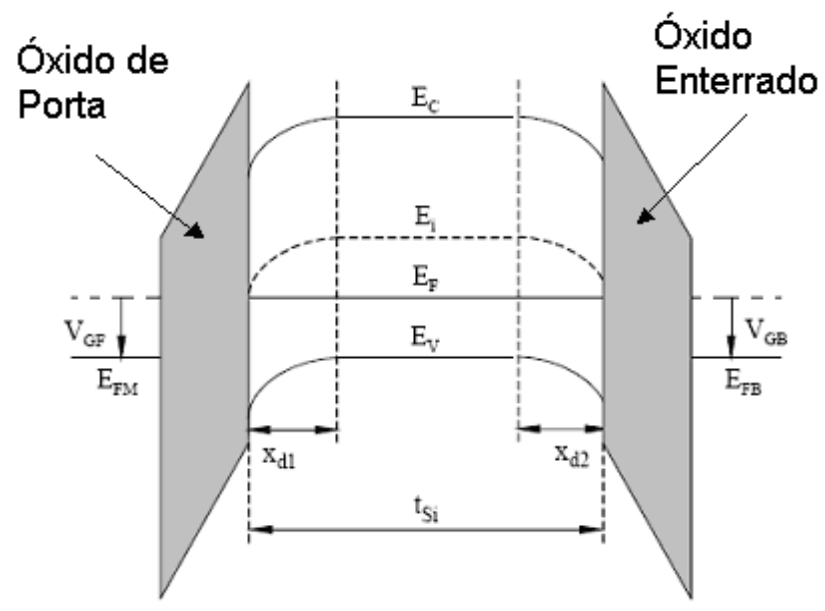

(C)

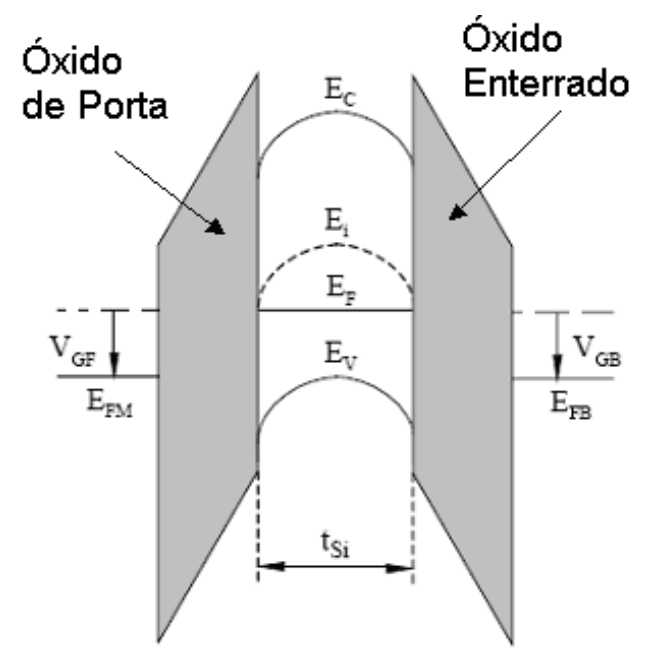

Figura 2. 2. Diagrama de faixas de energia para transistores nMOSFETs (a) com tecnologia MOSFET convencional, (b) com tecnologia SOI parcialmente depletado e (c) com tecnologia SOI totalmente depletado. 


\subsubsection{Principais parâmetros elétricos dos transistores SOI MOSFETs}

\subsubsection{Tensão de Limiar}

A tensão de limiar é definida como a tensão aplicada na porta capaz de formar um canal de inversão na interface entre óxido de porta e corpo de silício do transistor. Supondo um transistor com canal tipo $\mathrm{n}$, quando uma tensão positiva é aplicada na porta desse transistor, o campo elétrico repele as lacunas da interface criando assim uma região de depleção contendo cargas fixas negativas. Um posterior aumento na tensão de porta causa o aparecimento de elétrons na interface, sendo esta então chamada de camada de inversão ou canal. Sendo assim, a tensão aplicada na porta que faz com que a densidade de elétrons na interface seja a mesma da densidade de lacunas do material, é chamada de tensão de limiar. Em outras palavras, a tensão de limiar é a tensão na qual há elétrons suficientes na camada de inversão fazendo com que haja um caminho de condução de baixa resistência entre as regiões de fonte e dreno.

Em dispositivos MOSFETs convencionais, a tensão de limiar é dada pela expressão (2.3), sendo esta a mesma de dispositivos SOI parcialmente depletados $\left(t_{s i}>2 x_{\text {dmáx }}\right.$ ), onde não há interação das regiões de depleção da primeira (óxido de porta / camada de silício) e segunda (camada de silício / óxido enterrado) interfaces.

$$
V_{t h}=V_{F B}+2 \phi_{F}+\frac{q N_{B} x_{d m a ́ x}}{C_{O X}}
$$

Onde,

$$
V_{F B}=\phi_{M S}-\frac{Q_{O X}}{C_{O X}}
$$


Nas equações acima, $\mathrm{V}_{\mathrm{FB}}$ é a tensão de faixa plana, $\phi_{\mathrm{MS}}$ é a diferença da função trabalho entre o metal de porta e o semicondutor, Qox é a densidade de carga fixa no óxido de porta e $\mathrm{C}_{\mathrm{ox}}$ é a capacitância do óxido de porta por unidade de área.

Em dispositivos SOI totalmente depletados, onde há interação entre as regiões da primeira e segunda interfaces, a tensão de limiar pode ser obtida através do modelo clássico de Lim \& Fossum ${ }^{11}$. Esse modelo descreve a interdependência entre as tensões de porta $\left(V_{G F}\right)$ e substrato $\left(V_{G B}\right)$ e os potenciais de superfície da primeira $\left(\phi_{S_{1}}\right)$ e segunda ( $\left.\phi_{S_{2}}\right)$ interfaces. Desta forma, a tensão aplicada na porta $\mathrm{V}_{\mathrm{GF}}$ e no substrato $\left(\mathrm{V}_{\mathrm{GB}}\right)$ influenciarão os potenciais de superfície $\phi_{S 1}$ e $\phi_{S 2}$. As equações 2.5 e 2.6 descrevem essa relação.

$$
\begin{gathered}
V_{G F}=\phi_{M S 1}-\frac{Q_{o X 1}}{C_{o x 1}}+\left(1+\frac{C s i}{C_{o x 1}}\right) \phi_{S 1}-\frac{C s i}{C_{o x 1}} \phi_{S 2}-\frac{0.5 Q_{d e p 1}+Q_{i n v 1}}{C_{o x 1}} \\
V_{G B}=\phi_{M S 2}-\frac{Q_{o X 2}}{C_{o x 2}}+\left(1+\frac{C s i}{C_{o x 2}}\right) \phi_{S 2}-\frac{C s i}{C_{o x 2}} \phi_{S 1}-\frac{0.5 Q_{d e p 1}+Q_{S 2}}{C_{o x 2}}
\end{gathered}
$$

Nas equações acima, $\phi_{M S 1}$ e $\phi_{M S 2}$ são a diferença de função trabalho entre a porta e a camada de silício e entre o substrato e a camada de silício, respectivamente; $Q_{O X 1}$ e $Q_{O X 2}$ é a densidade de cargas fixas da primeira e segunda interface, respectivamente; Csi é a capacitância da camada de silício por unidade de área; $Q_{d e p 1}$ é a carga total de depleção na camada de silício por unidade de área; $Q_{i n v 1}$ é a carga de inversão por unidade de área na primeira interface; $Q_{S 2}$ é a carga de inversão por unidade de área ( $Q_{S 2}<0$ ), ou a carga de acumulação $\left(Q_{S 2}>0\right)$ na segunda interface.

Combinando as equações 2.5 e 2.6 acima, é possível obter as expressões da tensão de limiar da primeira interface em função da 
polarização do substrato e conseqüente condição de polarização da segunda interface:

a) Se a segunda interface estiver acumulada, e tornando: $\phi_{S 1}=2 \phi_{F}, \phi_{S 2}=0$, $Q_{\text {inv1 }}=0$, temos:

$$
V_{t h 1, a c c 2}=\phi_{M S 1}-\frac{Q_{o X 1}}{C_{o x 1}}+\left(1+\frac{C s i}{C_{o x 1}}\right) 2 \phi_{F}-\frac{Q_{d e p 1}}{2 C_{o x 1}}
$$

b) Se a segunda interface estiver invertida, e tornando: $\phi_{S 1}=2 \phi_{F}, \phi_{S 2}=2 \phi_{F}$, $Q_{\text {inv1 }}=0$, temos:

$$
V_{t h 1, i n v 2}=\phi_{M S 1}-\frac{Q_{O X 1}}{C_{o x 1}}+2 \phi_{F}-\frac{Q_{d e p 1}}{2 C_{o x 1}}
$$

c) Se a segunda interface estiver depletada, e tornando: $\phi_{S 1}=2 \phi_{F}$, $0<\phi_{S 2}<2 \phi_{F}$, temos:

$$
V_{t h 1, d e p l 2}=V_{t h 1, a c c 2}-\frac{C_{S i} C_{o x 2}}{C_{o x 1}\left(C_{S i}+C_{o x 2}\right)}\left(V_{G B}-V_{G B, a c c 2}\right)
$$

Na equação acima, $V_{G B, a c c 2}$ é determinado pela equação 2.10:

$$
V_{G B, a c c 2}=\phi_{M S 2}-\frac{Q_{o x 2}}{C_{o x 2}}+\frac{q N_{a} t_{S i}}{2 C_{o x 2}}-\left(\frac{C_{S i}}{C_{o \times 2}}\right) 2 \phi_{F}
$$

As expressões acima $(2.7$ - 2.10) são válidas se a espessura das camadas de inversão e acumulação forem muito menores que a espessura da camada de silício, o que não ocorre em dispositivos de filmes ultra-finos $\left(t_{S i}<10 \mathrm{~nm}\right)$, devido aos efeitos quânticos ${ }^{16}$. 


\subsubsection{Efeito de Canal Curto}

Conforme as dimensões dos transistores diminuem, as junções de fonte e dreno se aproximam e passam a controlar as cargas da região de depleção sob o canal, o que antes era controlado integralmente pela tensão na porta. Sendo assim, a porta perde parte do controle da região de depleção abaixo dela, ou seja, $Q_{\text {deplef }}<Q_{\text {depl }}$.

Em função da redução dessas dimensões e, conseqüentemente, da redução do canal, há o aparecimento de vários efeitos indesejáveis chamados de efeito de canal curto (SCE - Short Channel Effect). Entre esses efeitos destaca-se a redução da tensão de limiar $V_{t h F}($ Qdeplef $)<V_{t h F}($ Qdep $)$ e aumento da inclinação de sublimiar ${ }^{16}$.

A carga de depleção controlada pela porta nos transistores MOSFETs convencionais de canal longo é dada pela equação 2.11 .

$$
\text { Qdepl }=q N_{B} x_{d m a ́ x}
$$

Para transistores MOSFETs de canal curto, a carga de depleção controlada pela porta é dada pela equação 2.12 , onde $r_{j}$ é a profundidade da junção de fonte e dreno.

$$
Q_{\text {depl }, \text { ef }}=Q_{\text {depl }}\left[1-\frac{r_{j}}{L}\left(\sqrt{1+\frac{2 x_{d m a ́ x}}{r_{j}}}-1\right)\right]
$$

Já em transistores SOI MOSFETs totalmente depletados, o substrato participa do compartilhamento da carga de depleção com a porta, fonte e dreno influenciando na redução da tensão de limiar. A carga de depleção efetiva controlada pela porta é dada pela equação $2.13^{17}$.

$$
Q_{\text {depl,ef }}=q N_{B} t_{S i}\left(1-\frac{d}{L}\right)
$$


Esses dispositivos apresentam menor efeito de canal curto que dispositivos MOSFETs convencionais em relação à redução do comprimento de canal, embora a magnitude desses efeitos dependa da espessura do filme de silício $^{12}$. A figura 2.3 mostra a influência da redução do comprimento de canal em dispositivos MOSFETs convencionais e SOI MOSFETs totalmente depletados.
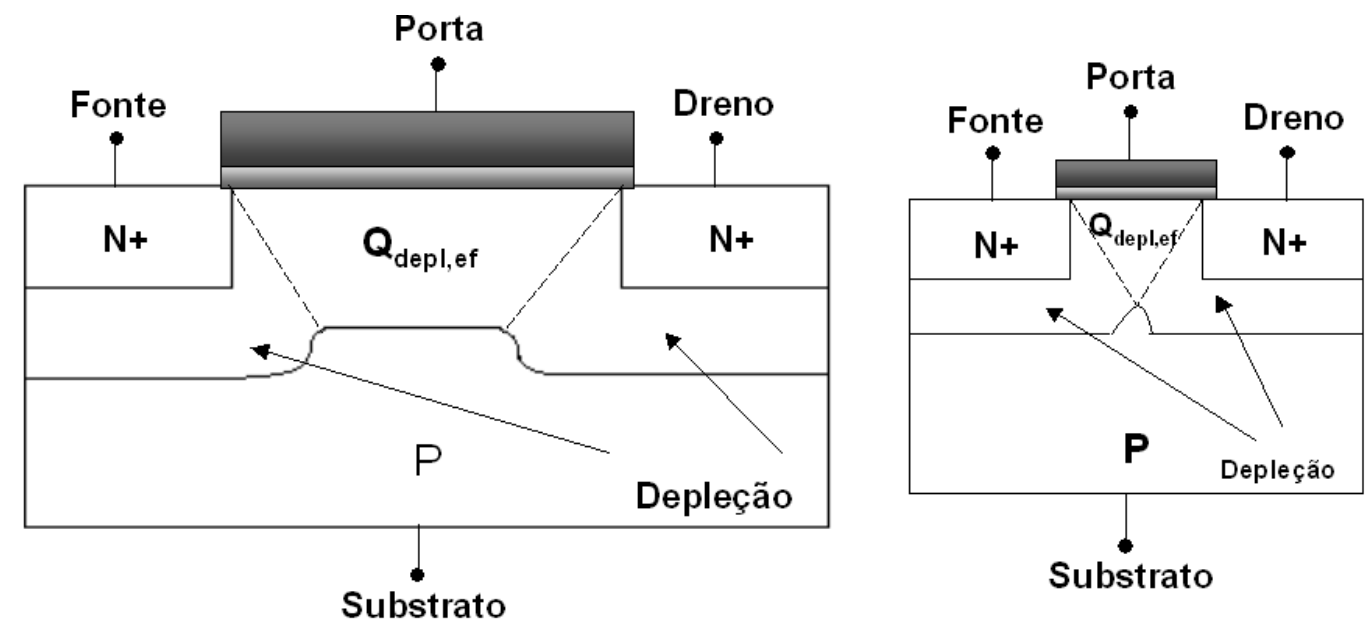

(a)
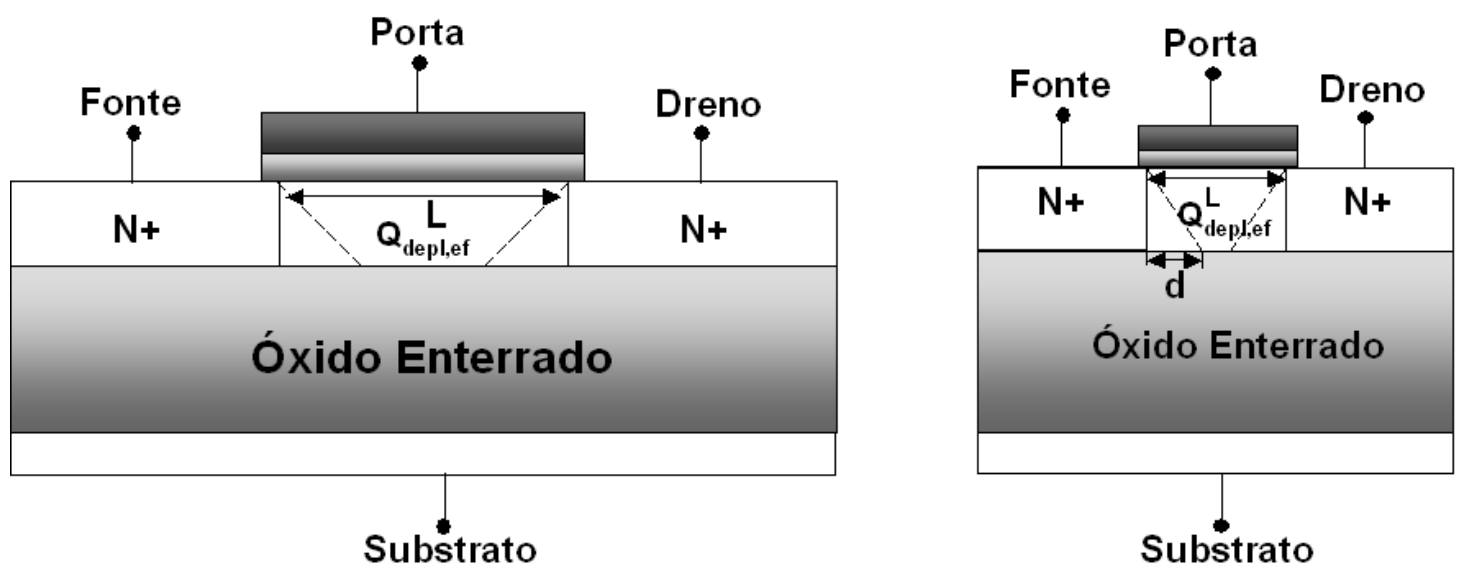

(b)

Figura 2. 3. Distribuição das regiões de depleção em transistores (a) MOSFETs convencionais e (b) SOI totalmente depletados. 
Como mostrado na figura 2.3, a quantidade de carga total efetivamente controlada pela porta em dispositivos SOI de canal curto é maior, se comparada com dispositivos MOSFETs convencionais.

A variação relativa da tensão de limiar em função do comprimento de canal em dispositivos MOSFETs convencionais (bulk) e SOI MOSFET totalmente depletado é mostrada na figura 2.4. Observa-se que os dispositivos SOI apresentam uma menor redução da tensão de limiar com o comprimento de canal se comparado aos dispositivos MOSFETs convencionais ${ }^{16,17,18}$.

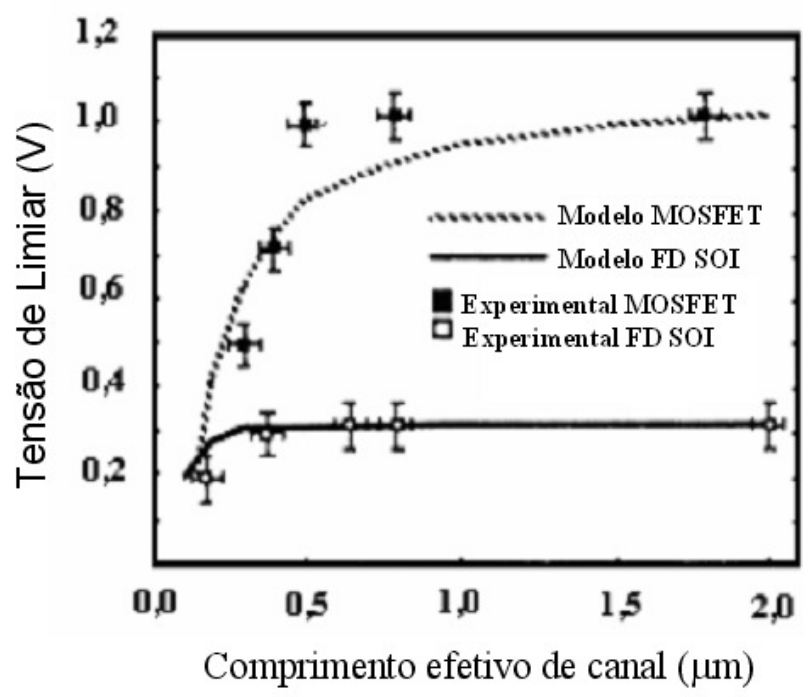

Figura 2. 4. Tensão de limiar em função do comprimento de porta de um dispositivo MOSFET convencional e de um SOI MOSFET canal $\mathrm{n}$ totalmente depletado ${ }^{16}$.

\subsubsection{Inclinação de Sublimiar}

A inclinação de sublimiar (S) é definida como o inverso da inclinação da curva $\log \left(I_{D S}\right)$ em função de $\mathrm{V}_{\mathrm{GF}}$, sendo determinada pela equação 2.14:

$$
S=\frac{d V_{G F}}{d\left(\log I_{D S}\right)}
$$


Em dispositivos MOSFETs e SOI parcialmente depletados, a inclinação de sublimiar é definida quando a região do canal estiver no regime de inversão fraca, sendo assim, o valor de $S$ é dado por ${ }^{18}$.

$$
S \cong \frac{k T}{q} \ln 10\left(1+\frac{C_{D}+C_{i t}}{C_{O X}}\right)
$$

Onde,

$$
\begin{aligned}
& C_{D}=\frac{\varepsilon_{S i}}{x_{d \max x}} \\
& C_{i t}=q N_{i t} \\
& \operatorname{Cox}=\frac{\varepsilon_{O X}}{t_{O X}}
\end{aligned}
$$

Nas equações acima, $C_{D}, C_{i t}, C_{O x}$ são a capacitância de depleção por unidade de área, a capacitância de armadilhas de interface por unidade de área e a capacitância de porta por unidade de área, respectivamente. Quanto menor a capacitância de depleção $C_{D}$ e $C_{i t}$, menor é a inclinação de sublimiar ${ }^{13}$.

Desprezando as armadilhas de interface obtém-se a expressão geral da inclinação de sublimiar, que pode ser obtida pela equação 2.19 , em função de n (fator de corpo),

$$
S \cong n \frac{k T}{q} \ln 10
$$


Dependendo do tipo de funcionamento do transistor, o fator de corpo pode ser determinado pelas equações a seguir:

$$
n_{M O S}=1+\frac{C_{D}}{C_{O X}} \quad \text { Transistor MOSFET convencional ou SOI }
$$

MOSFET parcialmente depletado.

$$
n_{a c c}=1+\frac{C_{S i}}{C_{O X}} \quad \text { Transistor SOI MOSFET totalmente depletado }
$$

com segunda interface acumulada.

$$
n_{\text {depl }}=1+\frac{C_{S i} C_{o x b}}{C_{O X}\left(C_{S i}+C_{o x b}\right)} \quad \text { Transistor SOI MOSFET totalmente }
$$
depletado com segunda interface depletada.

Os valores de $\mathrm{n}$ estão tipicamente na seqüência $n_{d e p l}<n_{M O S}<n_{a c c} \mathrm{e}$, conseqüentemente, $S_{d e p l}<S_{M O S}<S_{a c c}$.

Em dispositivos SOI parcialmente depletados, a capacitância de depleção está relacionada ao nível de dopagem, assim como em dispositivos MOSFETs convencionais. Por outro lado, em dispositivos totalmente depletados, a espessura do filme de silício pode ser menor que a máxima largura de depleção, para um nível de dopagem considerado. Conseqüentemente, uma vez que o filme esteja completamente depletado, qualquer aumento na tensão da porta não trará aumento nas cargas de depleção, mas sim um aumento no potencial de superfície, e um aumento da concentração de elétrons na camada de inversão. Assim, o valor da inclinação de sublimiar deverá ser menor em transistores SOI totalmente depletados do que em transistores parcialmente depletados, ou seja, para transistores de filme muito finos, a inclinação de sublimiar tende ao valor mínimo teórico enquanto que para filmes mais espessos, a inclinação de sublimiar atinge o valor convencional ${ }^{13}$. 


\subsection{A tecnologia SOI de Múltiplas Portas}

Os primeiros transistores SOI datam de antes de 1964. Esses dispositivos eram parcialmente depletados fabricados na tecnologia silício sobre safira (SOS), usados com sucesso em inúmeras aplicações militares e espaciais $^{19}$. A tecnologia SOS apresenta mobilidade elétrica inferior a mobilidade dos substratos de silício convencionais e uma grande quantidade de defeitos. Até a década de 80 era o único material utilizado para produção de circuitos VLSI em SOI.

A partir de meados de 1980, foi produzido o primeiro SOI MOSFET totalmente depletado apresentando como características principais o aumento da transcondutância, da condução de corrente, menor inclinação de sublimiar, menor efeito de canal curto, entre outros.

Por décadas, a integração da tecnologia CMOS seguiu a Lei de Moore ${ }^{1}$ trazendo o comprimento do canal a dimensões menores do que 100 $\mathrm{nm}$ e a espessura do óxido de porta a dimensões inferiores a $2 \mathrm{~nm}$. Entretanto, efeitos de canal curto, redução da barreira induzida pelo dreno (DIBL), perfuração superficial e tunelamento da porta são observados ${ }^{20}$. Com o intuito de superar essas limitações e continuar escalonando os dispositivos, novos materiais e novas arquiteturas se fazem necessárias.

Transistores SOI MOSFETs evoluíram da arquitetura clássica, planar, de única porta, para arquitetura tridimensional com estruturas de múltiplas portas (duas, três e quatro portas), sendo então chamados de dispositivos de múltiplas portas (MuGFET - Multi Gate Field Effect Transistor).

Os dispositivos de múltiplas portas são conhecidos como dispositivos de arquitetura promissora para aplicações em tecnologia CMOS abaixo de 20 $\mathrm{nm}^{21,22,23}$. A arquitetura tridimensional faz com que a porta do transistor apresente um melhor controle das cargas na região do canal permitindo o controle e conseqüentemente, a redução dos efeitos de canal curto e das 
correntes de fuga, e o aumento da mobilidade elétrica devido à região de canal, em geral, ser pouco dopada ${ }^{24}$.

A figura 2.5 mostra a evolução dos transistores SOI MOSFETs.

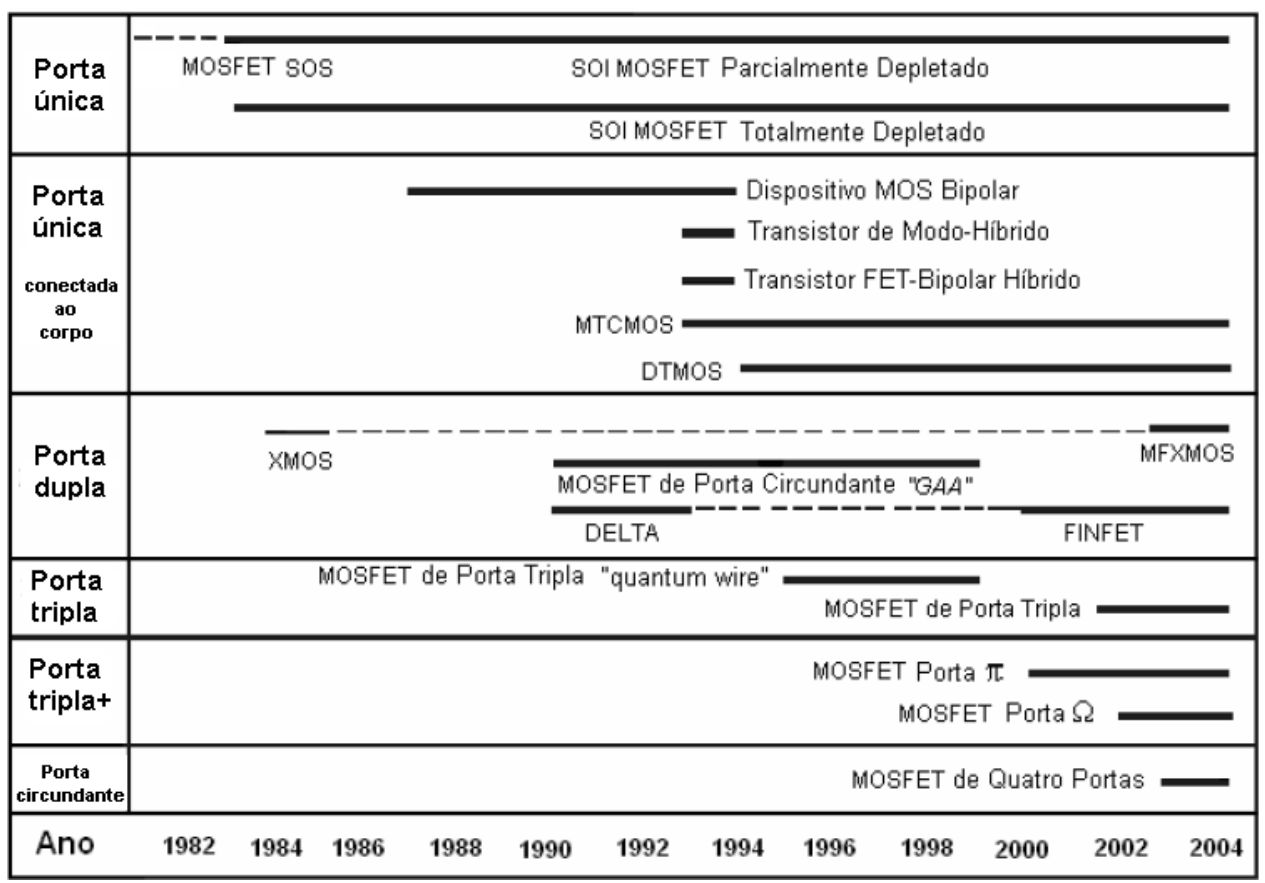

Figura 2. 5. Evolução dos transistores SOI MOSFETs ${ }^{25}$.

\subsubsection{Dispositivos SOI MOSFETs de porta dupla}

Um transistor que exibe excelente desempenho, inclinação de sublimiar perto do ideal, alta transcondutância, minimização dos efeitos de canal curto, se comparado a um dispositivo de porta única, é o dispositivo SOI MOSFET de porta dupla ${ }^{26}$. A complexidade do processo de fabricação, em particular, do alinhamento da porta superior com a porta inferior (transistor XMOS) ainda é um fator limitante para o desenvolvimento industrial da tecnologia de duas portas. Com o intuito de evitar esse problema tecnológico, foram propostas as estruturas DELTA ${ }^{27}$ e FinFET ${ }^{28}$ com portas laterais.

O transistor DELTA (fully DEpleted Lean- channel TrAnsistor), figura 2.6b, foi o primeiro dispositivo SOI MOSFET de porta dupla fabricado, datando 
de 1989. Esse transistor apresenta como características uma nova estrutura de porta que induz verticalmente os efeitos dos dispositivos SOI ultrafinos, substrato SOI formado por oxidação seletiva e canal formado com superfície vertical, sendo a largura do canal dependente da altura da ilha de silício, chamada de "dedo", fin.

A estrutura FinFET é similar ao DELTA exceto pela presença de uma camada dielétrica chamada de hard mask no topo do filme de silício. Essa camada é usada para prevenir a formação de canal de inversão parasita nos cantos superiores do dispositivo. Nesses dispositivos, a porta cobre os três lados do fin, tanto no canal superior como nos canais laterais. A presença de um óxido mais espesso na porta superior faz com que essa região tenha uma menor contribuição no controle das cargas, focando assim que o controle dessas seja feito pelas portas laterais.

Em 1990, o primeiro dispositivo de porta dupla implementado na prática $^{25}$ foi o transistor de porta circundante GAA (gate-all-around). Esse transistor apresenta canal na forma horizontal, envolto por isolante e material de porta. Apesar de apresentar material de porta circundando toda a região do canal, esse dispositivo é considerado de porta dupla, pois a largura do seu canal é muito maior do que a espessura da camada de silício, fazendo com que duas de suas portas não influenciem no comportamento do dispositivo. A figura 2.6 apresenta os exemplos de dispositivos de porta-dupla e tripla.

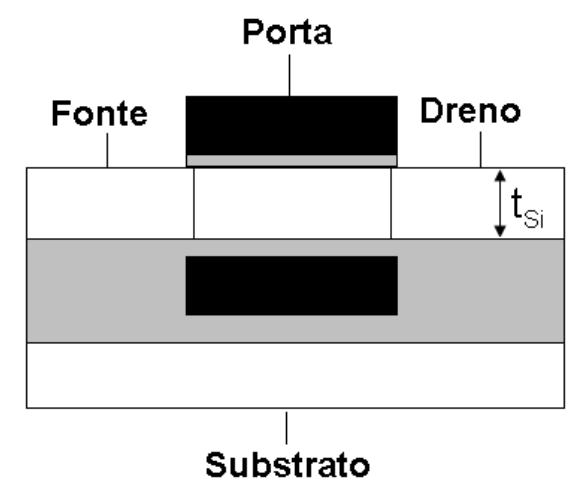

(a)

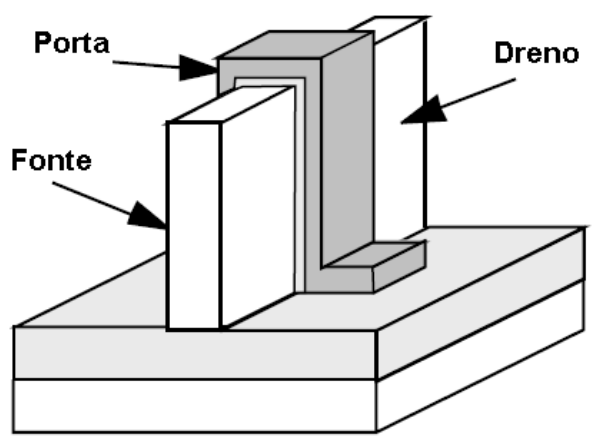

(b)

Figura 2. 6. Exemplos de estruturas de porta dupla e tripla SOI MOSFETs (a) Transistor XMOS, (b) DELTA MOSFET. 


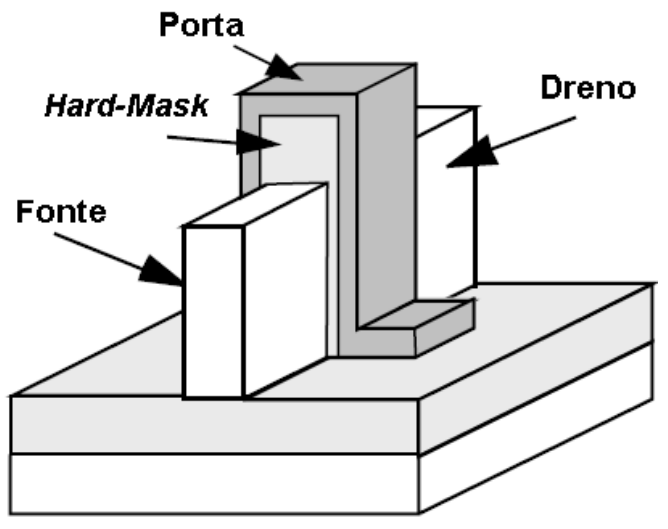

(c)

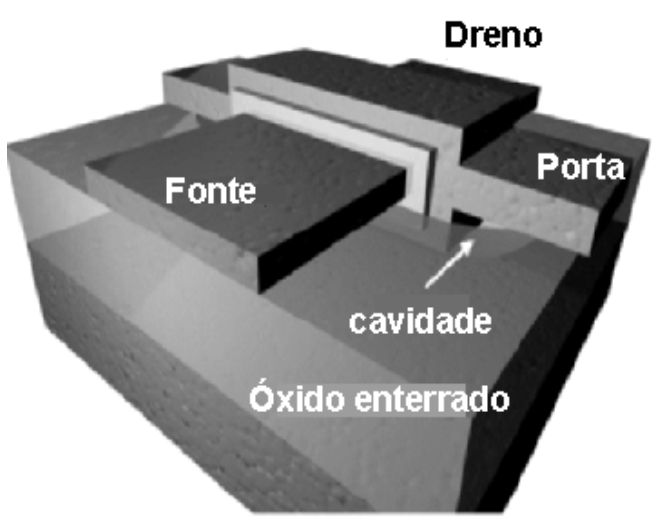

(d)

Figura 2. 6. Exemplos de estruturas de porta dupla, (c) FinFET e (d) GAA MOSFET.

\subsubsection{Dispositivos FinFETs de porta tripla e porta tripla+}

Um dispositivo FinFET com a porta superior ativa pode ser chamado de FinFET de porta tripla (Figura 2.7). Esses dispositivos apresentam a região do canal envolvida por três portas. Nesse caso, o óxido de porta deve ser igualmente fino nos três lados do canal com o intuito de se evitar tensões de limiar múltiplas ${ }^{29}$.

O FinFET de porta tripla chama atenção devido a sua elevada corrente no estado ligado ${ }^{30}$ com o uso de múltiplos fins ${ }^{31}$, e melhora no efeito de canal curto. Uma desvantagem desse dispositivo em relação ao FinFET é a presença do efeito de canto (corner effect) mais pronunciado ${ }^{32}$.

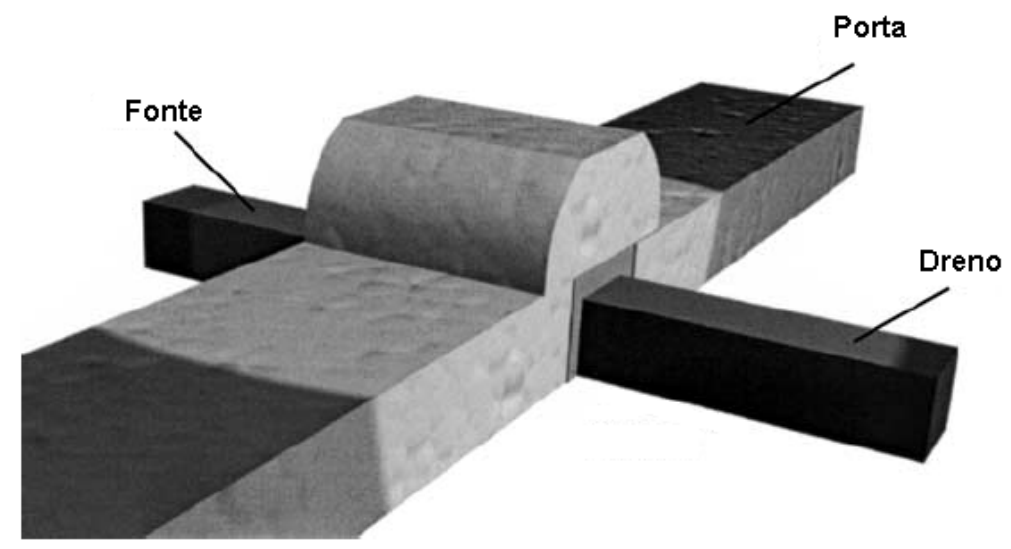

Figura 2. 7. Estrutura SOI FinFET de porta tripla ${ }^{25}$. 
O efeito de canto ocorre devido à influência do raio de curvatura nas extremidades ("cantos") do transistor, podendo dar origem a correntes parasitárias indesejáveis. Esse efeito pode ser minimizado usando material de porta midgap, dopagem reduzida na região do canal ou cantos com raios de curvatura de valores altos ${ }^{33}$. A figura 2.8 mostra o efeito de canto onde $t_{\mathrm{Si}} \mathrm{e}$ $W_{\text {FIN }}$ são a espessura e a largura do dispositivo, r_sup e $r_{-}$inf são os raios de curvatura do canto superior e inferior, respectivamente e $t_{\text {ext }}$ é a profundidade da extensão de porta no óxido enterrado.

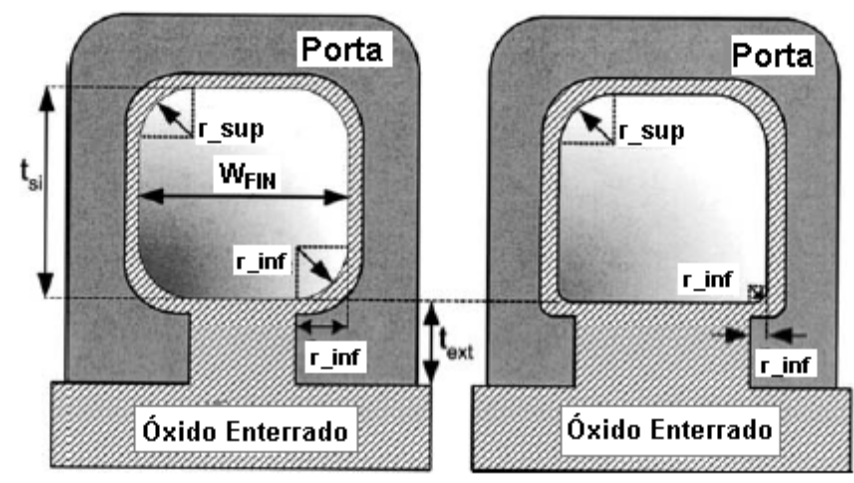

(A)

(B)

Figura 2. 8. Seção transversal das estruturas de Porta $\Omega$, onde $r$ sup é diferente de $r$ inf (a); e Porta $\Pi$, onde $r \_s u p$ é igual a $r$ inf (b).

Em um estudo feito para analisar o comportamento do efeito de canto em dispositivos de múltiplas portas com alta concentração de dopantes através de curvas de corrente de dreno e capacitância ${ }^{34}$, foi observado a presença de mais de uma tensão de limiar, resultado da inversão dos cantos superiores gerando uma menor tensão de limiar. Essas curvas indicaram que a diferença entre essas tensões de limiar, de canto e das laterais, aumenta juntamente com a concentração de dopantes do canal.

Os dispositivos FinFETs de porta tripla+, tais como o de estrutura de Porta $\Pi$ e Porta $\Omega$ (Figura 2.9), apresentam características semelhantes aos FinFETs de porta tripla, porém há uma extensão do eletrodo de porta abaixo da camada ativa de silício, fazendo com que haja um aumento na condução 
de corrente e melhora dos efeitos de canal curto. Esses dispositivos são chamados de FinFETs de porta tripla+ pois, suas características situam-se entre os FinFETs de porta tripla e quatro portas.

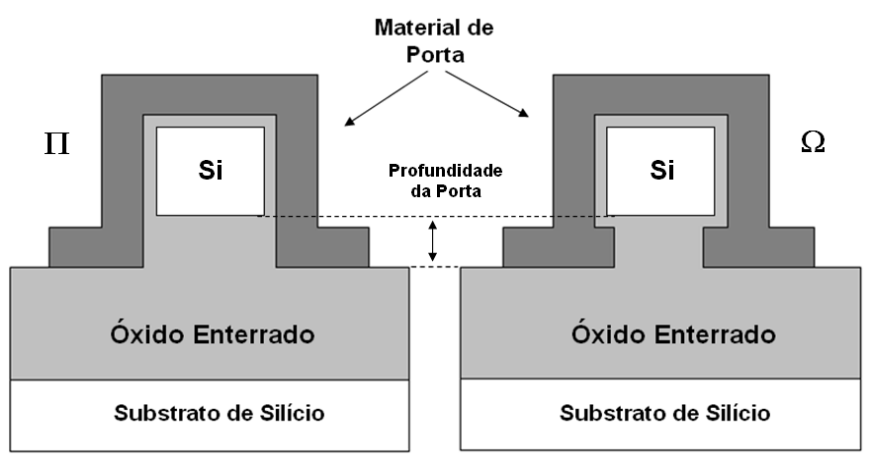

Figura 2. 9. Seção transversais de transistores FinFETs de Porta П e Porta $\Omega$.

A extensão de porta é formada utilizando uma taxa de corrosão maior no óxido enterrado durante a etapa de definição da camada de silício ${ }^{25}$. Essa extensão, abaixo da região ativa, forma um campo induzido na parte inferior do dispositivo que bloqueia o espalhamento das linhas de campo elétrico provenientes do dreno na região do canal, fazendo assim com que o esse campo elétrico se limite às extensões de porta, como pode ser visto na figura 2.10 .

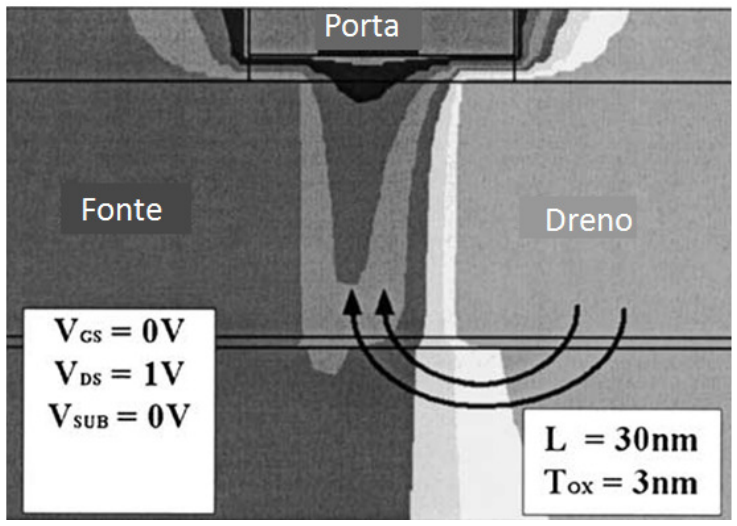

(a)

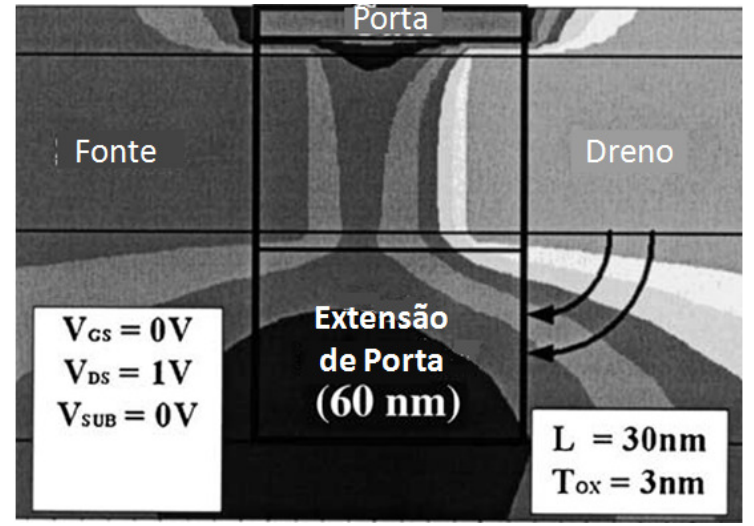

(b)

Figura 2. 10. Distribuição de potencial em transistores FinFETs de Porta tripla (a) e Porta $\Pi^{25}$.

A figura 2.10a mostra que há invasão do campo elétrico do dreno na região do canal no FinFET de porta tripla, o que não ocorre no FinFET de 
porta $\Pi(b)$. Podendo observar a eficácia do campo induzido pela pseudo-porta criada pela extensão do eletrodo de porta.

A figura 2.11 apresenta as diferentes configurações de porta de transistores SOI MOSFETs.

Porta Única

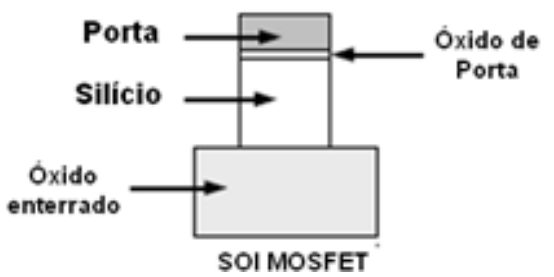

\section{Porta Tripla}
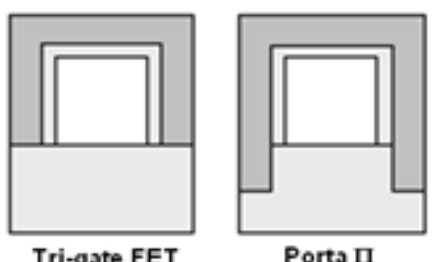

Porta II

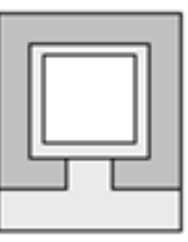

Porta Q

\section{Porta Dupla}
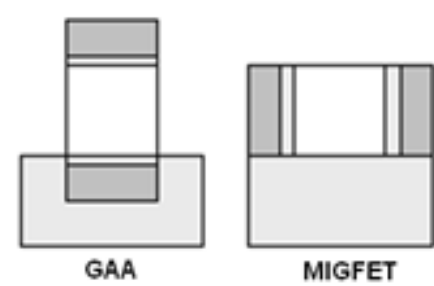

MIGFET

Porta Circundante

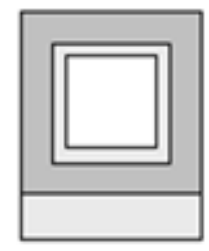

Porta Quádrupla

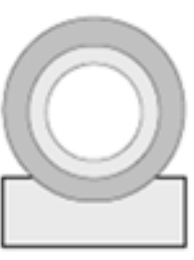

Porta Cilindrica

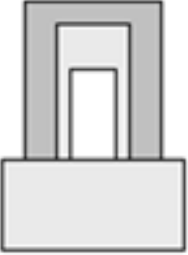

FinfET

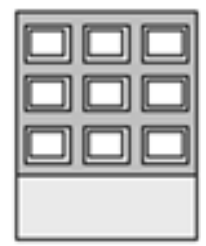

Nanowire FET

Figura 2. 11. Diferentes configurações de Porta de transistores SOI MOSFETs ${ }^{35}$.

\subsection{Características elétricas dos transistores de múltiplas portas}

\subsubsection{Corrente de Dreno}

Em dispositivos SOI de múltiplas portas, a corrente de dreno é igual a somatória das correntes que fluem ao longo de todas as interfaces cobertas pelo eletrodo de porta, podendo-se dizer que a corrente de dreno de um dispositivo de múltiplas portas é no mínimo igual a corrente de um dispositivo de porta única multiplicado pelo seu número de portas, desde que os portadores tenham a mesma mobilidade em todas as interfaces $\mathrm{Si}_{-} \mathrm{SiO}_{2}$.

Com o intuito de aumentar a corrente de dreno, dispositivos com configuração de múltiplos fins são usados (figura 2.12). A corrente de dreno 
de um dispositivo de múltiplos "dedos" é igual a corrente de um único fin multiplicado pelo número total de fins.

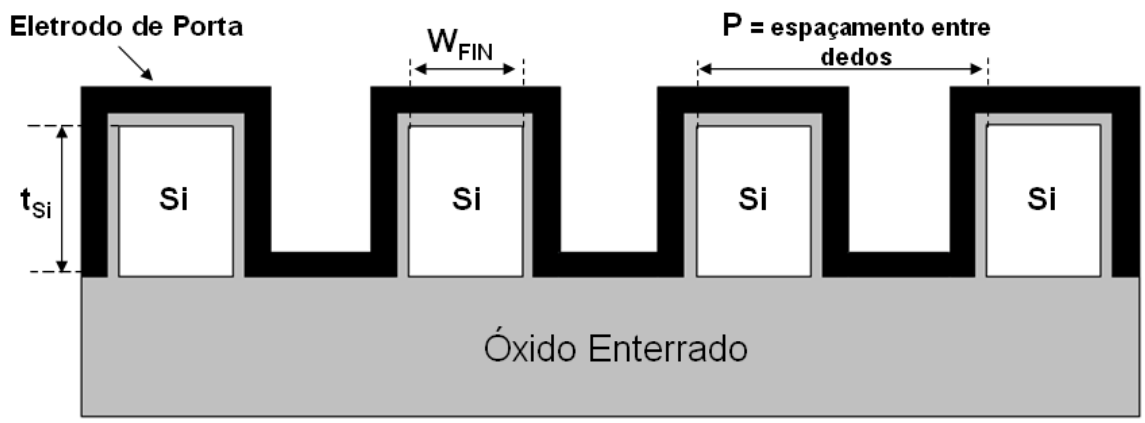

Figura 2. 12. Estrutura de múltiplos "dedos" (multi-fins) ${ }^{36}$.

Considerando P o espaçamento entre fins, a corrente de dreno em dispositivos de múltiplas portas é dada pela equação 2.23:

$$
I_{D}=I_{D 0} \frac{\theta \mu_{T O P O} W_{F I N}+2 \mu_{L A T} t_{S i}}{\mu_{T O P O} P}
$$

Onde, I I é a corrente de um dispositivo planar de porta única, $W_{\mathrm{FIN}}$ é a largura de cada fin, $t_{S i}$ é a espessura do filme de silício, $\mu_{\text {TOPO é a mobilidade }}$ da interface superior, $\mu_{\mathrm{LAT}}$ é a mobilidade das interfaces laterais. Para FinFETs de porta tripla $\theta=1$, pois a condução de corrente ocorre nas três interfaces e, para dispositivos de porta dupla (FinFETs) $\theta=0$, pois a condução de corrente é feita somente nas interfaces laterais ${ }^{37}$.

\subsubsection{Efeito de Canal Curto}

Efeito de canal curto pode ser definido como sendo efeitos indesejáveis que ocorrem nos dispositivos como, a degradação da inclinação de sublimiar e a redução da tensão de limiar, devido a redução do comprimento de canal desses dispositivos. Esse efeito é causado pela invasão das linhas de campo elétrico provenientes do dreno na região do canal, competindo com a porta pela carga de depleção disponível. 
A figura 2.13 mostra como a porta e o dreno competem pela carga de depleção do dispositivo. Observa-se que o controle da porta é exercido nas direções y e $z$, competindo com a variação do campo elétrico na direção $x$ devido a tensão aplicada no dreno.

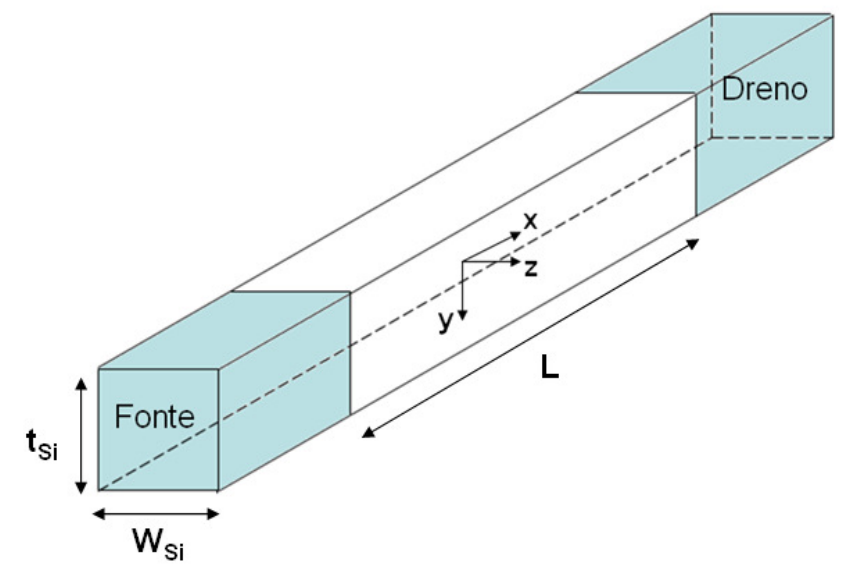

Figura 2. 13. Definição do sistema de coordenadas de um dispositivo de múltiplas portas ${ }^{16}$.

A distribuição do potencial na região do canal de um dispositivo SOI MOSFET totalmente depletado pode ser obtida a partir da equação de Poisson, equação 2.24:

$$
\frac{d^{2} \phi(x, y, z)}{d x^{2}}+\frac{d^{2} \phi(x, y, z)}{d y^{2}}+\frac{d^{2} \phi(x, y, z)}{d z^{2}}=\frac{q N_{A}}{\varepsilon_{S i}}
$$

Em dispositivos de porta dupla ou porta única com largura suficientemente grande, considera-se que o campo elétrico na direção z seja nulo, ou seja, $\frac{d \phi}{d z}=0$, portanto a equação 2.24 acima passa a ser:

$$
\frac{d^{2} \phi(x, y)}{d x^{2}}+\frac{d^{2} \phi(x, y)}{d y^{2}}=\frac{q N a}{\varepsilon_{S i}}
$$

Através de uma análise unidimensional sabe-se que o perfil do potencial em função da profundidade de um SOI MOSFET totalmente depletado é parabólico. Assumindo uma distribuição similar na direção y para uma análise bidimensional pode-se escrever ${ }^{12}$ : 


$$
\phi(x, y)=c_{0}(x)+c_{1}(x) y+c_{2}(x) y^{2}
$$

A partir das equações acima e através de algumas condições de contorno, é possível determinar qual o comprimento natural para cada tipo de estrutura.

O comprimento natural $(\lambda)$ é um parâmetro dependente do óxido de porta e da espessura da camada de silício, que representa a distância de penetração das linhas de campo elétrico do dreno no corpo do dispositivo, controlando assim o espalhamento do potencial elétrico na direção $x$.

Com o intuito de se evitar o efeito de canal curto, ou pelo menos, manter uma inclinação de sublimiar razoável, é possível prever o quanto se pode reduzir a espessura do filme de silício, através do comprimento natural. Sendo assim, quanto menor for 0 valor de $\lambda$, menor será o efeito de canal curto na inclinação de sublimiar.

Em dispositivos SOI MOSFETs de porta única, seguindo algumas condições de contorno para resolução da equação 2.26 , o comprimento natural pode ser escrito como $^{16}$ :

$$
\lambda_{1}=\sqrt{\frac{\varepsilon_{S i}}{\varepsilon_{O X}} t_{O X} t_{S i}}
$$

Em dispositivos de porta dupla, obtém-se:

$$
\lambda_{2}=\sqrt{\frac{\mathcal{E}_{S i}}{2 \varepsilon_{O X}} t_{O X} t_{S i}}
$$

Esses dispositivos com o dobro da espessura de silício de um dispositivo de porta única apresentam controle do efeito de canal curto idênticos. 
Em dispositivos de porta circundante (4 portas), onde a largura e altura são idênticas $\left(\mathrm{t}_{\mathrm{Si}}=\mathrm{W}\right)$, obtém-se ${ }^{16}$ :

$$
\lambda_{3}=\sqrt{\frac{\varepsilon_{S i}}{4 \varepsilon_{O X}} t_{O X} t_{S i}}
$$

O conceito de comprimento natural pode ser usado para estimar a espessura máxima do filme de silício e a largura do dispositivo que pode ser usada para se evitar os efeitos de canal curto. Estudos feitos por simulações numéricas mostram que o comprimento efetivo de porta de um dispositivo deve ser de cinco a dez vezes maior que o seu comprimento natural para prevenir os efeitos de canal curto ${ }^{38}$.

\subsubsection{Tensão de Limiar}

Em dispositivos de múltiplas portas, a definição da tensão de limiar é diferente dos dispositivos de porta única, pois a condução de corrente nesses dispositivos ocorre na inversão fraca quando $\phi_{S}<2 \phi_{F}$. Em dispositivos FinFETs de porta tripla e porta quádrupla, a inversão pode ser alcançada em diferentes partes da região do canal, para diferentes tensões aplicadas.

Vários métodos podem ser usados para a extração da tensão de limiar $^{39}$. Francis et al. desenvolveu um extensivo método para transistores SOI de porta dupla no modo inversão. Nesse método a tensão de limiar é definida pelo método Transcondutance Change (TC). Segundo esse método, a tensão de limiar pode ser definida quando a derivada da transcondutância atingir seu valor máximo, sendo assim, o potencial de superfície na região de limiar pode ser obtido através da equação $2.30^{40}$ :

$$
\phi_{S}^{*}=2 \phi_{F}+\frac{k T}{q} \ln \left[\delta \frac{1}{1-e^{(-\alpha)}}\right]
$$


Onde $\alpha=\frac{q}{k T} \frac{Q_{D}}{8 C_{S i}}, \delta=\frac{C_{O X}}{4 C_{S i}}, \phi_{F}$ é o potencial de Fermi, $\frac{k T}{q}$ é o potencial térmico, $Q_{D}$ é a carga de depleção, $C_{S i}$ é a capacitância do silício e Cox é a capacitância do óxido de porta.

A tensão de limiar pode ser determinada substituindo os valores de $\alpha$ e $\delta$ na equação 2.30 e 2.31 , obtendo o potencial de superfície $\phi_{S}^{*}$ equivalente a $2 \phi_{F}$, entre 10 e $90 \mathrm{mV}$, o que corresponde a uma corrente de inversão fraca. Sendo assim, a tensão de limiar é dada por:

$$
V_{T}=\phi_{S}^{*}+V_{F B}+\frac{k T}{q} \frac{\alpha}{\delta} \sqrt{1+\frac{\delta}{\alpha}}
$$

$\mathrm{Na}$ equação 2.31, observa-se que o potencial de superfície em inversão fraca depende da espessura do filme de silício, da espessura do óxido de porta e da concentração de dopantes.

Para FinFETs de porta tripla, porta tripla + e de quatro portas, devido a presença de cantos nas interfaces silício e óxido de porta, a inversão pode ocorrer para diferentes tensões de porta nos cantos, nos topos ou nas laterais das interfaces $\mathrm{Si}_{-} \mathrm{SiO}_{2}$. É possível observar até quatro tensões de limiar devido ao efeito de canto, de espessuras de filme e de óxido dependendo da concentração de dopantes ${ }^{41}$.

Dispositivos com baixa concentração de dopantes exibem apenas uma única tensão de limiar, indicando que os cantos e as laterais formaram canal gradualmente. Em dispositivos com concentração de dopantes na região de canal mais elevada, observa-se a presença de dois máximos; 0 primeiro corresponde à inversão dos cantos superiores, e o segundo corresponde à formação de canal na interface superior e nas laterais, figura 2.14 . 


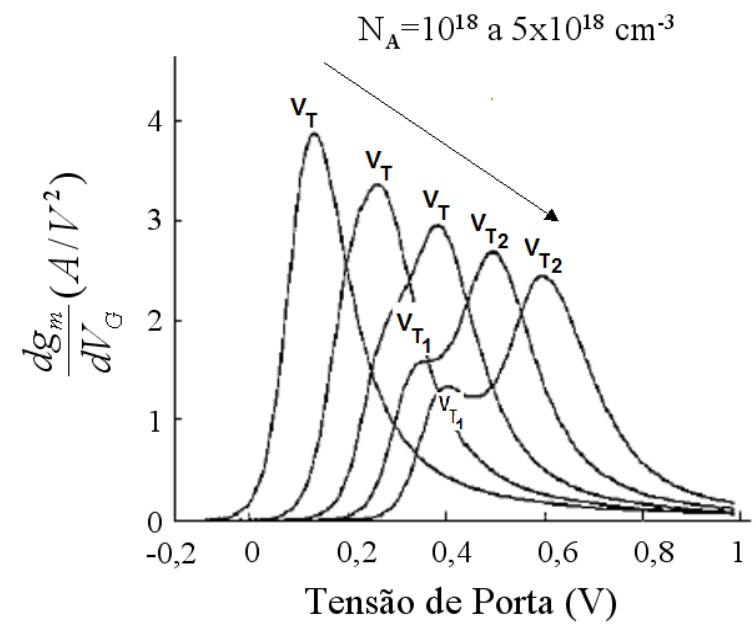

Figura 2. 14. Derivada da curva de gm em função da tensão aplicada na porta para FinFETs de porta tripla+ com diferentes concentrações de dopantes e com raio de curvatura

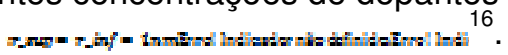

Esse efeito pode ser eliminado usando materiais de porta midgap, baixa concentração de dopantes na região do canal, ou cantos com raio de curvatura suficientemente grandes ${ }^{42,43}$. 


\section{ESTUDO DA RESISTÊNCIA SÉRIE DE FONTE E DRENO E MÉTODOS DE EXTRAÇÃO}

Neste capítulo é apresentado o conceito de resistência série de fonte e dreno em dispositivos SOI MOSFETs planares e de múltiplas portas, assim como alguns métodos de extração desse parâmetro existentes na literatura.

\subsection{Definição da Resistência série de fonte e dreno}

Com o constante avanço da tecnologia de circuitos integrados e com a conseqüente diminuição do comprimento de canal dos dispositivos, a determinação do comprimento de canal efetivo ( $\left.L_{\text {eff }}\right)$ e da resistência série de fonte e dreno $\left(R_{S D}\right)$ torna-se cada vez mais importante.

A resistência série de fonte e dreno pode ser entendida como um problema intrínseco aos dispositivos SOI MOSFETs devido à pequena camada de silício utilizada na fabricação desses dispositivos.

A medida que as dimensões dos dispositivos diminuem a valores submicrométricos, o alto campo elétrico lateral adjacente ao dreno gera problemas de confiabilidade na tecnologia. Com o intuito de se reduzir esse elevado campo elétrico, o conceito de uma região de dreno menos dopada (LDD -Lightly Doped Drain) é utilizado ${ }^{44}$.

A estrutura LDD representa uma solução para minimizar os problemas decorrentes do elevado campo elétrico junto ao dreno do transistor. O campo elétrico numa junção PN é função, além do potencial aplicado, das concentrações dos materiais que a compõe. Deste modo, para reduzir o campo elétrico lateral deve-se reduzir a concentração das junções.

Ao reduzir as concentrações de fonte e dreno, haverá um aumento na resistência série associado ao dispositivo. Na estrutura LDD, criam-se extensões das regiões de fonte e dreno, porém menos dopadas. 0 
comprimento dessas regiões deve ser projetado de modo a incrementar o menos possível a resistência de fonte e dreno.

A utilização de uma estrutura LDD reduz os efeitos causados pelo campo elétrico junto ao dreno, mas dificulta a extração dos parâmetros básicos do transistor, devido ao aumento da resistência série de fonte e dreno.

\subsubsection{Dispositivos SOI MOSFETs}

Em dispositivos SOI MOSFETs de camada fina com estrutura LDD, a resistência série de fonte e dreno pode ser considerada como a soma de todas as resistências desde a região da fonte até o dreno com exceção da resistência da região do canal. Na figura 3.1 estão representadas as principais componentes da resistência série desse tipo de transistor.

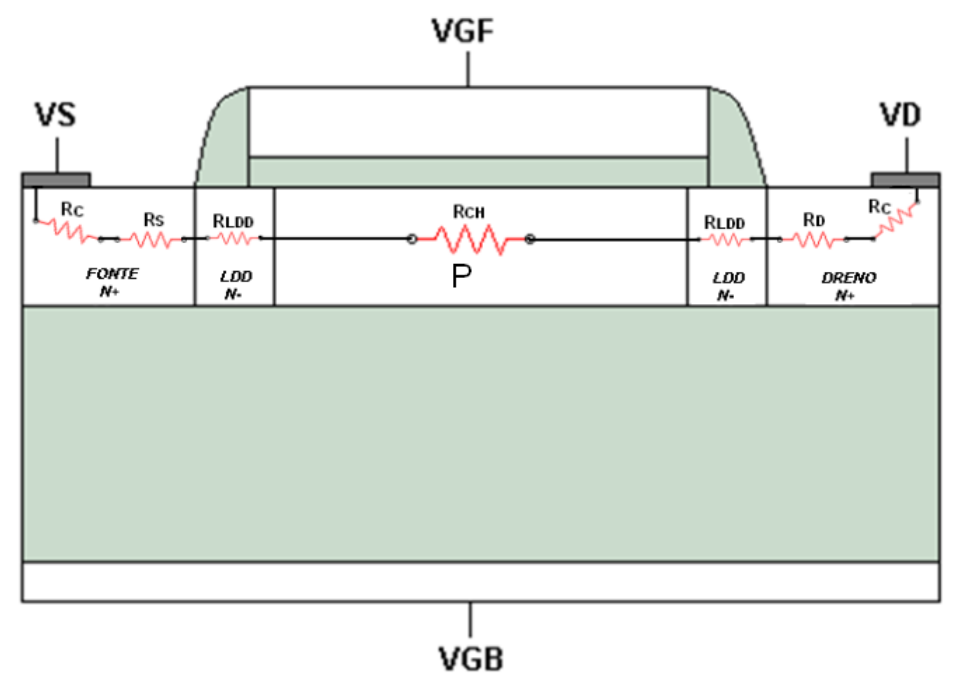

Figura 3. 1. Principais componentes da resistência série de fonte e dreno de um transistor SOI nMOSFET.

$R_{C}$ representa a resistência de contato, $R_{S}$ e $R_{D}$ a resistência da região da fonte e dreno, respectivamente, $R_{L D D}$ a resistência da região menos dopada e $\mathrm{R}_{\mathrm{CH}}$ a resistência da região do canal.

As resistências das regiões de fonte $\left(R_{S}\right)$, dreno $\left(R_{D}\right)$ e LDD têm seus valores afetados pelas condições de polarização e temperatura, enquanto que 
a resistência de contato $\left(R_{C}\right)$ pode ser considerada praticamente independente da polarização ${ }^{44}$.

Devido ao fato de uma parte da região $\mathrm{N}$ - da fonte e do dreno abaixo da região de porta ser modulada pela polarização de porta, a resistência série de fonte e dreno de um dispositivo com estrutura LDD torna-se dependente desta polarização ${ }^{45,46}$.

Genericamente, a resistência série de fonte e dreno ( $\left.R_{\mathrm{SD}}\right)$, a resistência efetiva do canal $\left(R_{C H}\right)$ e a resistência total $\left(R_{\text {TOTAL }}\right)$, em função da polarização aplicada na porta de um dispositivo SOI MOSFET operando na região linear ${ }^{47}$, podem ser obtidas através das equações 3.1 e 3.2 e 3.3 , respectivamente.

$$
R_{S D}=2 R_{C}+R_{S}+2 R_{L D D}+R_{D}
$$

Normalmente, $R_{S}=R_{D}$, então:

$$
\begin{gathered}
R_{S D}=2 R_{C}+2 R_{D}+2 R_{L D D} \\
R_{C H}\left(V_{G F}\right)=\frac{L_{e f f}\left(V_{G F}\right)}{W_{e f f} \mu_{e f f} C_{O X}\left(V_{G F}-V_{T}-0.5 V_{D}\right)} \\
R_{\text {TOTAL }}\left(V_{G F}\right)=R_{S D}\left(V_{G F}\right)+R_{C H}\left(V_{G F}\right)
\end{gathered}
$$

Onde, $W_{\text {eff }}$ é a largura efetiva do canal do transistor, $\mu_{\text {eff }}$ é a mobilidade efetiva dos portadores no canal, $\mathrm{C}_{\mathrm{Ox}}$ é a capacitância de porta e, $\mathrm{V}_{\mathrm{T}}$ é a tensão de limiar do transistor. 


\subsubsection{Dispositivos SOI MOSFETs de Múltiplas Portas}

Os dispositivos de múltiplas portas representam uma arquitetura promissora proposta para a tecnologia CMOS com nó tecnológico de $45 \mathrm{~nm}$, pois com a dificuldade de se reduzir os transistores convencionais a escalas cada vez menores houve a necessidade de se desenvolver uma nova arquitetura para os dispositivos que mantivessem ou melhorassem suas características.

Entretanto, esses dispositivos também chamados de não planares apresentam elevada resistência parasita devido ao estreitamento da largura de suas regiões de fonte e dreno.

Para que a tecnologia CMOS continue escalando os dispositivos, há a necessidade de melhorar o transporte de portadores e diminuir a resistência série de fonte e dreno ${ }^{48}$ também chamada por alguns autores de resistência parasita, sendo esse um dos principais desafios em tornar os dispositivos de múltiplas portas competitivos com os dispositivos tradicionais.

A resistência série de fonte e dreno de um dispositivo de múltiplas portas apresenta componentes provenientes das diferentes partes de sua geometria ${ }^{49}$. A figura 3.2 mostra um esquema das componentes da resistência série de fonte e dreno de um dispositivo de múltiplas portas.

Nesse esquema, $R_{a c}$ é a resistência de acumulação na região das extensões de fonte e dreno sobrepostas pela porta, $R_{s p 1}$ é a resistência de espraiamento devido ao espraiamento da corrente da fina camada de acumulação para as extensões de fonte e dreno, $R_{s h}$ é a resistência da extensão de fonte e dreno abaixo dos spacers, $R_{\mathrm{sp2}}$ é a resistência devido ao espraiamento da corrente das extensões de fonte e dreno para a região mais dopada (Heavily Doped Drain) e $\mathrm{R}_{\text {con }}$ é a resistência de contato, em função da área, entre as regiões de fonte e dreno de silício e siliceto. 


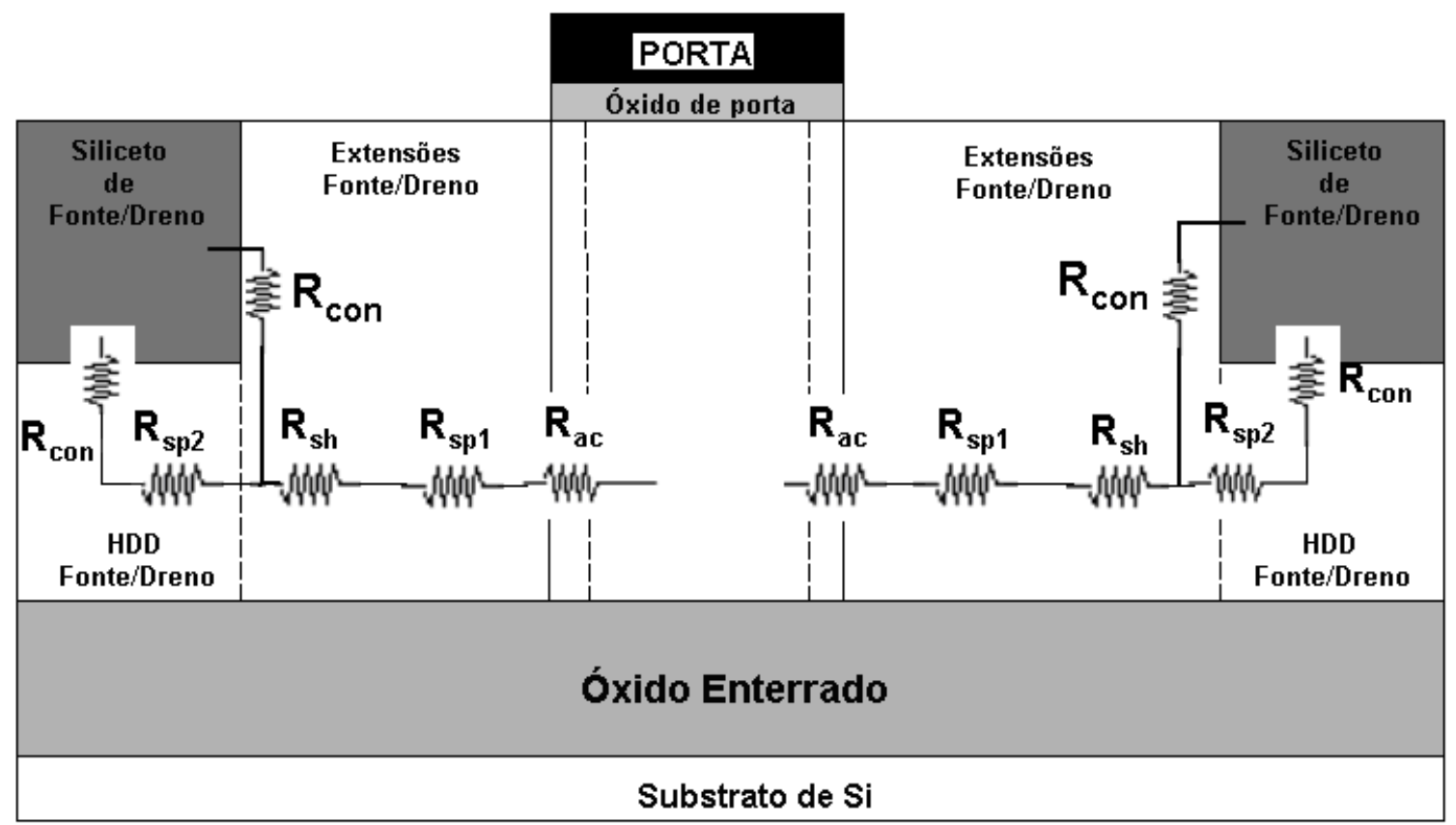

Figura 3. 2. Seção transversal de um transistor de múltiplas portas mostrando as componentes da resistência série de fonte e dreno.

Em dispositivos de múltiplas portas, as extensões de fonte e dreno podem ser entendidas como a região LDD se comparada com dispositivos SOI planares, visto anteriormente.

\subsection{Métodos de Extração da Resistência Série de Fonte e Dreno}

\subsubsection{Método de Terada e Muta ${ }^{50}$}

Em 1979, Kazuo Terada e Hiroki Muta propuseram um novo método para determinação do comprimento efetivo do canal, onde através desse método seria possível distinguir as resistências extrínsecas (de folha, de contato e da camada de difusão de fonte e dreno) da resistência intrínseca do canal, sem que um teste especial fosse feito no dispositivo.

Toda a resistência do canal $(R)$ de um dispositivo MOSFET foi dividida em resistência intrínseca do canal $R_{i}$, sendo esta controlada pela tensão 
aplicada na porta $V_{G F}$, e resistência extrínseca $R_{0}$, incluindo todas as outras resistências, como pode ser visto na figura 3.3.

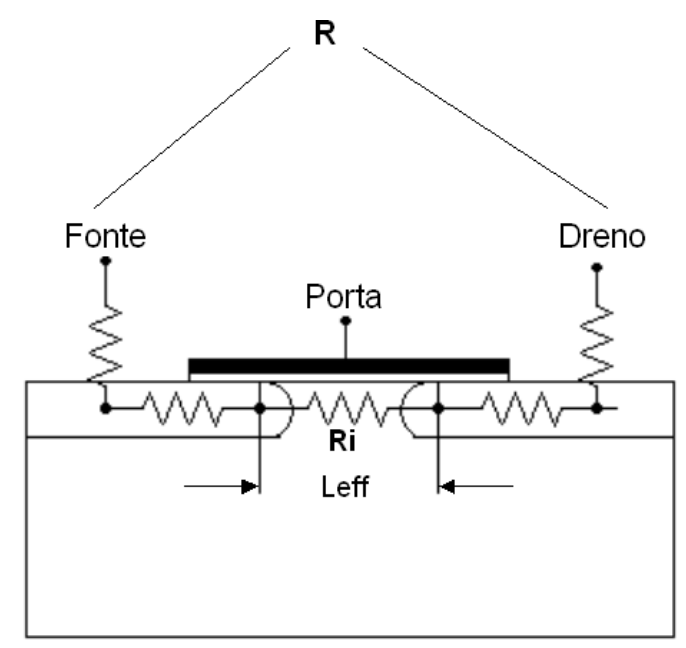

Figura 3. 3. Resistências da região do canal de um dispositivo MOSFET.

A resistência de todo o transistor $\mathrm{R}$, pode ser expressa por:

$$
R=R_{i}+R_{0}
$$

A resistência intrínseca é diretamente proporcional ao comprimento efetivo do canal $L_{\text {eff }}$ e varia com qualquer variação da tensão aplicada na porta, enquanto que $\mathrm{R}_{0}$ mantêm-se aproximadamente constante. Para se determinar o comprimento efetivo de canal, é necessário que o termo $\Delta \mathrm{L}$ seja definido. Esse $\Delta \mathrm{L}$ é causado pelo processo de redução da dimensão da máscara principalmente devido à corrosão e difusões laterais de fonte e dreno e pode ser expresso pela equação 3.5 .

$$
\Delta L=L_{M}-L_{e f f}
$$

Para baixos valores de tensão aplicada ao dreno $\left(\mathrm{V}_{\mathrm{D}}\right)$, as características de corrente e tensão são aproximadamente lineares e $R_{i}$ pode ser expressa por: 


$$
R_{i}=\frac{\rho L_{e f f}}{W}
$$

Onde $\rho$ é a resistência de folha e W é a largura do canal. A partir das equações 3-4 a 3-6 é possível escrever a resistência de todo o canal:

$$
R=A+\left(\frac{\rho}{W}\right) L_{M}
$$

O termo A é definido por:

$$
A=R_{0}+\left(\frac{\rho}{W}\right) \Delta L
$$

A partir das equações 3-7 e 3-8, o termo $\Delta \mathrm{L}$ é determinado seguindo os seguintes passos:

(1) Medem-se os valores de $L_{M}$ de diversos dispositivos MOSFETs.

(2) Extraem-se os valores da tensão de limiar.

(3) Medem-se os valores de R para várias polarizações de porta, mantendo $\mathrm{V}_{\mathrm{G}}-\mathrm{V}_{\mathrm{T}}$ constante para cada MOSFET medido.

(4) Determinam-se os termos A e $\frac{\rho}{W}$ pelo método dos mínimos quadrados usando dados experimentais de $R$ e $L_{M}$.

(5) Determinam-se os termos $\mathrm{R}_{0}$ e $\Delta \mathrm{L}$ também pelo método dos mínimos quadrados.

Um exemplo prático do método proposto é ilustrado na figura 3.4. Essa figura mostra exemplos de medidas da relação $R$ em função de $L_{M}$ para três diferentes polarizações de porta. As relações de $R$ em função de $L_{M}$ mostram uma boa linearidade. 


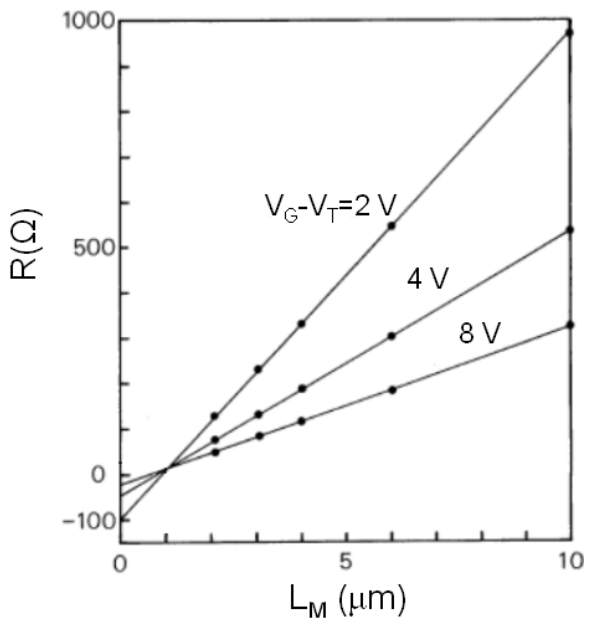

(a)

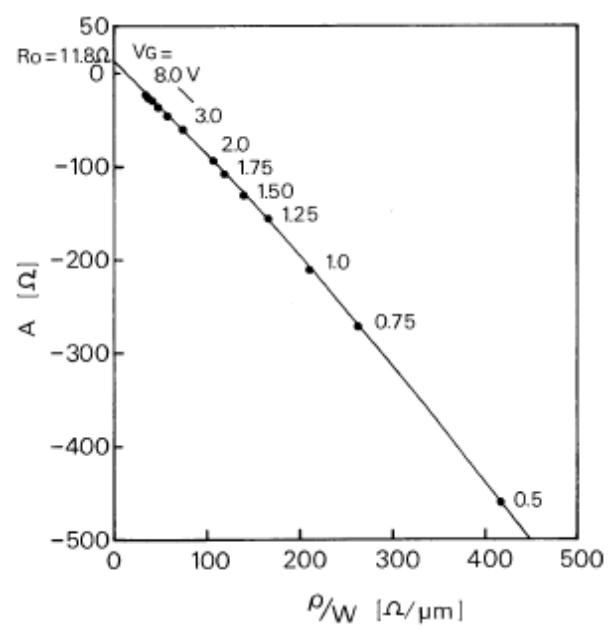

(b)

Figura 3. 4. Resistência total da região do canal em função do comprimento de máscara para diferentes tensões aplicadas na porta ${ }^{50}$.

Do gráfico da figura 3.4a e da expressão 3.7, é possível determinar o valor de $\frac{\rho}{W}$. Observa-se que para $L_{M}$ igual a zero, a resistência total do canal tende ao valor de $\mathrm{A}$.

Através da figura 3.4b e da expressão 3.8, é possível determinar o valor de $\Delta$ L. Observa-se que para $\frac{\rho}{W}$ igual a zero, a resistência extrínseca do canal tende ao valor de A.

Resumidamente, a resistência $R_{0}$ e o termo $\Delta L$ podem ser obtidos diretamente do gráfico de $R$ em função de $L_{M}$, mostrado na figura 3.5:

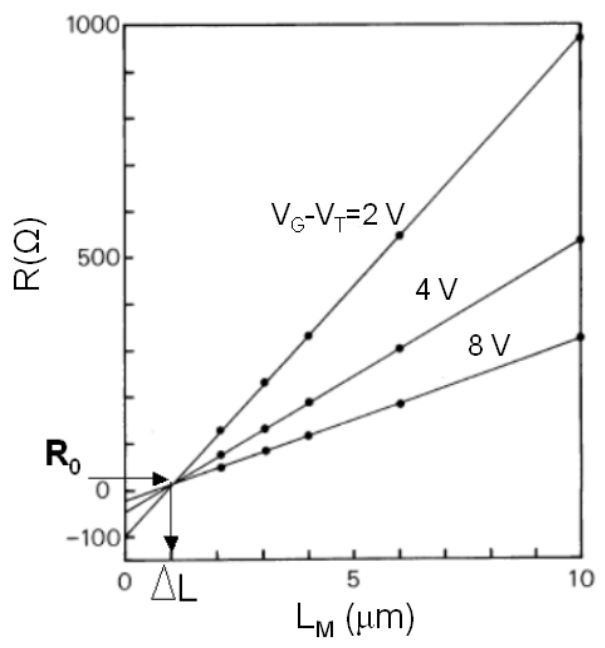

Figura 3. 5. Obtenção da resistência extrínseca $R_{0}$ e do termo $\Delta L$ diretamente da curva de $R$ em função de $L_{M}{ }^{50}$. 
Nesse método, é importante que a resistência $R_{0}$ seja estimada precisamente e que a resistência $R$ possa ser medida para altas polarizações de porta, mostrando-se falho quando aplicado em dispositivos com estrutura LDD, pois nesse tipo de geometria a resistência série de fonte e dreno, chamada por Terada e Muta de resistência extrínseca, é dependente da tensão aplicada na porta ${ }^{24,45,47}$.

Se esse método for aplicado em uma estrutura LDD, as retas resultantes da extrapolação linear não necessariamente se cruzarão em um mesmo ponto e obtenção dos parâmetros $R_{0} \mathrm{e} \Delta \mathrm{L}$ se mostrará imprecisa.

\subsubsection{Método de Hu, J. et al. ${ }^{47}$}

Esse método proposto para extrair a resistência série de fonte e dreno e o comprimento efetivo do canal foi desenvolvido para ser utilizado tanto em dispositivos convencionais como em dispositivos com estrutura LDD.

Parte-se da curva da resistência total de fonte e dreno $\mathrm{R}_{\text {TOTAL }}$ em função do comprimento de máscara $L_{M}$ a partir das características de $I_{D S}$ em função de $V_{G F}$ de um dispositivo MOSFET convencional operando na região linear. Sendo assim, RTOTAL pode ser expressa pela seguinte equação:

$$
R_{\text {TOTAL }}\left(V_{G F}\right)=R_{c h}\left(V_{G F}\right)+R_{e x t}\left(V_{G F}\right)
$$

Onde $R_{C H}$ é a resistência efetiva do canal que pode ser expressa pela equação 3.10 abaixo:

$$
R_{C H}\left(V_{G F}\right)=\frac{L_{e f f}\left(V_{G F}\right)}{W \mu C_{O X}\left(V_{G F}-V_{T}-0.5 V_{D S}\right)}
$$

$R_{\text {ext }}$ é toda a resistência fora do canal, que inclui uma parte da região da fonte e do dreno até os contatos, sendo que os outros parâmetros da equação 
apresentam seus significados convencionais. Nota-se que na equação acima, que tanto $L_{\text {eff }}$ como $R_{\text {ext }}$ são dependentes de $V_{G F}$.

Para se determinar o termo $\Delta \mathrm{L}$ e $\mathrm{R}_{\text {ext }}$ para uma dada tensão de porta $V_{G X}$, denotados $\Delta L_{x}$ e $R_{X}$, esse método utiliza duas tensões de porta $V_{G 1}$ e $V_{G 2}$ com valores muito próximos expressas por:

$$
\begin{aligned}
& V_{G 1}=V_{G X}-\frac{\Delta V_{G}}{2} \\
& V_{G 2}=V_{G X}+\frac{\Delta V_{G}}{2}
\end{aligned}
$$

Onde $\Delta \mathrm{L}$ é uma tensão arbitrária de baixo valor. Seguindo o gráfico convencional de $R_{\text {TOTAL }}$ em função de $L_{M}$, duas retas são obtidas, uma para cada valor de tensão aplicada correspondente. Cada reta contém sua própria solução de $\Delta \mathrm{L}$ e $\mathrm{R}_{\text {ext. }}$. No gráfico da figura 3.6 a tensão aplicada $\mathrm{V}_{\mathrm{G} 1}$ corresponde à reta com círculo fechado e $\mathrm{V}_{\mathrm{G} 2}$ com círculo aberto.

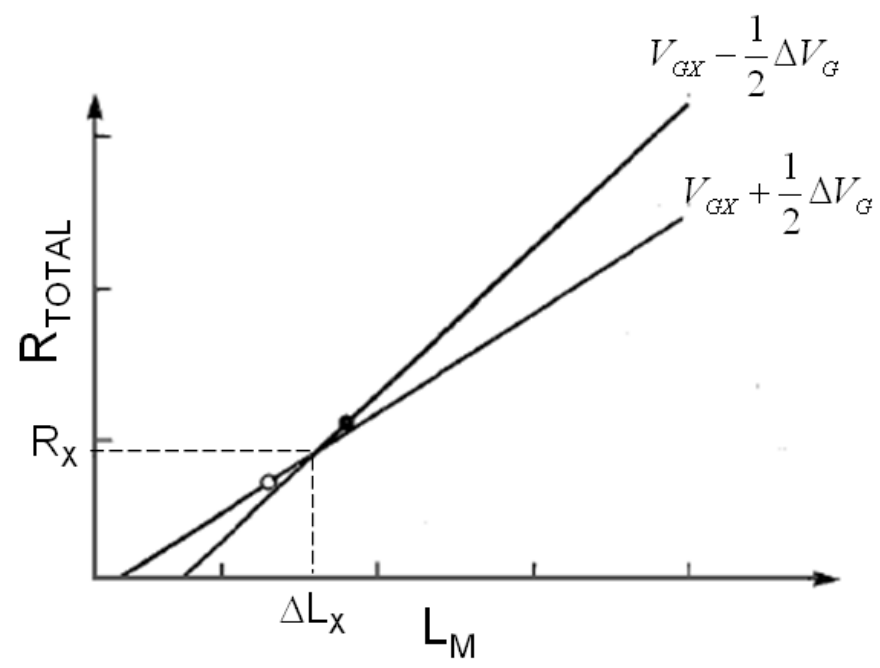

Figura 3. 6. RTOTAL em função de $L_{M}$ para duas polarizações de porta de valores aproximados $^{47}$.

No gráfico acima, no ponto de intersecção das curvas, outra solução para o termo $\Delta \mathrm{L}$ e $\mathrm{R}_{\text {ext }}$ é obtida. Essa solução proporciona uma aproximação 
da solução verdadeira em $\mathrm{V}_{\mathrm{Gx}}$. Quanto menor for $\mathrm{o}$ valor de $\Delta \mathrm{V}_{\mathrm{G}}$, melhor solução será proporcionada pela intersecção das retas. Repetindo esse método para diferentes pares de $V_{G X}$ é possível de se obter os termos $\Delta L$ e $R_{\text {ext }}$ em função da tensão aplicada na porta.

Esse método pode então ser chamado de "Método de Pares de $\mathrm{V}_{\mathrm{G}}$ ", pois para cada par de tensão aplicada há uma solução original. Nas medidas, é preferível que seja sobretensão de condução ${ }^{51}\left(V_{G X}-V_{T}\right)$ para que os efeitos de geometria dos dispositivos sejam evitados e a extração dos parâmetros seja mais exata.

\subsubsection{Método de Dixit, A. et al. ${ }^{49}$}

Esse método, também chamado de método exponencial de primeira ordem, faz uma análise do comportamento da resistência de fonte e dreno em dispositivos de múltiplas portas através de um modelo analítico baseado na geometria de fonte e dreno, sendo validado por simulação tridimensional e resultados experimentais.

O grande inconveniente da aplicação dos métodos anteriores em dispositivos de múltiplas portas, segundo Dixit, é a incapacidade desses métodos em capturar a resistência de fonte e dreno proveniente do estreitamento dessas regiões e, a condução de corrente nos planos perpendiculares aos contatos de fonte e dreno.

Para o desenvolvimento desse método, uma estrutura de porta dupla foi escolhida a fim de se evitar os problemas de mobilidade devido à condução de corrente em planos cristalográficos diferentes. No caso dos FinFETs de porta tripla, por exemplo, o plano cristalográfico da porta superior tem orientação $<100>$ enquanto que os das laterais têm orientação $<110>$. O uso de uma estrutura de porta dupla foi assegurado nas simulações dos dispositivos através do uso de um óxido espesso na superfície superior dos fins. 
Todas as resistências existentes entre fonte e dreno do dispositivo de porta dupla estudado, foram modeladas por Dixit, A. et al.. Um circuito equivalente das resistências entre fonte e dreno é mostrado na figura 3.7. Esse circuito mostra como as várias componentes da $R_{S D}$ estão conectadas no modelo analítico.

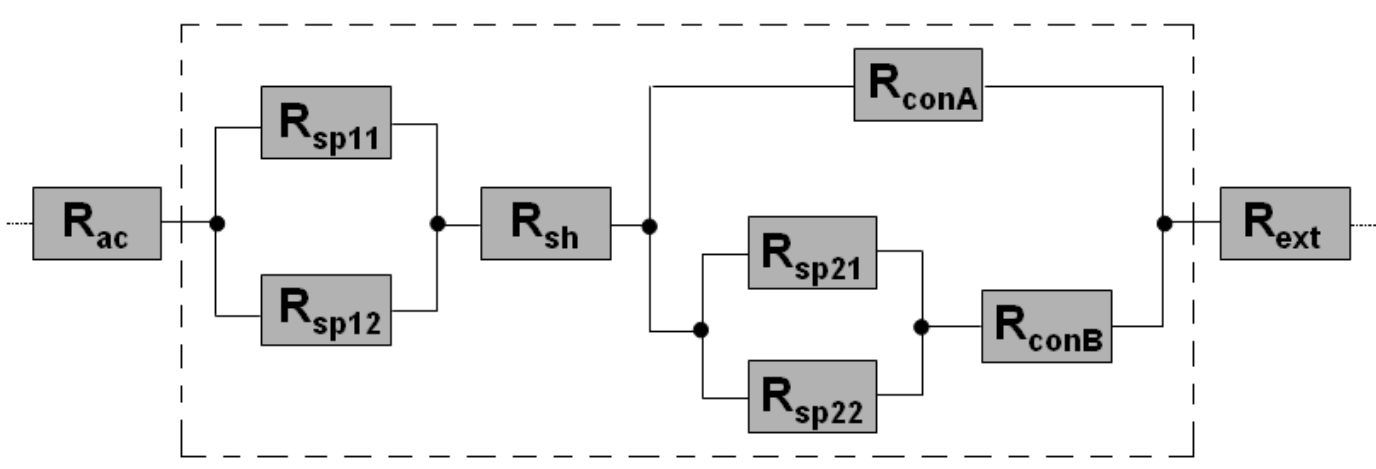

Figura 3. 7. Componentes da $R_{S D}$ como conectadas no modelo analítico. Os índices adicionais '1' e '2' em $R_{\text {sp1 }}$ e $R_{\text {sp2 }}$ são usados com intuito de representar essas componentes nas duas metades do dispositivo. $R_{\text {ext }}$ representa as resistências externas às regiões de fonte e dreno. Somente as resistências inscritas na área quadriculada foram modeladas por Dixit, A. et al. ${ }^{52}$.

Apesar de o método ter sido formulado para FinFETs de porta dupla, este pode ser usado em FinFETs de porta tripla. A única diferença esperada no comportamento do FinFET de porta tripla se comparado ao FinFET de porta dupla, é a resistência de espraiamento $R_{\mathrm{sp} 1}$, vista na figura 3.2 e 3.7 , pois haverá uma combinação paralela de três resistores idênticos distribuídos nas faces de condução de corrente do fin. Assim, aumentando o número de faces condutoras (no caso do FinFET de porta tripla há 3 faces condutoras), é esperado que $\mathrm{R}_{\mathrm{sp} 1}$ diminua.

A extração da resistência série de fonte e dreno se dá através da equação, já conhecida, da resistência total de um MOSFET:

$$
R_{T O T A L}=\frac{V_{D}}{I_{S}}=R_{C H}+R_{S D}
$$

A corrente absoluta Is é plotada em função da tensão aplicada na porta $V_{G F}$. Para baixo valor de $V_{D}$ e elevado $V_{G F}$, a resistência do canal diminui 
assintoticamente e a resistência total ( $R_{\text {TOTAL }}$ ) torna-se igual à $R_{S D}$. Depois de obtido o gráfico $I_{S}$ em função de $V_{G F}$, a resistência total, com baixo $V_{D}$, é extraída em função de $\mathrm{V}_{\mathrm{GF}}$.

Uma curva exponencial de primeira ordem é ajustada à curva de $\mathrm{R}_{\text {TOTAL }}$ em função de $V_{G F}$ gerando a parte assíntota da curva (figura 3.8). $O$ autor conclui que para elevados valores de $\mathrm{V}_{\mathrm{GF}}$, $\mathrm{R}_{\mathrm{TOTAL}}$ torna-se constante levando ao valor de $R_{S D}$.

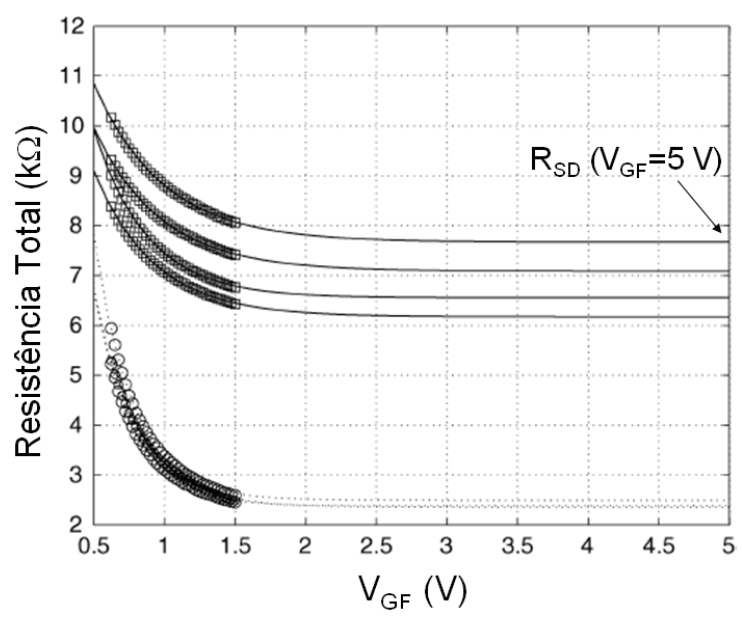

Figura 3. 8. $R_{\text {TOTAL }}$ em função de $V_{\text {GF. }}$. A resistência de fonte e dreno foi extraída dessas curvas para $\mathrm{V}_{\mathrm{GF}}$ igual a $5 \mathrm{~V}$. Os símbolos de quadrado e círculo mostram as curvas obtidas dos dispositivos com $\mathrm{W}_{\mathrm{FIN}}$ de 18 e $120 \mathrm{~nm}$, respectivamente. As linhas cheias e tracejadas foram ajustadas às medidas dos dispositivos de $\mathrm{W}_{\mathrm{FIN}}$ de 18 e $120 \mathrm{~nm}$, respectivamente ${ }^{49}$.

Do gráfico acima, observa-se que a resistência de fonte e dreno é extraída das curvas quando a polarização de porta atingir 5 V. Com o intuito de validar o modelo analítico, simulações foram feitas para dispositivos com diferentes larguras de fin ( $\left.\mathrm{W}_{\mathrm{FIN}}\right)$, sendo a $\mathrm{R}_{\mathrm{SD}}$ extraída da curva simulada $I_{S}$ em função de $V_{G F}$. A figura 3.9 mostra a comparação feita entre os valores extraídos de $R_{S D}$ com aqueles calculados pelo modelo analítico para um mesmo conjunto de dispositivos. 


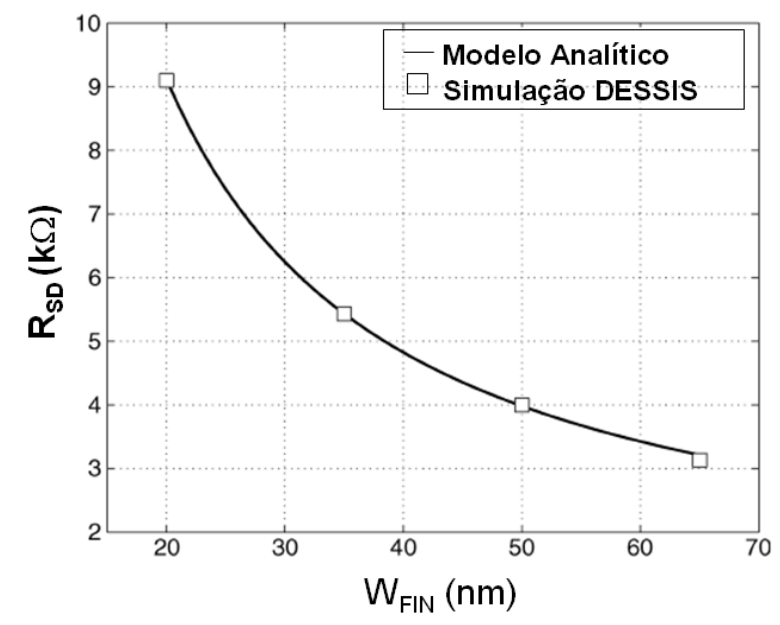

Figura 3. 9. $R_{S D}$ em função de $W_{\mathrm{FIN}}$ onde o modelo analítico foi comparado com a simulação tridimensional do dispositivo usando o simulador ISE-DESSIS ${ }^{49,53,}$.

Como pode ser observado na figura 3.9, o modelo analítico desenvolvido apresenta boa concordância com as simulações tridimensionais dos dispositivos.

Os autores concluem que o modelo analítico desenvolvido para resistência parasita de fonte e dreno em dispositivos de múltiplas portas foi validado com a ajuda de simulações tridimensionais e resultados experimentais; que essa resistência parece aumentar com a diminuição da largura do fin; e que a resistência de contato domina o comportamento parasitário em dispositivos com fins estreitos. 


\section{A TECNOLOGIA DE CANAL TENSIONADO E 0 CRESCIMENTO SELETIVO EPITAXIAL (SEG)}

Nesse capítulo é apresentado o conceito da tecnologia de canal tensionado, assim como as técnicas para introdução de tensão mecânica no canal dos dispositivos e, o conceito de crescimento seletivo epitaxial e sua influência na resistência total dos dispositivos estudados.

\subsection{A Tecnologia de Canal Tensionado (Strained Silicon)}

O grande sucesso da indústria de circuitos integrados, nos últimos 30 anos, deve-se ao contínuo escalamento das dimensões dos transistores. Com o passar dos anos, o comprimento de porta dos transistores MOSFETs foi reduzido de $10 \mu \mathrm{m}$ para $45 \mathrm{~nm}$. A capacidade de melhorar o desempenho diminuindo o consumo de potência fez a arquitetura CMOS dominar a tecnologia para circuitos integrados. Entretanto, manter o crescimento exponencial ditado pela famosa Lei de Moore torna-se cada vez mais difícil à medida que as dimensões dos transistores entram em escala nanométrica.

Com o escalamento da tecnologia, alguns problemas, que reduzem os benefícios desses dispositivos, tornam-se evidentes, como aumento da corrente de fuga da porta devido à redução da espessura do óxido de porta, aumento do campo elétrico lateral devido à redução do comprimento do canal e dos efeitos de canal curto e degradação da mobilidade efetiva de elétrons e lacunas devido ao aumento da rugosidade da superfície.

Com o intuito de continuar reduzindo os dispositivos e melhorar a velocidade dos circuitos integrados faz-se necessário o uso de novos materiais e novas arquiteturas. Dielétricos com alta permissividade podem ser usados como dielétrico de porta ao invés de óxido de silício mantendo a corrente de fuga da porta sob controle. Novas arquiteturas de transistores, como os transistores de múltiplas portas, minimizam os efeitos de canal curto. 
Outra opção para continuar a redução dos dispositivos é a introdução de tensão mecânica no canal do transistor (strained silicon). A técnica de canal tensionado (strain) foi desenvolvida com o intuito de aumentar a condução de corrente através do aumento da mobilidade de portadores no canal $^{54,55}$.

Ao longo do texto, aparecerão expressões como stress e strain e deve-se ficar claro a diferença entre elas. Stress significa força por unidade de área atuando em um sólido, sua unidade é Pascal [Pa], podendo também ser entendido como esforço. O termo Strain significa variação no comprimento de um objeto sob ação de uma força se comparado ao seu comprimento original (deformação).

Combinando a arquitetura MOSFET de múltiplas portas com a tecnologia de metal de porta/dielétricos com alta permissividade (high-K dielectric materials) e a engenharia de canal tensionado, esses dispositivos podem ser considerados como o estado-da-arte para operações de alta velocidade com excelente controle de canal, reduzida corrente de fuga e baixa potência ${ }^{56}$.

O uso de tensão mecânica no canal de um transistor CMOS tem sido muito aceito como forma de impulsionar o desempenho de circuitos integrados, permitindo um escalamento menos agressivo do comprimento de porta e da espessura do óxido ${ }^{57}$. O aumento do desempenho desses dispositivos é alcançado através da elevada mobilidade de portadores e da redução da resistência série de fonte e dreno. A técnica do uso de tensão mecânica tornou-se parte integrante do "International Technology Roadmap for Semiconductor" (ITRS) ${ }^{58}$ para o nó tecnológico de $90 \mathrm{~nm}$ sendo considerada importante, pois possibilita a postergação da implementação de mais opções de processos como material de porta e dispositivos não planares por uma ou mais gerações.

O conceito de silício tensionado (strained $\mathrm{Si}$ ) depende basicamente da alteração do equilíbrio da rede cristalina de silício através da aplicação de 
uma tensão mecânica externa. Devido à modificação na rede cristalina, a banda de energia do silício é alterada resultando em melhores propriedades elétricas ${ }^{59}$.

Basicamente, a tensão mecânica pode ser introduzida no canal do transistor através de técnicas que tornam o processo de fabricação repetitivo e compatível com os já existentes. Dentre essas técnicas, podemos citar o uso de camadas tensionadas (CESL ${ }^{60}$ - contact etch stop layers) conduzindo a uma tensão uniaxial local e também o uso de material tensionado induzido no substrato ( $\mathrm{SSO}^{61}$ - strained silicon) conduzindo a uma tensão biaxial global.

\subsubsection{Tensão Uniaxial Local (CESL)}

Essa técnica é considerada uma das mais populares para se introduzir tensão mecânica no transistor, mais efetiva, barata e fácil de ser implentada $^{62}$ e consiste, basicamente, na deposição de uma camada de Nitreto de Silício (CESL), com um stress intrínseco, sobre o transistor, transferindo, então, stress ao canal (figura 4.1) e levando a um processo de stress induzido somente em uma direção, por isso chamado de uniaxial. $O$ stress junto ao canal apresenta impactos diferentes em lacunas e elétrons e, por essa razão, há a necessidade de se obter dois tipos de stress: tensivo para transistores nMOS e compressivo para transistores pMOS.

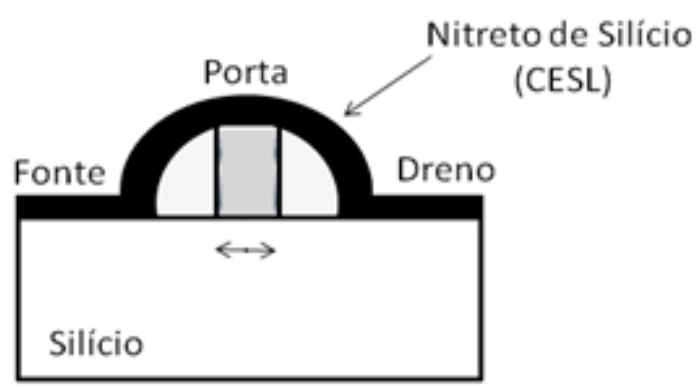

Figura 4. 1. Perfil transversal de um transistor com camada de Nitreto de Silício (CESL). As setas indicam as componentes do stress dominante na região do canal ${ }^{36}$. 
A quantidade de deformação no canal é função do nível de stress no filme tensionador (nesse caso Nitreto de Silício), da largura do espaçador (spacer) do transistor, da altura e comprimento da porta e do tamanho da fonte e do dreno. Espaçadores estreitos aproximam o filme tensionador à porta e, conseqüentemente, aumenta o stress do canal. Portas altas permitem um aumento de volume do filme induzindo stress compressivo ${ }^{36}$. Pela mesma razão, fontes e drenos mais longos produzem elevado stress no canal (figura 4.2).

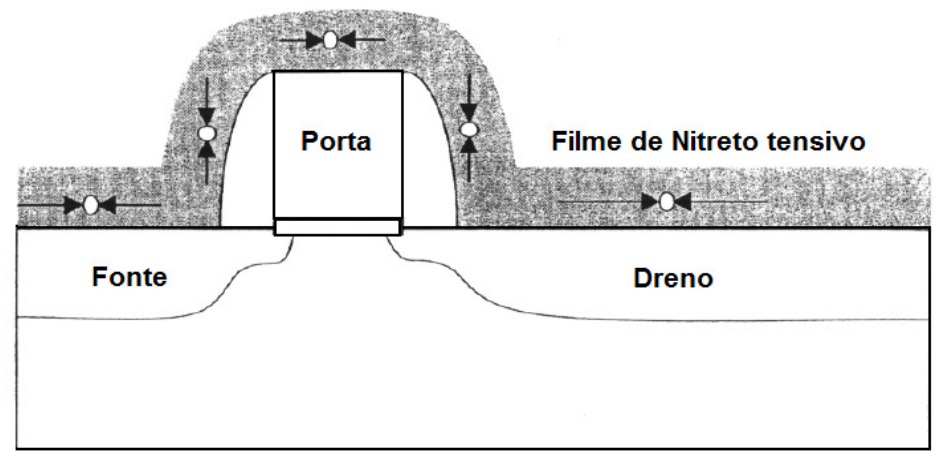

Figura 4. 2. Perfil transversal de um transistor com região de dreno mais longa mostrando a influência das dimensões das regiões de fonte e dreno na deformação induzida ao canal ${ }^{36}$.

Como conseqüência da região de dreno da figura 4.2 ser mais longa que a região da fonte, o dreno induzirá maior deformação no canal que a fonte. Com o aumento do comprimento da porta, o filme tensionador é localizado distante do centro do canal por esse motivo, toda a deformação induzida nessa região torna-se menor.

O problema de se usar tensão mecânica uniaxial para melhorar o desempenho dos dispositivos está na dificuldade em melhorar, simultaneamente, a mobilidade para elétrons e para lacunas ${ }^{63}$. Para 0 aumento da mobilidade dos elétrons há a necessidade de se ter no canal uma deformação tensiva e para elétrons uma tensão compressiva.

Estudos mostram que dispositivos que usam essa técnica de tensão mecânica apresentam um aumento na degradação da mobilidade por campo elétrico devido à presença de defeitos no material, o que conseqüentemente 
aumenta o espalhamento de elétrons para uma maior tensão aplicada na porta $^{64}$.

A técnica de canal tensionado uniaxial mostra-se mais efetiva se for aplicada em transistores de canal curto, pois, como a deformação mostra-se não uniforme ao longo do canal tornando-se mais pronunciada em suas bordas, a deformação efetiva nesses dispositivos, mostra-se maior.

\subsubsection{Tensão Biaxial Global (sSOI)}

A tensão mecânica biaxial global apresenta grande importância para a tecnologia CMOS, tendo como vantagem a introdução de deformação que melhora a mobilidade para elétrons e lacunas. Essa técnica ainda não foi aplicada na fabricação comercial devido aos desafios de integração, complexidade dos processos e custo ${ }^{63}$. Além disso, mostra uma melhora insignificante na mobilidade para dispositivos tipo $\mathrm{p}$ sob elevado campo elétrico vertical, onde operam os dispositivos comerciais MOSFETs ${ }^{65}$.

Nessa técnica, o stress é introduzido em todo o substrato através do crescimento epitaxial de uma camada de SiGe sobre o substrato de silício. O processo inicia-se com um substrato de silício tensionado, onde um filme fino de silício é crescido sobre uma camada relaxada de SiGe. A lâmina de silício tensionada é, inicialmente, implantada com hidrogênio e colada em uma lâmina reserva. Então, após a transferência do processo, a camada de SiGe é seletivamente corroída, deixando a camada de silício tensionada diretamente sobre o isolante. $\mathrm{O}$ óxido abaixo do silício tensionado ajuda a manter o stress intacto. Um processo epitaxial opcional pode ser usado para aumentar a espessura da camada de silício tensionado sem reduzir a deformação (figura $4.3)^{36}$. 


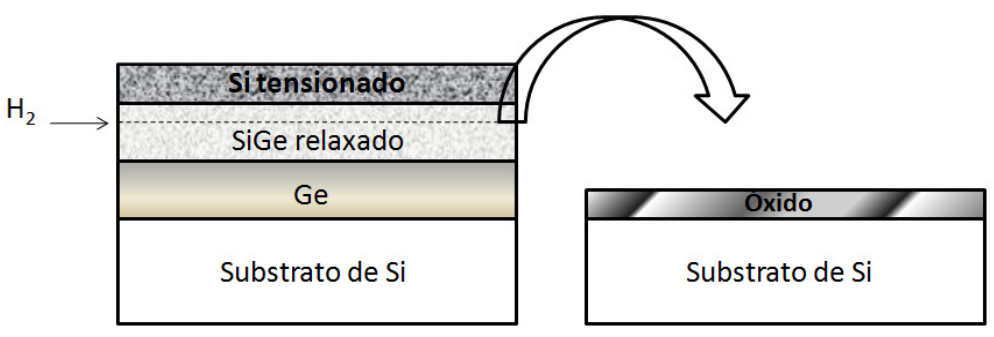

(A)

(B)

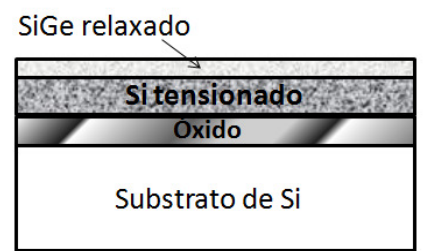

(C)

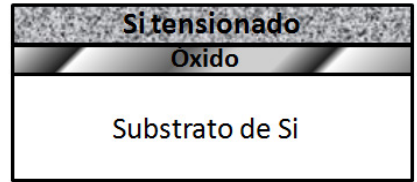

(D)

Figura 4. 3. Sequência do processo de fabricação de uma lâmina sSOI. a) Substrato de Si tensionado é implantado com $\mathrm{H}_{2}$. b) A lâmina de Si tensionado é colada em uma lâmina reserva. c) Transferência do processo para lâmina reserva. d) A camada remanescente de SiGe é seletivamente corroída da camada de Si tensionado sobre o óxido ${ }^{36}$.

Quando silício, é então, crescido sobre essa camada de SiGe, os átomos da camada de silício alinham-se àqueles da camada de SiGe, que apresentam uma rede cristalina ligeiramente maior (figura 4.4). Com isso, há um aumento em espaçamento de aproximadamente $4 \%$ entre os átomos de silício produzindo, assim, deformação biaxial (longitudinal e transversal) no canal e mudando o formato das bandas de energia tanto para elétrons como para lacunas ${ }^{57}$.

Silicio

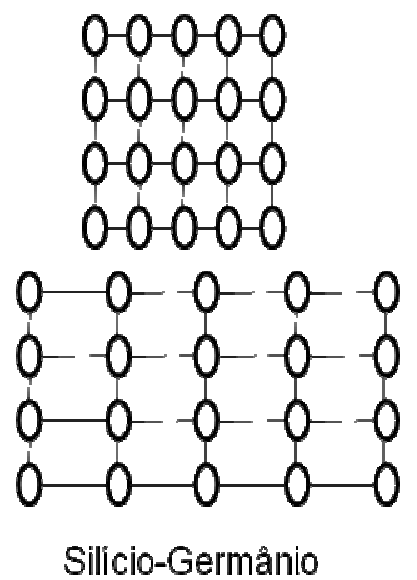

Silicio-tensionado

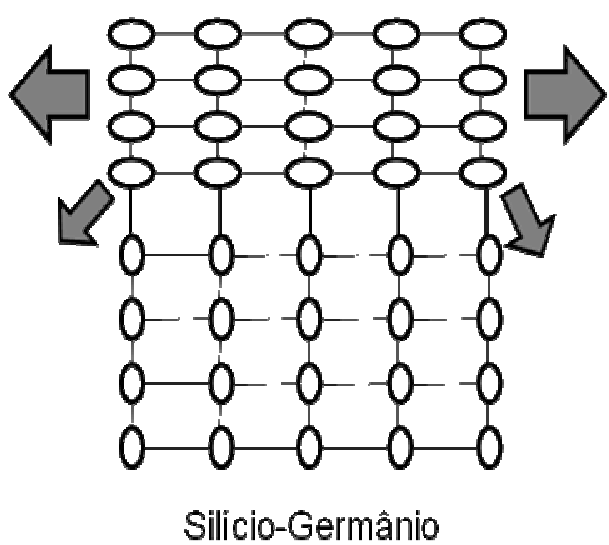

Figura 4. 4. Alteração da rede cristalina do silício após sua deposição sobre a camada de SiGe gerando uma tensão biaxial. 
A tensão biaxial global depende mais da engenharia dos materiais do que do projeto do dispositivo. Os principais desafios em se introduzir substrato biaxial consistem na redução dos defeitos do cristal e imperfeições, assim como a redução do custo da lâmina. Estudos ${ }^{66}$ mostram que para transistores de canal curto, os benefícios no desempenho desse tipo de deformação diminuem, melhorando para dispositivos de canal longo.

Para entender por que tensionando a rede cristalina o fluxo de portadores é melhorado, deve-se observar o comportamento dos elétrons nos níveis de energia que estes ocupam. No silício não tensionado, o menor nível de energia na banda de condução apresenta seis estados de elétrons discretos, sendo que uma pequena energia é necessária para que um elétron migre de um estado para outro. Quando a rede cristalina é tensionada, sua simetria física é quebrada e, assim, a simetria eletrônica. O menor nível de energia da banda de condução é dividido, com dois dos seis estados originais caindo para um menor nível de energia e quatro subindo para um maior nível de energia. Sendo assim, fica mais difícil para os elétrons serem dispersos entre os estados de menor energia, pois existem somente dois estados a serem ocupados. Reduzindo a dispersão, aumenta a distância média que um elétron pode percorrer antes de se chocar em seu trajeto, aumentando sua velocidade média na direção da condução. Outro efeito importante, que melhora a condução em silício tensionado, é a redução da massa efetiva do elétron, sendo uma medida de quanto este irá acelerar em um dado campo ${ }^{67}$.

\subsection{O Crescimento Seletivo Epitaxial (SEG)}

Dispositivos FinFETs de múltiplas portas têm sido intensamente estudados como alternativa para continuar reduzindo o nó tecnológico abaixo de $32 \mathrm{~nm}^{68}$. Entretanto, para esse nó tecnológico, há a necessidade de reduzir a largura do fin para manter um bom comportamento de canal curto. Tal estreitamento do fin gera um aumento na resistência série parasita devido ao estreitamento das regiões de fonte e dreno, sendo esse aumento considerado como uma das limitações quanto à introdução desses dispositivos em nós 
tecnológicos futuros. A resistência série parasita é responsável pela degradação da condução de corrente e da transcondutância.

Uma possibilidade de reduzir substancialmente a resistência série parasita sem comprometer a condução de corrente e a transcondutância é o uso da técnica de crescimento seletivo epitaxial de silício nas regiões de fonte e dreno ${ }^{69}$. O crescimento seletivo epitaxial é usado para aumentar a espessura do silício (fin) fora da região de porta e do espaçador, ou seja, elevando as regiões de fonte e dreno de alta dopagem ${ }^{70,71}$ que ajuda a reduzir a resistência série parasita total como pode ser vista na figura 4.5 .

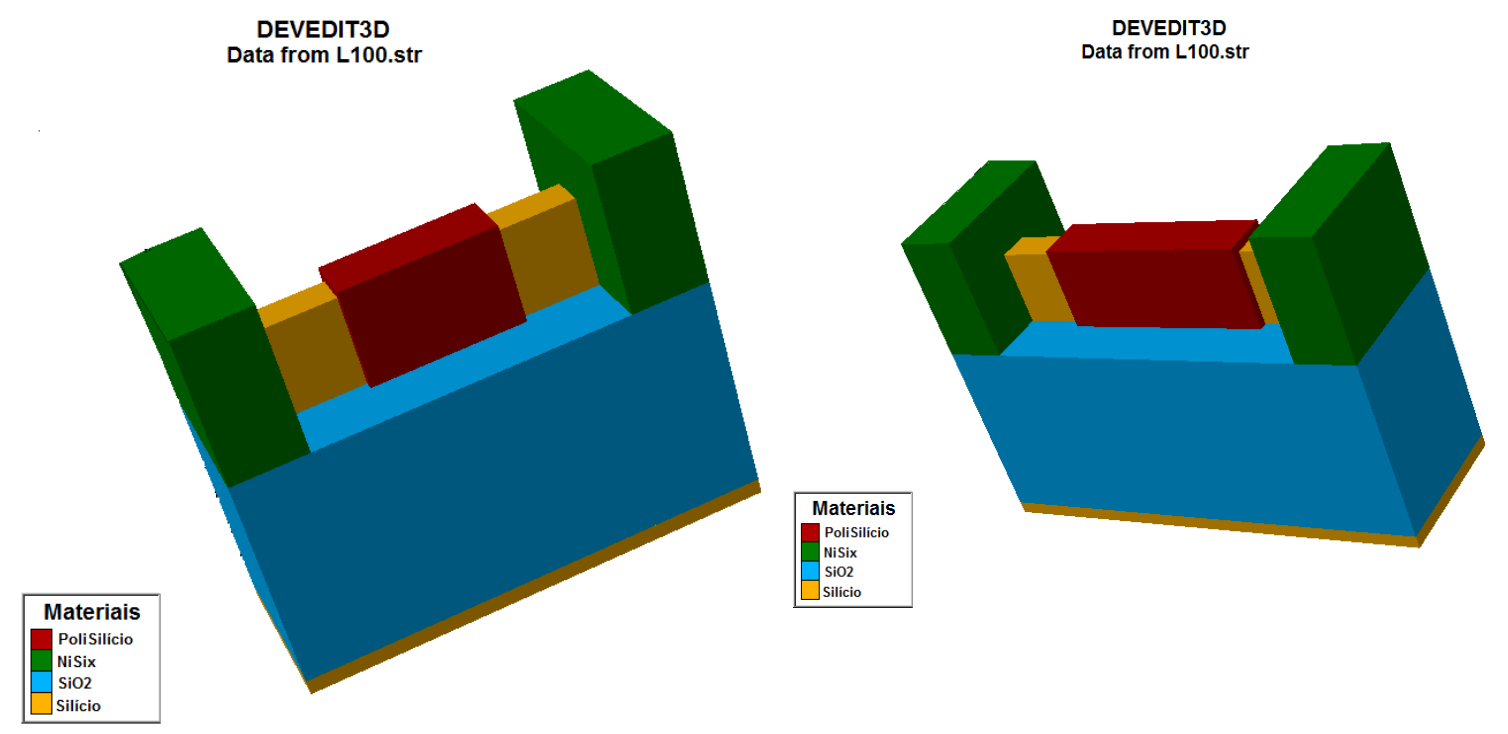

Figura 4. 5. Visão tridimensional de um FinFET de porta tripla com elevação das regiões de fonte e dreno para demonstração do SEG.

Com o uso de SEG nas regiões de fonte e dreno acontece o aumento da condução de corrente relacionado à redução da resistência série que em alguns casos chega a $50 \%{ }^{72}$.

Para que o SEG seja possível nas laterais do fin, os espaçadores que são formados devido à topografia devem ser removidos ${ }^{36}$. Isso pode ser feito através de uma corrosão controlada onde os espaçadores são reduzidos em sua altura sem que os espaçadores de porta sejam muito reduzidos em suas laterais. Como os dispositivos de múltiplas portas apresentam diferentes 
orientações cristalográficas no topo $<100>$ e em suas laterais $<110>$, o SEG será fortemente dependente do layout do dispositivo. Para que essa dependência seja menos significativa, os fins devem ser rotacionados em $45^{\circ}$ para que as orientações cristalográficas do topo e das laterais tornem-se idênticas $\langle 100\rangle$, sendo assim, um melhor controle da espessura em dispositivos de fins estreitos será esperado ${ }^{72}$.

A componente dominante da resistência série em dispositivos com fins estreitos, já visto anteriormente, é a resistência de contato $\left(R_{\text {con }}\right)^{49}$. Essa resistência pode ser diminuída aumentando a área de contato e/ou diminuindo sua resistividade, mas para isso há a necessidade de altos níveis de dopagem, sendo um desafio em dispositivos de fins estreitos, ou o desenvolvimento de novos silicetos. O uso de SEG tipicamente nas regiões altamente dopadas (HDD) de fonte e dreno possibilita o aumento da área de contato necessário para redução da $R_{\text {con }}$. 


\section{CARACTERIZAÇÃO ELÉTRICA}

Nesse capítulo são apresentados, primeiramente, os resultados obtidos por caracterização elétrica da primeira parte desse trabalho, onde o objetivo foi estudar a resistência série de fonte e dreno e, aplicar os métodos de extração vistos no capítulo 3. Em seguida, serão apresentados os resultados obtidos por caracterização elétrica das tecnologias de canal tensionado e com o uso de SEG em uma nova série de dispositivos medidos.

\subsection{Estudo da Resistência Série de Fonte e Dreno}

Para a caracterização elétrica dos transistores foi utilizada uma pastilha de silício contendo diversos dispositivos, entre eles o FinFET de porta tripla como mostrado na figura 5.1a. A figura 5.1b, mostra a posição das regiões de fonte, dreno e porta e, a figura 5.1c mostra o perfil transversal de um FinFET de porta tripla assim como a identificação de suas regiões.

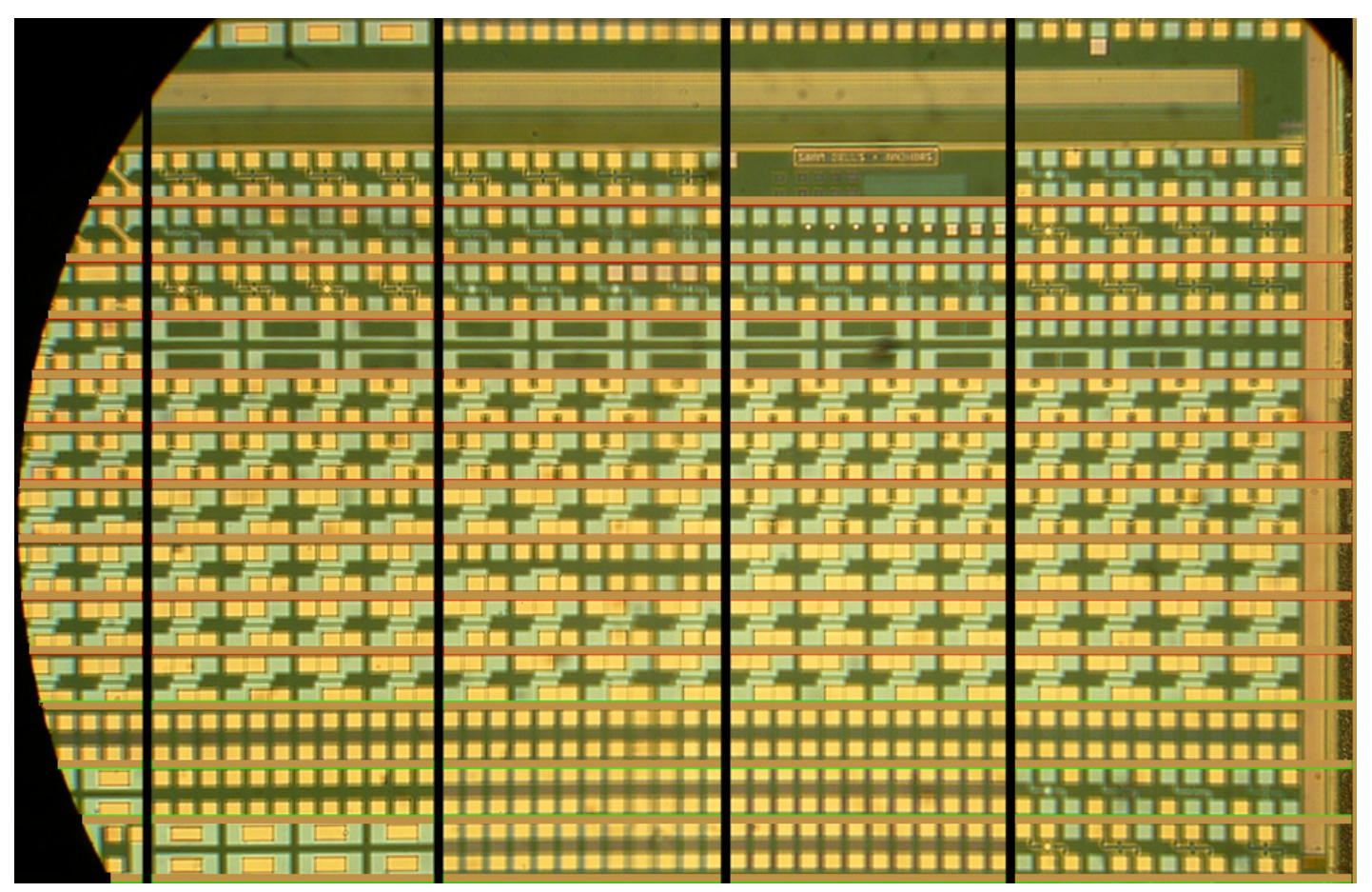

(a)

Figura 5.1. Pastilha contendo todos os dispositivos (a); Posição das regiões de fonte e dreno (b); Perfil transversal do FinFET de porta tripla identificando os materiais de suas regiões (c). 


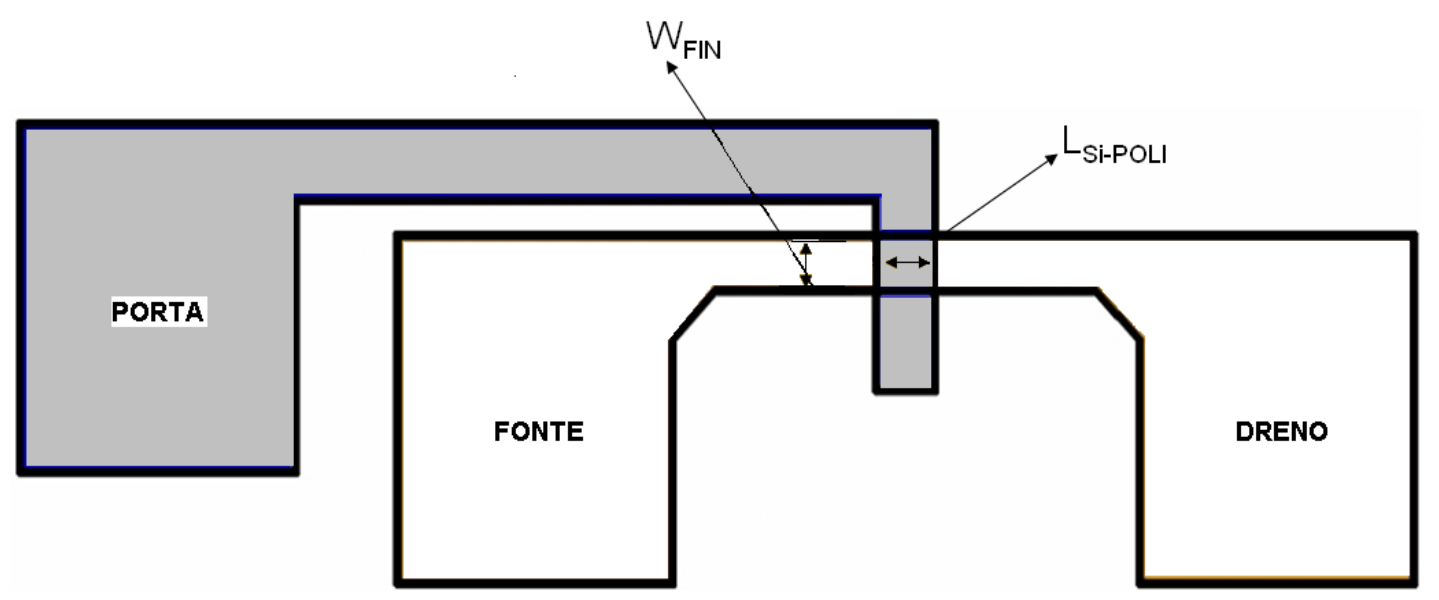

(b)

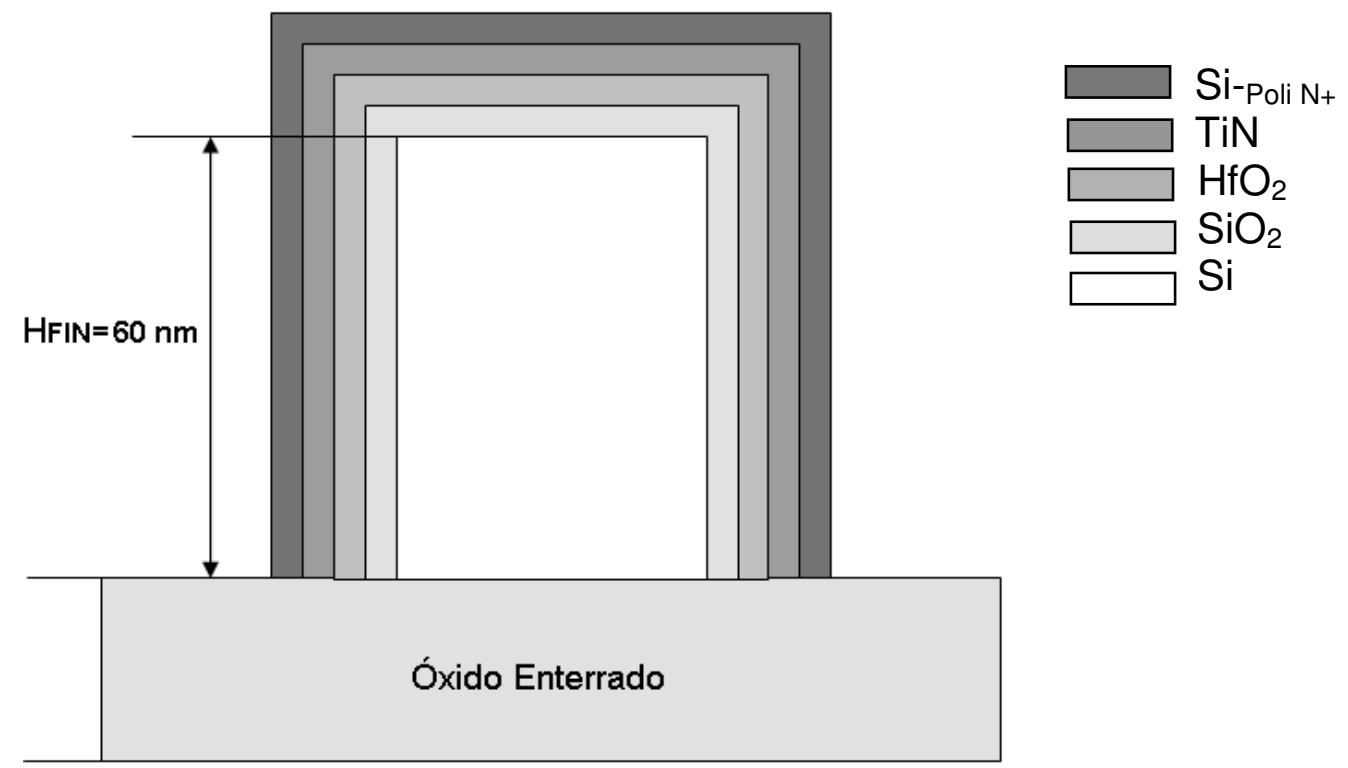

(c)

Figura 5. 1. Pastilha contendo todos os dispositivos (a); Posição das regiões de fonte e dreno (b); Perfil transversal do FinFET de porta tripla identificando os materiais de suas regiões (c).

Os FinFETs de porta tripla caracterizados contém múltiplos fins, foram fabricados no IMEC/Bélgica e apresentam as seguintes características: comprimento das regiões de fonte e dreno $L_{D}=L_{S}=50 \mathrm{~nm}$; comprimento das regiões $L_{L D D}$ de $50 \mathrm{~nm}$; espessura do óxido enterrado $t_{0 \times b}=145 \mathrm{~nm}$; altura do fin $\mathrm{H}_{\mathrm{FIN}}=60 \mathrm{~nm}$; dielétrico de porta constituído de $1 \mathrm{~nm}$ de óxido de silício e $2 \mathrm{~nm}$ de óxido de Háfnio; número de fins igual a 30, e como materiais de porta 0 Nitreto de Titânio (TiN), seguido de silício policristalino $\mathrm{N}^{+}$. 
A região do canal é constituída de silício tipo $\mathrm{P}$ com concentração de dopantes $\mathrm{N}_{\mathrm{A}}$ de $1 \times 10^{15} \mathrm{~cm}^{-3}$. A região de fonte e dreno é constituída de silício tipo $\mathrm{N}$ com concentração de dopantes de $\mathrm{N}_{\mathrm{D}}$ de $1 \times 10^{20} \mathrm{~cm}^{-3} \mathrm{e}$, a região LDD por sua vez, tem concentração de dopantes de $1 \times 10^{18} \mathrm{~cm}^{-3}$. A largura efetiva do fin $\mathrm{W}_{\mathrm{FIN}}$ é de $20 \mathrm{~nm}$ e o comprimento de canal varia de $610 \mathrm{~nm}$ a 19,91 $\mu \mathrm{m}$.

A tabela 5.1 mostra as características da cascata dos transistores medidos.

Tabela 5. 1. Características da cascata de dispositivos medidos.

\begin{tabular}{|l|c|c|c|}
\hline & $\mathrm{W}_{\text {FIN }}(\mathrm{nm})$ & $\mathrm{N}^{\circ}$ fins & $\mathrm{L}(\boldsymbol{\mu m})$ \\
\hline E6T6 & $\mathbf{2 0}$ & $\mathbf{3 0}$ & $\mathbf{0 , 6 1}$ \\
\hline E6T7 & $\mathbf{2 0}$ & $\mathbf{3 0}$ & $\mathbf{0 , 9 1}$ \\
\hline E6T1 & $\mathbf{2 0}$ & $\mathbf{3 0}$ & $\mathbf{4 , 9 1}$ \\
\hline E6T2 & $\mathbf{2 0}$ & $\mathbf{3 0}$ & $\mathbf{9 , 9 1}$ \\
\hline E6T3 & $\mathbf{2 0}$ & $\mathbf{3 0}$ & $\mathbf{1 9 , 9 1}$ \\
\hline
\end{tabular}

\subsubsection{Curvas Características $\mathrm{I}_{\mathrm{D}} \times \mathrm{V}_{\mathrm{GF}}$}

$\mathrm{Na}$ figura 5.2 são apresentadas as curvas características $I_{D}$ em função de $V_{\text {GF }}$ para os FinFETs de porta tripla com $W_{\text {FIN }}$ de $20 \mathrm{~nm}$ e com diferentes comprimentos de canal $(L)$.

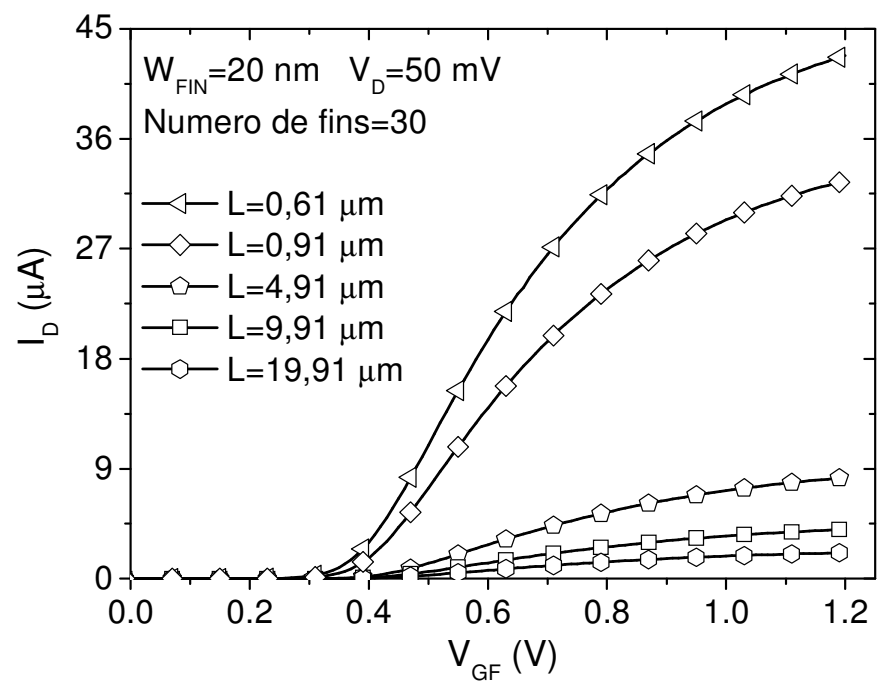

Figura 5. 2. Resultados obtidos por caracterização elétrica da corrente de dreno $\left(I_{D}\right)$ em função da tensão aplicada na porta $\left(\mathrm{V}_{\mathrm{GF}}\right)$ para os FinFETs de porta tripla com $\mathrm{V}_{\mathrm{D}}=50 \mathrm{mV}, \mathrm{H}_{\mathrm{FIN}}=60 \mathrm{~nm}$; $\mathrm{W}_{\mathrm{FIN}}=20 \mathrm{~nm}$ para diferentes comprimentos de canal. 
A figura 5.3 mostra as curvas obtidas da tensão de limiar e inclinação de sublimiar em função do comprimento do canal dos dispositivos medidos.

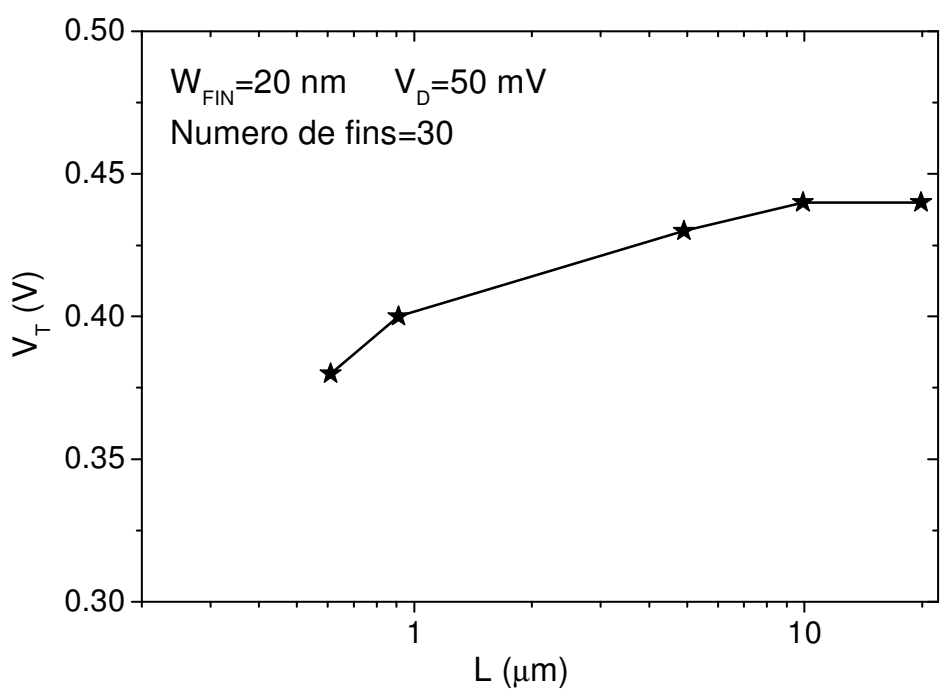

(a)

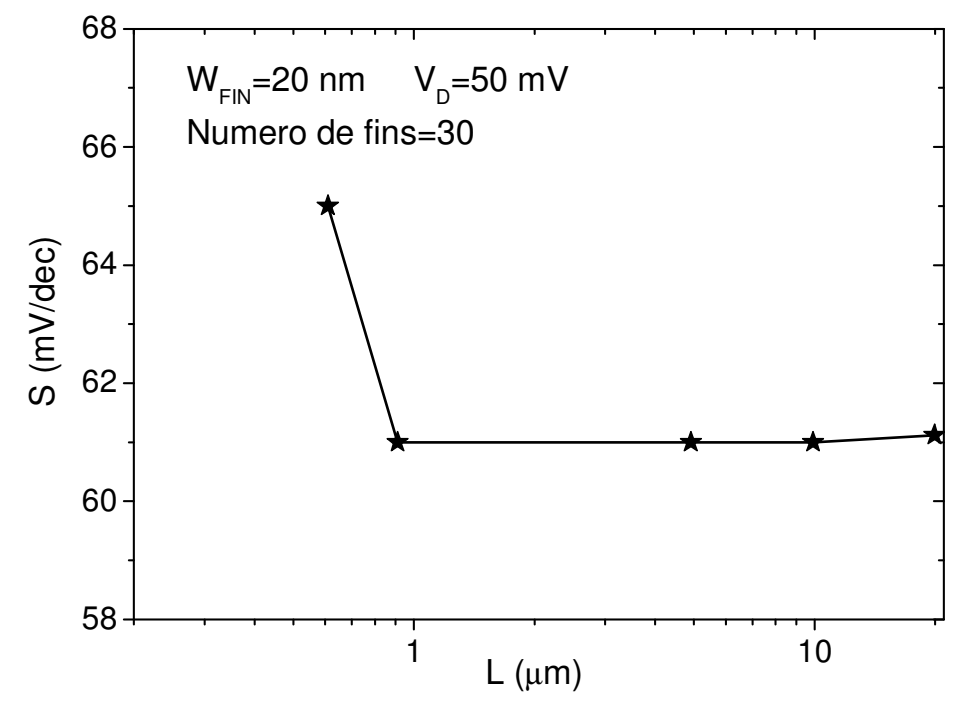

(b)

Figura 5. 3. Resultados obtidos por caracterização elétrica da tensão de limiar em função do comprimento de canal (a) e da inclinação de sublimiar em função do comprimento de canal (b).

À medida que o comprimento de canal dos transistores diminui e a porta passa a perder o controle total das cargas na região do canal para as junções de fonte e dreno, há uma diminuição da tensão de limiar, pois esta é proporcional a quantidade de cargas controladas pela porta, ocorrendo o mesmo efeito com a inclinação de sublimiar. 


\subsubsection{Extração da Resistência Série de Fonte e Dreno}

$\mathrm{Na}$ caracterização elétrica dos dispositivos medidos, a extração da resistência série deu-se a partir da aplicação de dois métodos ${ }^{49,50}$.

A figura 5.4 mostra o gráfico obtido da resistência total em função da tensão aplicada na porta para $\mathrm{W}_{\mathrm{FIN}}$ de $20 \mathrm{~nm}$ e diferentes comprimentos de canal $(L)$, através do método da extrapolação exponencial de primeira ordem, onde $\mathrm{R}_{\mathrm{TOTAL}}=\mathrm{R}_{\mathrm{SD}}$ para $\mathrm{V}_{\mathrm{GF}}$ de $5 \mathrm{~V}$.

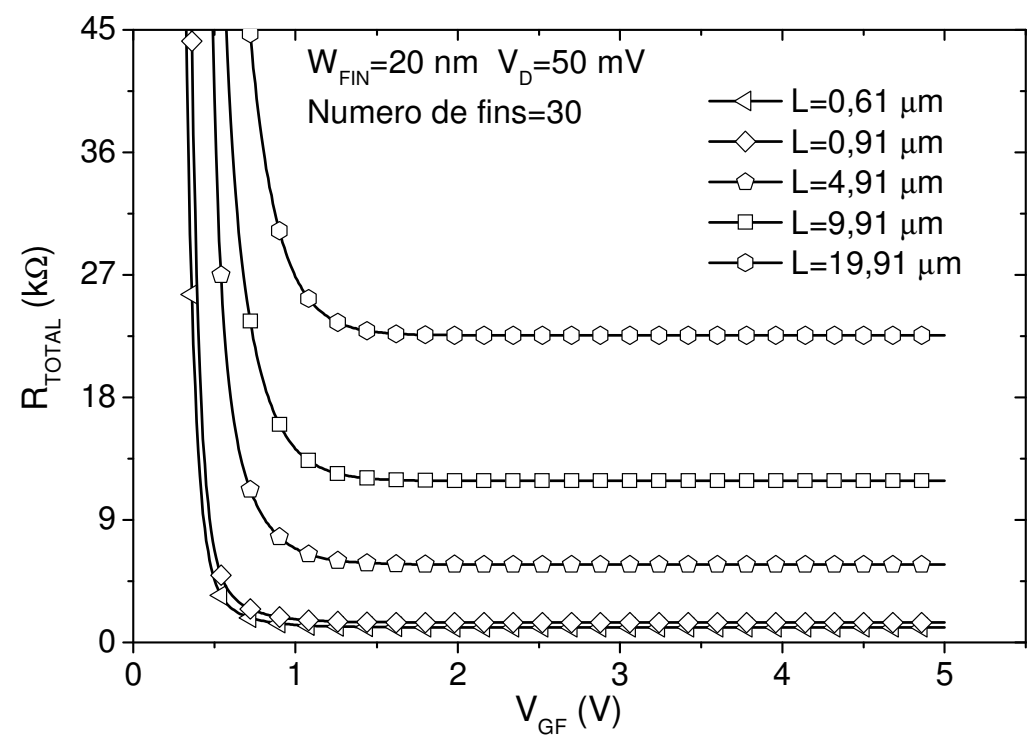

Figura 5. 4. Resultados obtidos através da caracterização elétrica da resistência total em função da tensão aplicada na porta para $W_{\text {FIN }}$ de $20 \mathrm{~nm}, V_{D S}$ de $50 \mathrm{mV}$ e diferentes comprimentos de porta $(L)$.

Observa-se que a resistência total aumenta com 0 aumento do comprimento do canal, pois quanto maior o comprimento de canal do dispositivo, maior será a influência da resistência do canal no valor da resistência total. Observa-se também que para $\mathrm{V}_{\mathrm{GF}}$ de $5 \mathrm{~V}$, a resistência de fonte e dreno extraída para diferentes comprimentos de canal também aumenta, devido à limitação no método de extração utilizado, que não se aplica adequadamente em transistores com comprimentos de canal maiores. 
A figura 5.5 apresenta o gráfico da resistência série de fonte e dreno em função do comprimento do canal dos dispositivos medidos, extraída pelo método da extrapolação exponencial de primeira ordem.

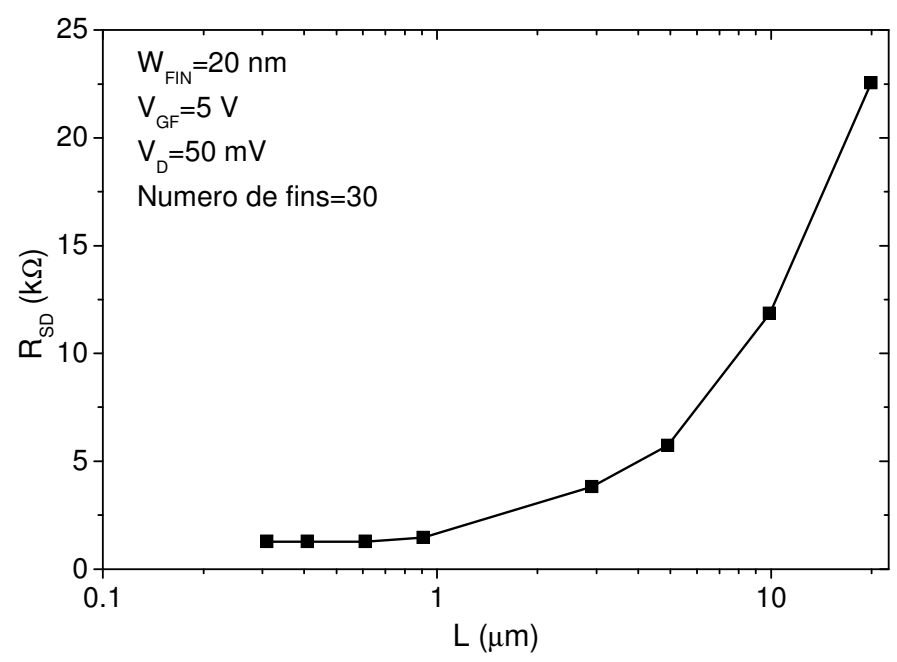

Figura 5. 5. Resistência Série de fonte e dreno em função do comprimento de canal com $V_{D}$

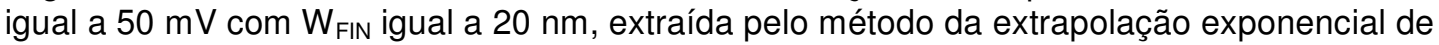
primeira ordem.

A partir da figura 5.5 verifica-se que esse método estudado aplica-se bem para transistores com comprimentos de canal abaixo de $1 \mu \mathrm{m}$, pois nesses transistores observa-se que há uma tendência no valor da resistência série em tornar-se constante.

Utilizando o método da extrapolação linear ${ }^{47,50}$, para diferentes valores de tensões aplicados na porta, independente do comprimento da região do canal, a resistência de fonte e dreno não tem seu valor alterado, o que não ocorre com a resistência total do dispositivo.

A resistência total do dispositivo é dependente da tensão aplicada na porta e esta aumenta à medida que se diminui a tensão $V_{\mathrm{GF}}$, pois haverá uma menor quantidade de portadores na região do canal. A figura 5.6 mostra o gráfico da resistência total em função do comprimento de canal dos dispositivos medidos para várias polarizações de porta. 


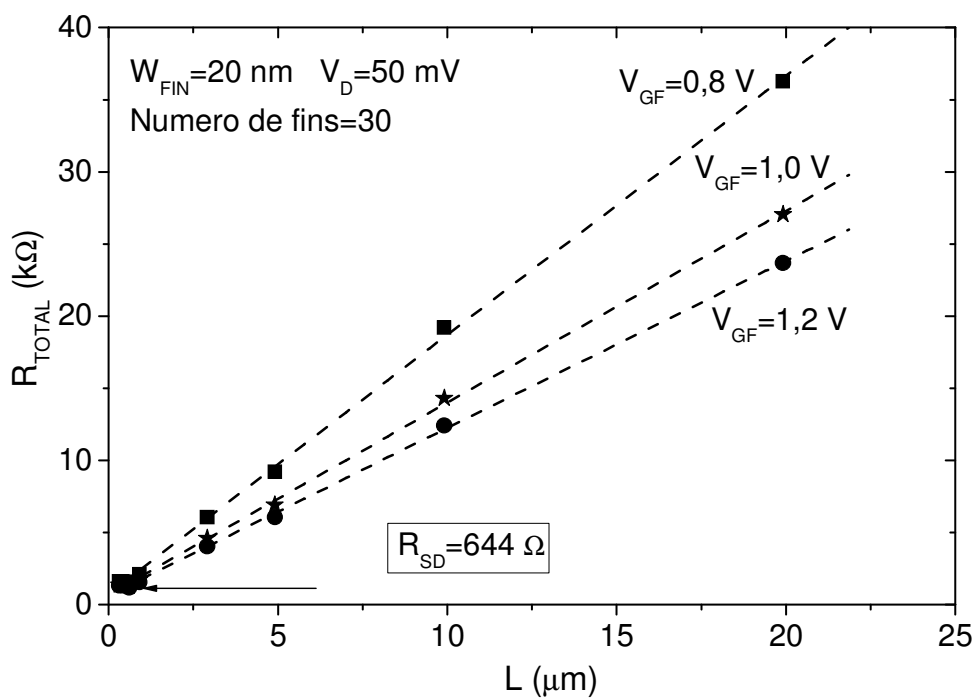

Figura 5. 6. Resistência total em função do comprimento de porta para diferentes tensões aplicadas na porta.

A máxima tensão aplicada na porta desses dispositivos foi de $1,2 \mathrm{~V}$, então a extrapolação linear para a obtenção da resistência série levou em conta a limitação da tensão aplicada, pois um valor maior do que esse poderia causar o rompimento do óxido de porta, danificando o dispositivo.

\subsubsection{Comparação da Influência do Número de Fins na $\mathbf{R}_{\mathrm{SD}}$}

Foi feita a caracterização elétrica de dois dispositivos com as mesmas dimensões exceto pelo número de fins, com o intuito de verificar a influência do número destes na resistência série de fonte e dreno.

Para aumentar a condução de corrente, dispositivos de múltiplos fins são utilizados como pode ser visto na figura 5.7. A condução de corrente de um dispositivo de múltiplos fins é igual a corrente de seu fin (single-fin) multiplicada pelo número de fins. 


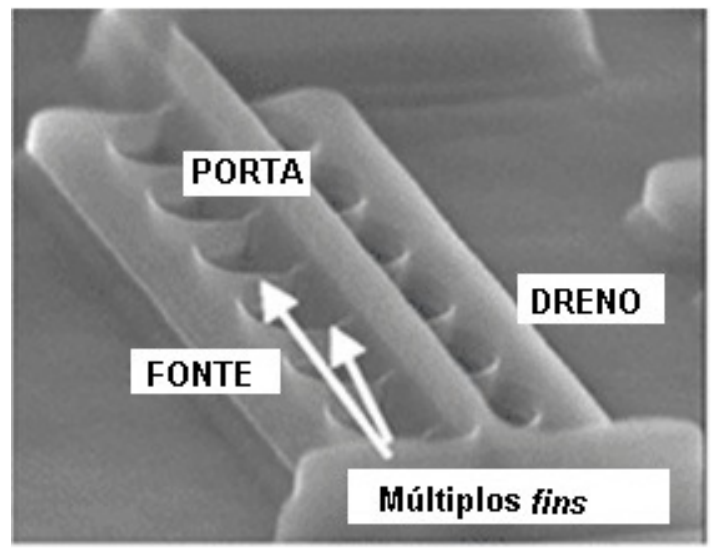

Figura 5. 7. Figura SEM de um dispositivo de múltiplos dedos.

A figura 5.8 faz uma comparação da condução de corrente de um dispositivo MOSFET planar de porta única (figura 5.8a), com um dispositivo de múltiplas portas e múltiplos fins (figura 5.8b) ambos com a mesma área, $W \times L$.

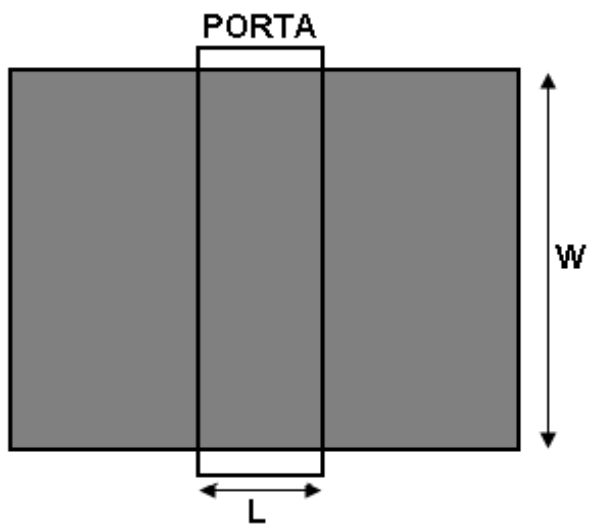

(a)

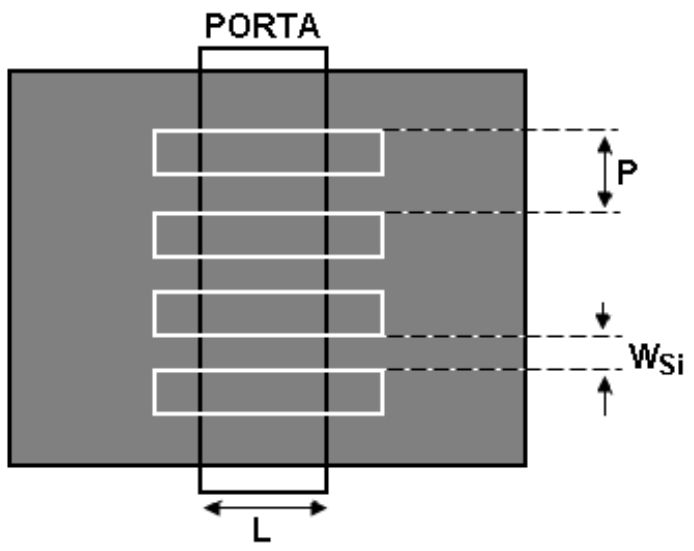

(b)

Figura 5. 8. Layout de um dispositivo MOSFET planar de porta única (a) e layout de um dispositivo de múltiplos fins $(b)^{36}$.

Como visto anteriormente, considerando o espaçamento entre fins $(\mathrm{P})$, a corrente de um dispositivo de múltiplas portas pode ser escrita como:

$$
I_{D}=I_{D O} \frac{\theta \mu_{\text {Topo }} W_{S i}+2 \mu_{\text {Lateral }} t_{S i}}{\mu_{\text {Topo }} P}
$$


As dimensões dos dispositivos medidos são: $W_{\mathrm{FIN}}$ igual a $20 \mathrm{~nm}$, comprimento de canal de $40 \mathrm{~nm}$, com número de fins igual a 10 e 30. A figura 5.9 mostra as curvas obtidas da resistência total em função de $V_{\mathrm{GF}}$ para os dois dispositivos.

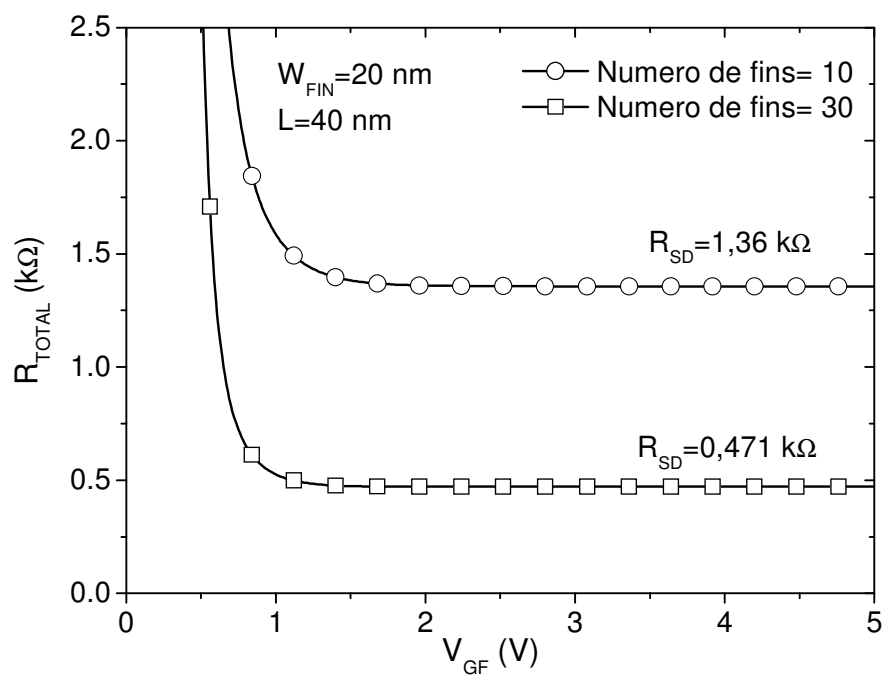

Figura 5. 9. Resultados obtidos por caracterização elétrica da resistência total em função da tensão aplicada na porta para dispositivos com as mesmas dimensões e número de fins diferentes.

Analisando as curvas obtidas por caracterização elétrica desses dispositivos, observa-se que quanto maior o número de fins, menor a resistência total associada, isso se deve ao fato de que aumentando o número de fins, aumenta-se a condução de corrente $I_{D}$, e como a condução de corrente é inversamente proporcional à resistência associada, haverá uma diminuição da resistência total do dispositivo.

Comparando os dispositivos medidos, observa-se que há uma relação esperada no valor da resistência série de fonte e dreno, extraída pelo método da extrapolação exponencial de primeira ordem em $V_{G F}=5 \mathrm{~V}$, para os dispositivos com número de fins diferentes.

A razão $R_{S D(10 \text { fins })} / R_{S D(30 f i n s)}=1,36 k \Omega / 0,471 k \Omega=2,9$ sendo próxima do esperado (3:1). 


\subsection{Análise da Resistência Total em Dispositivos FinFETs de Porta Tripla com e sem deformação e com e sem SEG}

A melhora no desempenho dos dispositivos com o uso da tecnologia de canal tensionado é alcançada através do aumento da mobilidade de portadores e da redução da resistência série de fonte e dreno, diminuindo assim a resistência total. Nesse trabalho foram considerados somente dispositivos de canal tipo $\mathrm{n}$, embora o comportamento dos dispositivos de canal tipo p também seja de grande importância. Entretanto, ao se tratar de dispositivos de canal tensionado a mobilidade das lacunas tem sido teoricamente menos estudada que a dos elétrons devido à complexidade de sua banda de valência ${ }^{73,74}$.

\subsubsection{Características dos Dispositivos Medidos}

Os dispositivos aqui estudados também bforam fornecidos pelo laboratório de pesquisas IMEC (Interuniversity Microelectronics Center) localizado na Bélgica, sendo todos FinFETs de porta tripla, apresentando as seguintes características: número de fins igual a 5 , largura de fin $\left(\mathrm{W}_{\mathrm{FIN}}\right)$ variando de 25 a $2875 \mathrm{~nm}$, altura do fin $\left(\mathrm{H}_{\mathrm{FIN}}\right)$ iguais a $65 \mathrm{~nm}$ para FinFET convencional e $55 \mathrm{~nm}$ para FinFET tensionado, óxido enterrado ( $\left.\mathrm{t}_{\mathrm{oxb}}\right)$ e espessura do óxido equivalente (EOT) de 150 e 1,9 nm, respectivamente e comprimento de porta variando de 60 a $920 \mathrm{~nm}$. O "empilhamento" do material de porta (gate stack) consiste em $1 \mathrm{~nm}$ de $\mathrm{SiO}_{2}$ e $2 \mathrm{~nm}$ de $\mathrm{HfO}_{2}$, nivelado por TiN e polisilício. As concentrações de dopantes na regiões do canal $\left(\mathrm{N}_{\mathrm{A}}\right)$ e extensões de fonte e dreno (LDD) são de $10^{15}$ e $10^{19} \mathrm{~cm}^{-3}$, respectivamente. Serão estudados dispositivos sem tensionamento, com tensionamento uniaxial (CESL) e biaxial (sSOI). 


\subsubsection{Resultados Experimentais sem SEG}

Primeiramente, foram feitas as análises das curvas características de corrente de dreno e transcondutância em função da tensão aplicada na porta para os dispositivos com e sem tensionamento de diversas dimensões. Em seguida, serão apresentadas as análises da influência da resistência total em dispositivos com e sem tensionamento.

A figura 5.10 mostra as curvas da corrente de dreno em função da tensão aplicada na porta ( $\mathrm{V}_{\mathrm{GF}}$ de 0 a 1,2 $\mathrm{V}$ ), para polarização de dreno de 50 $\mathrm{mV}$, dos transistores de referência e sob influência de tensão mecânica (uniaxial: CESL e biaxial: sSOI) com comprimento de canal de $60 \mathrm{~nm}$.

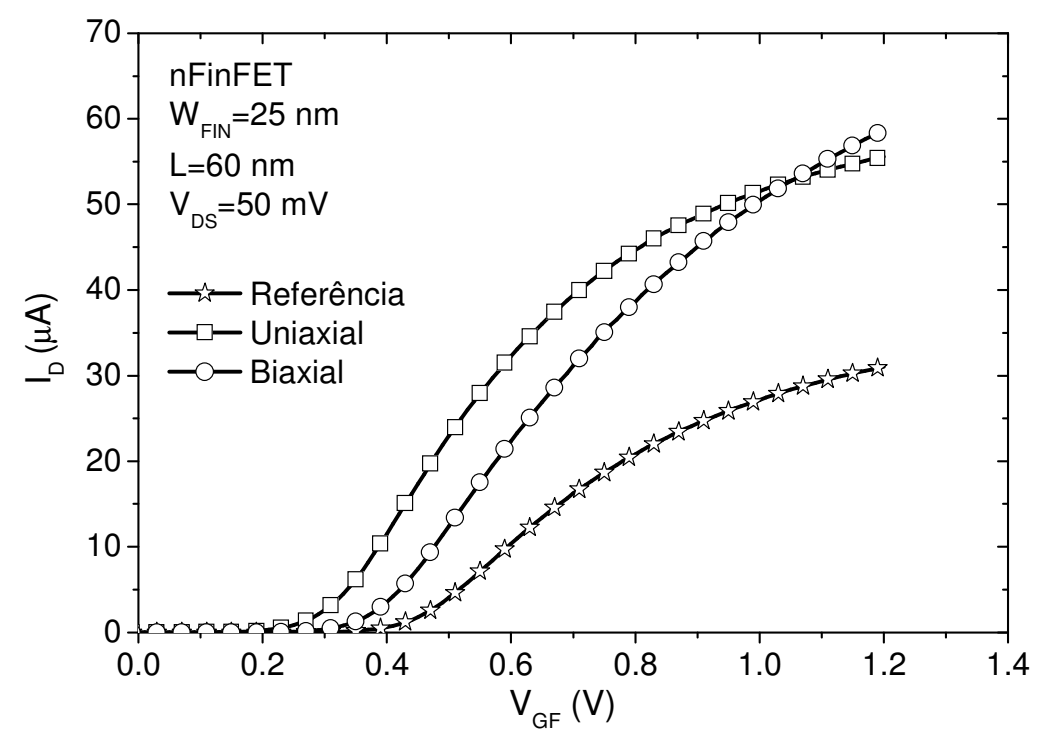

Figura 5. 10. Corrente de dreno ( $\left.\mathrm{I}_{\mathrm{D}}\right)$ em função da tensão aplicada na porta $\left(\mathrm{V}_{\mathrm{GF}}\right)$ para dispositivos de referência e sob influência de canal tensionado uniaxial e biaxial com comprimento de canal de $60 \mathrm{~nm}$.

Analisando a figura 5.10, nota-se que os dispositivos de canal tensionado apresentam um aumento da condução da corrente de dreno em relação ao dispositivo de referência devido ao tensionamento da rede cristalina facilitando, assim, o fluxo dos portadores. A maior corrente de dreno é obtida nos dispositivos com tensão uniaxial local visto que, para dispositivos de canal curto, no caso para comprimento de canal de $60 \mathrm{~nm}$, esse tipo de tensão mecânica é mais efetiva, pois o stress é maior ao longo de todo o canal. 
Assim como há um aumento na condução de corrente dos dispositivos com canal tensionado, o mesmo observa-se no comportamento da transcondutância (figura 5.11).

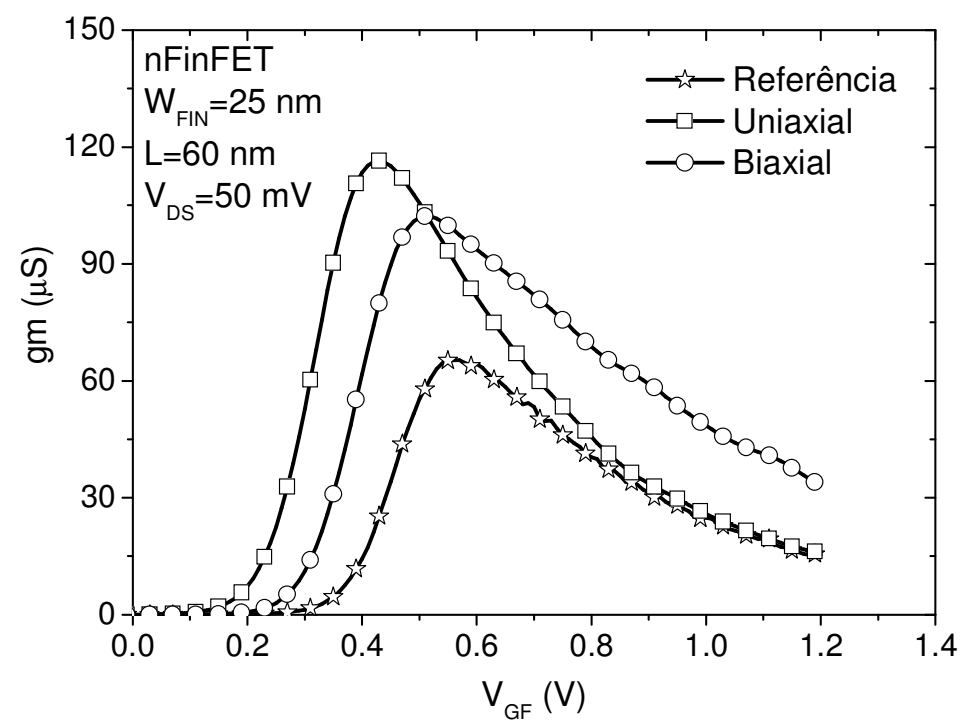

Figura 5.11. Curva da transcondutância $(\mathrm{gm})$ em função da tensão aplicada na porta $\left(\mathrm{V}_{\mathrm{GF}}\right)$ para diferentes tipos de dispositivos com comprimento de canal de $60 \mathrm{~nm}$.

Da figura 5.11 é possível constatar um aumento da transcondutância máxima para transistores tensionados. Isso acontece devido ao aumento da mobilidade de baixo campo elétrico. O valor dessa mobilidade é dependente do espalhamento das impurezas que atuam com o intuito de diminuir a mobilidade. Como em dispositivos de canal tensionado há alteração da rede cristalina, isso favorecerá a melhora da mobilidade dos portadores.

A mobilidade dos portadores é dada por:

$$
\mu=\frac{q \tau}{m^{*}}
$$

Onde $1 / \tau$ é a taxa de espalhamento (dispersão) e $\mathrm{m}^{*}$ é a massa efetiva. O aumento da mobilidade obtido nos dispositivos com canal tensionado é resultado da redução da massa efetiva e da redução da taxa de espalhamento ${ }^{75}$. Reduzindo o espalhamento, aumenta a distância média que um elétron pode percorrer antes de se chocar com a rede. Para elétrons, a redução tanto da massa efetiva como da taxa de dispersão é considerada 
muito importante para a melhora da mobilidade. Também é possível constatar através da figura 5.11, que a técnica de deformação uniaxial apresenta uma maior degradação da mobilidade. Esse aumento da degradação está relacionado à presença de defeitos no material aumentando conseqüentemente, o espalhamento dos elétrons a medida que há um aumento na polarização da porta.

A partir da figura 5.11 verifica-se então que, as duas técnicas de tensionamento melhoram a mobilidade se comparado com o dispositivo de referência. Porém, a maior mobilidade é obtida quando a técnica de deformação uniaxial é usada devido a maior intensidade de stress na região do canal favorecendo a mobilidade dos portadores nos dispositivos de menor comprimento de canal.

A mesma análise na curva da corrente de dreno em função da tensão aplicada na porta foi feita em dispositivos com comprimento de canal de $920 \mathrm{~nm}$ para as três tecnologias usadas, como pode ser visto na figura 5.12 .

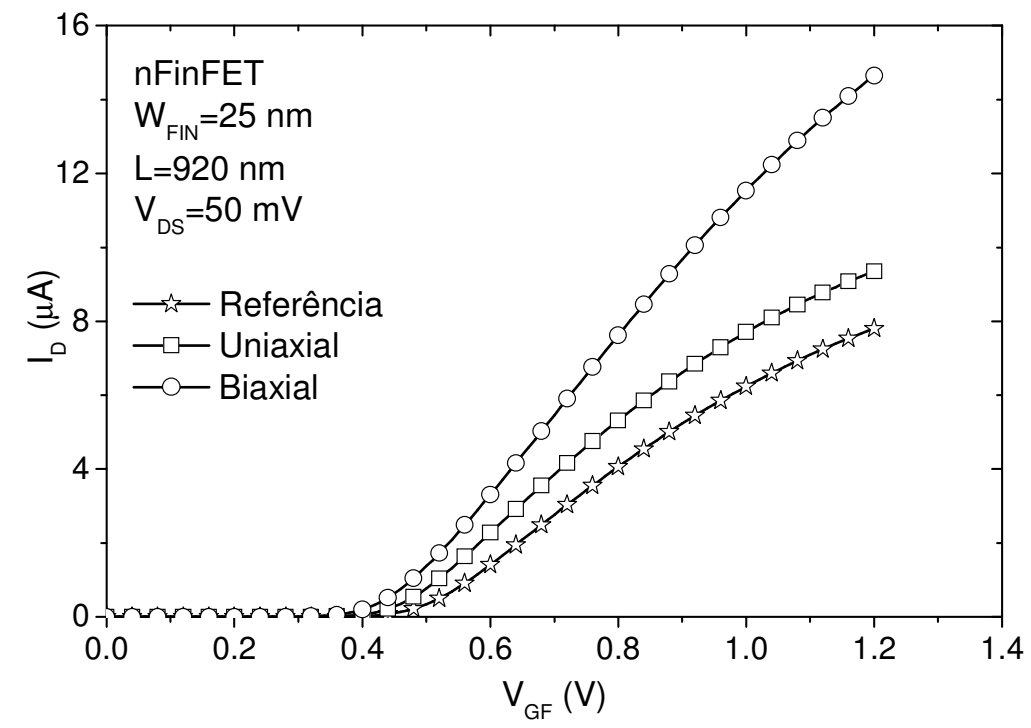

Figura 5.12. Corrente de dreno $\left(I_{D}\right)$ em função da tensão aplicada na porta $\left(V_{G F}\right)$ para dispositivos de referência e sob influência de canal tensionado com comprimento de canal de $920 \mathrm{~nm}$.

Através das curvas da figura 5.12, é possível verificar um melhor comportamento, ou seja, uma maior corrente de dreno no dispositivo com tensão biaxial global. Isso por que, em dispositivos de canal longo, o efeito do 
tensionamento em todas as regiões favorece a passagem dos elétrons facilitando sua condução. Para transistores de canal longo o efeito da tensão uniaxial mostra-se não muito vantajoso aproximando seu comportamento a um dispositivo de referência sobressaindo então o efeito da tensão biaxial global.

A figura 5.13 mostra o comportamento da transcondutância para transistores com comprimento de canal de $920 \mathrm{~nm}$ nas três diferentes tecnologias.

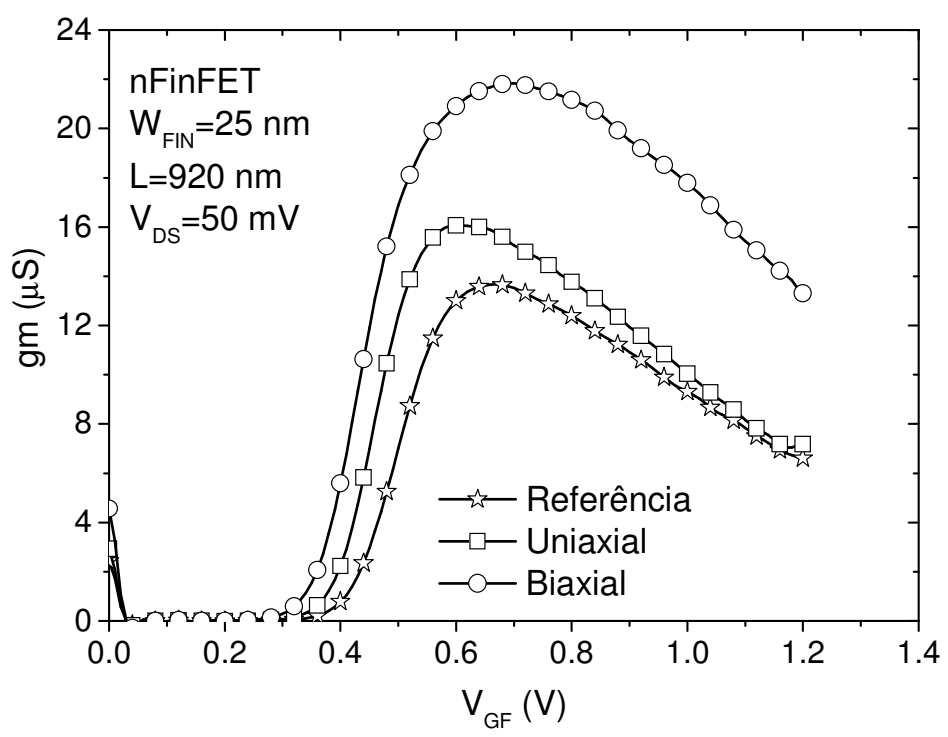

Figura 5. 11. Curva da transcondutância (gm) em função da tensão aplicada na porta ( $\left.\mathrm{V}_{\mathrm{GF}}\right)$ para diferentes tipos de dispositivos com comprimento de canal de $920 \mathrm{~nm}$.

Para transistores com comprimento de canal de $920 \mathrm{~nm}$ pode-se notar através da figura 5.13 que há um aumento da transcondutância máxima nos dispositivos de canal tensionado se comparado ao dispositivo de referência e, que para o dispositivo com tensão biaxial esse aumento da transcondutância mostra-se muito mais significativo se comparado à referência confirmando que para dispositivos de canal longo a técnica biaxial melhora o desempenho.

Analisando simultaneamente as figuras 5.11 e 5.13 , observa-se que a melhora na transcondutância máxima de dispositivos tensionados aumenta reduzindo o comprimento de canal, tal fato pode ser explicado devido à maior intensidade de deformação em dispositivos de canal curto. 
A figura 5.14 mostra a curva da transcondutância em função da tensão aplicada na porta para os dispositivos com comprimento de canal intermediários ao intervalo de 60 e $920 \mathrm{~nm}$.

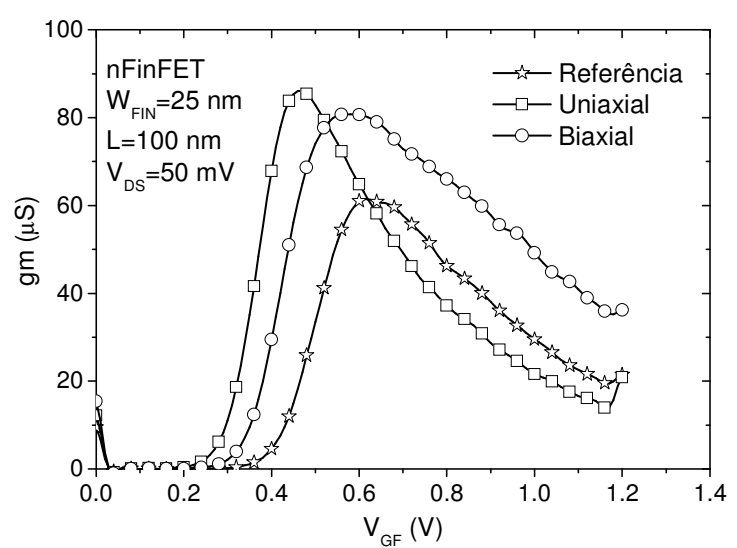

(a)

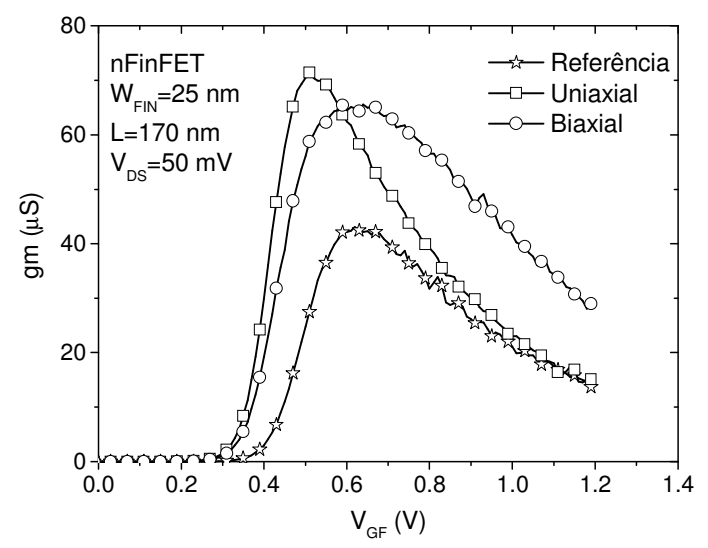

(b)

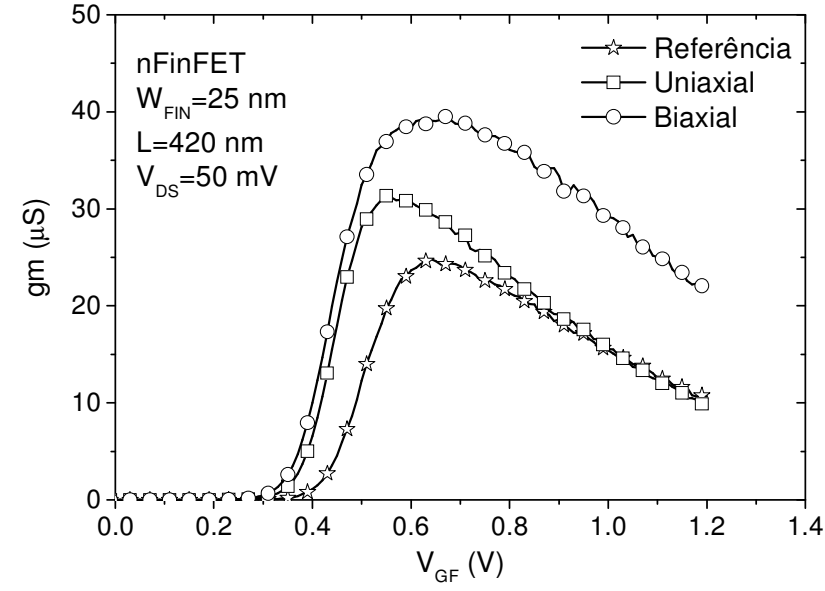

(c)

Figura 5. 12. Curva da transcondutância em função da tensão aplicada à porta para dispositivos com e sem deformação com comprimento de canal de a) 100, b) 170 e c) $420 \mathrm{~nm}$.

Verifica-se pelas curvas da figura 5.14 que, para comprimentos de canal de 100 e $170 \mathrm{~nm}$, esses dispositivos comportam-se como dispositivos de canal curto, prevalecendo o melhor desempenho para a tecnologia uniaxial, enquanto que para o dispositivo de $420 \mathrm{~nm}$, o melhor desempenho na curva da transcondutância é obtido quando a tecnologia biaxial é usada, já podendo ser então considerado como dispositivo de canal longo.

A partir dos gráficos obtidos da transcondutância em função da tensão aplicada na porta para os diferentes comprimentos de canal medidos, 
pode-se concluir, por conseqüência, que os dispositivos com tensão mecânica apresentam as melhores características como aumento da mobilidade se comparados aos dispositivos de referência sendo que a maior degradação da mobilidade decorrente da redução da mobilidade em função do campo elétrico vertical ao canal de inversão,é obtida nos dispositivos com tensão uniaxial local, como pode ser visto na tabela 5.2, abaixo, onde o fator da degradação da mobilidade efetiva (MDF) obtido através do coeficiente angular da curva $\mu_{0} / \mu_{\mathrm{N}}$ em função de $V_{G F}-V_{T}$, é mostrado para os dispositivos com comprimento de canal de $920 \mathrm{~nm}$ nas diferentes tecnologias.

Tabela 5. 2. Fator de degradação da Mobilidade efetiva [V-1] para $L=920 \mathrm{~nm}$

\begin{tabular}{|l|c|}
\hline \multicolumn{1}{|c|}{ TECNOLOGIA } & MDF \\
\hline Referência & 1,95 \\
\hline Uniaxial & 2,57 \\
\hline Biaxial & 1,31 \\
\hline
\end{tabular}

Da tabela 5.2, o maior fator de degradação da mobilidade efetiva é obtido quando a tecnologia uniaxial é usada devido à presença de defeitos no material. Entretanto, nota-se que o menor MDF é obtido para a tecnologia biaxial devido à menor degradação obtida com a deformação biaxial apesar da $R_{S D}$ ser maior para essa tecnologia como será visto posteriormente.

A resistência total dos dispositivos estudados foi extraída por $V_{D S} / l_{D}$ para $V_{G T}=V_{G F}-V_{T}=0,6 \mathrm{~V}$ com polarização de dreno de $50 \mathrm{mV}$. A figura 5.15 mostra a resistência total ( $\mathrm{R}_{\text {TOTAL }}$ ) extraída em função do comprimento de porta $(\mathrm{L})$ para os dispositivos tensionados e de referência. 


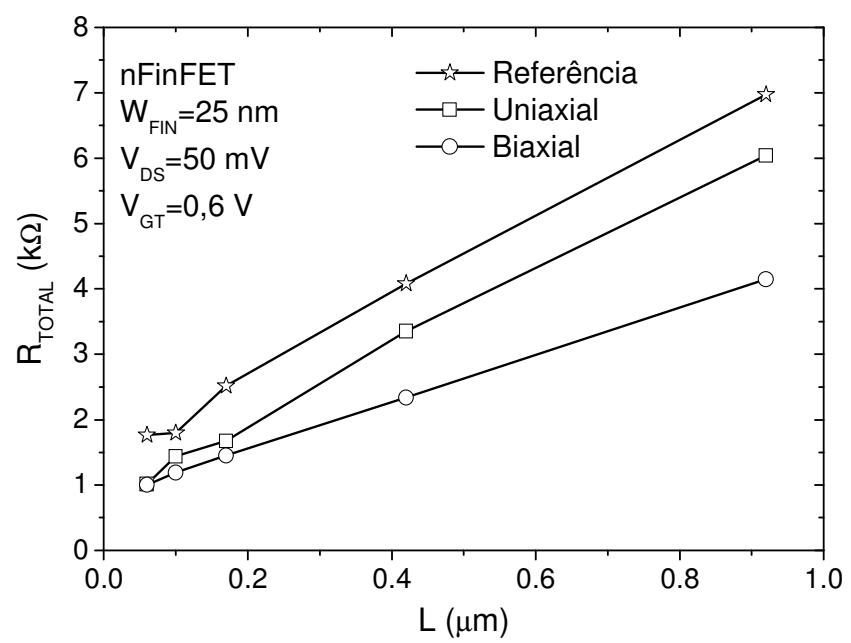

Figura 5. 13. Resistência Total em função do comprimento de porta para dispositivos com e sem o uso de deformação.

Através da figura 5.15 , é possível observar que, para os comprimentos de canal usados ( $L$ de $60,100,170,420$ e $920 \mathrm{~nm}$ ), a resistência total apresenta um melhor comportamento para dispositivos com tensão biaxial global (sSOI) do que para dispositivos de referência e com tensão uniaxial local (CESL). À medida que o comprimento de canal dos dispositivos diminui, a diferença entre os valores da resistência total entre os dispositivos com deformação vai ficando menos significativa, mostrando que, para tais dispositivos, o comportamento de ambos os tipos de deformações são semelhantes, ou seja, se o dispositivo apresentar canal com dimensão muito pequena, tanto a técnica uniaxial como a biaxial melhorará o comportamento do dispositivo em relação à sua resistência total. Observa-se também que, para transistores de canal longo, a diferença entre os valores da resistência total torna-se mais significante, o que pode ser explicado pelas características do biaxial como aumento da mobilidade e da condução de corrente em transistores de canal longo melhorando seu desempenho.

A resistência total nos transistores com tensão uniaxial é menor do que nos transistores de referência, pois nos transistores com tecnologia uniaxial, a mobilidade é maior devido à deformação uniaxial, como observado em transistores com a tecnologia biaxial

Através das análises das curvas da transcondutância e, como conseqüência, da mobilidade dessas tecnologias, é possível concluir que como a tecnologia de canal tensionado apresenta maior mobilidade dos portadores devido à alteração da rede cristalina e com isso, a alteração das 
bandas de energia, favorecendo a mobilidade, como conseqüência há diminuição da resistência total do dispositivo.

A figura 5.16 mostra as resistências série de fonte e dreno estimadas para os dispositivos medidos. As $\mathrm{R}_{\mathrm{SD}}$ foram estimadas através da regressão linear $^{50}$ das curvas da $\mathrm{R}_{\text {TOTAL }}$ em função do comprimento do canal dos dispositivos para as três tecnologias onde $R_{S D} \cong R_{\text {TorAL }}$ para $L=0$. Esse método foi usado, pois é o mais confiável para estimar o valor da $R_{S D}$ nesses dispositivos.

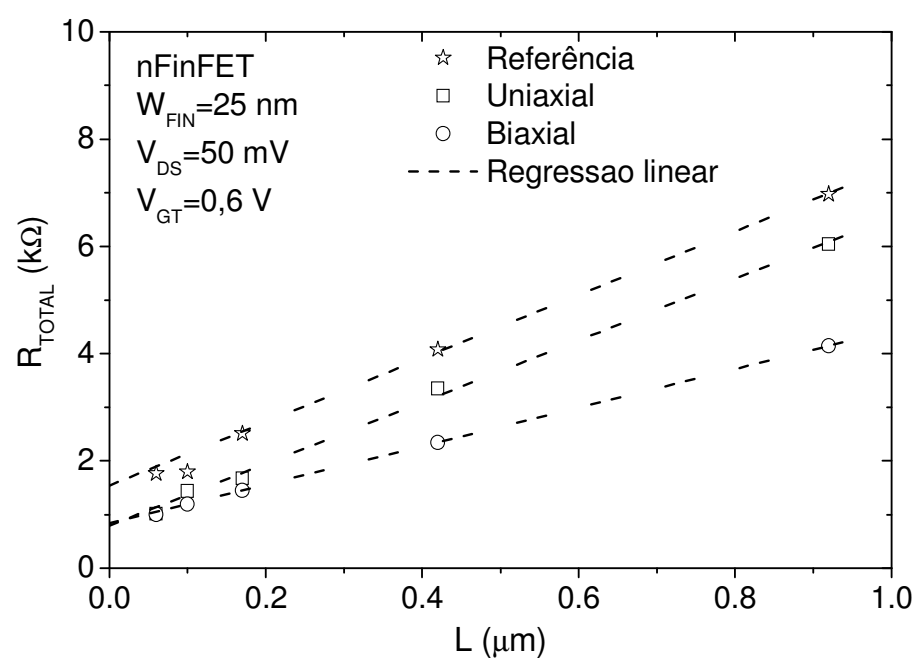

Figura 5. 14. Curvas da $R_{\text {TOTAL }}$ em função dos comprimentos de canal para estimar a $R_{S D}$ através da regressão linear dessas curvas para as três tecnologias usadas.

A tabela 5.3 mostra o valor da $R_{S D}$ estimada para cada tecnologia estudada.

Tabela 5. 3. $\mathbf{R}_{\mathrm{SD}}[\Omega]$ estimadas para as tecnologias estudadas obtidas através da regressão linear das curvas $\mathbf{R}_{\text {TOTAL }} X L$

\begin{tabular}{|l|c|}
\hline \multicolumn{1}{|c|}{ TECNOLOGIA } & $\mathrm{R}_{\mathrm{SD}}[\Omega]$ \\
\hline Referência & 1542 \\
\hline Uniaxial & 794 \\
\hline Biaxial & 836 \\
\hline
\end{tabular}

Na tabela 5.3, nota-se que o dispositivo de referência apresenta 0 maior valor da $R_{S D}$ enquanto que para os dispositivos com deformação esse valor é menor. Isso significa que o uso da tecnologia de canal tensionado, aparentemente influencia no valor da $R_{S D}$ diminuindo então o valor da $R_{T O T A L}$, já que esta é a soma das parcelas da $R_{C H}$ e $R_{S D}$. 
Um importante parâmetro geométrico nos dispositivos FinFETs é a largura do fin $\left(\mathrm{W}_{\mathrm{FIN}}\right)$ sendo que nesses dispositivos a largura efetiva é dada por:

$$
W e_{f f} \cong 2 H_{F I N}+W_{F I N}
$$

Estreitando esse parâmetro, uma melhora no controle dos efeitos de canal curto é obtida, mas como desvantagem, há o aumento da $R_{S D}$ que degrada a condução de corrente e a transcondutância. A figura 5.17 mostra a $\mathrm{R}_{\text {TOTAL }}$ extraída em função da largura do fin comparando as três tecnologias para comprimento de canal de $100 \mathrm{~nm}$, assim como a degradação da corrente de dreno (figura 5.17b) e transcondutância (figura 5.17c) resultado desse estreitamento.

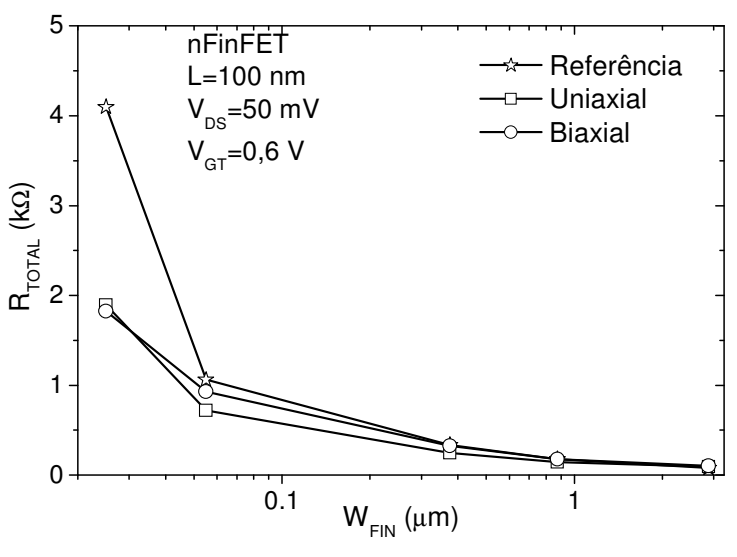

(a)

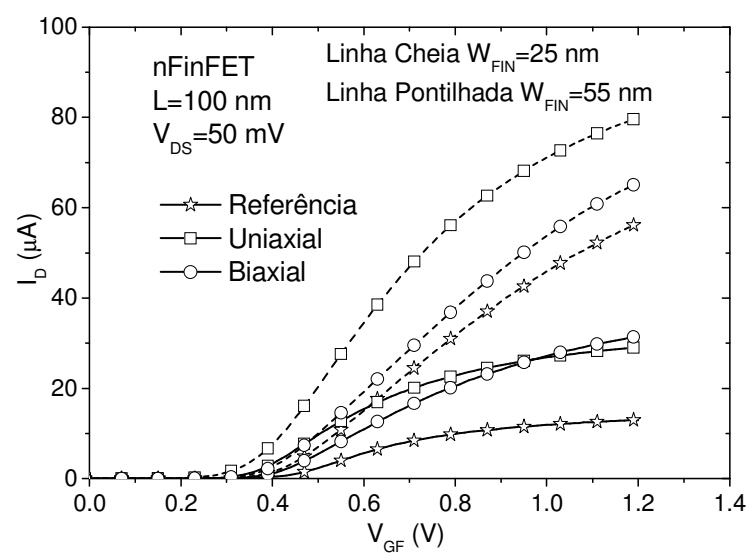

(b)

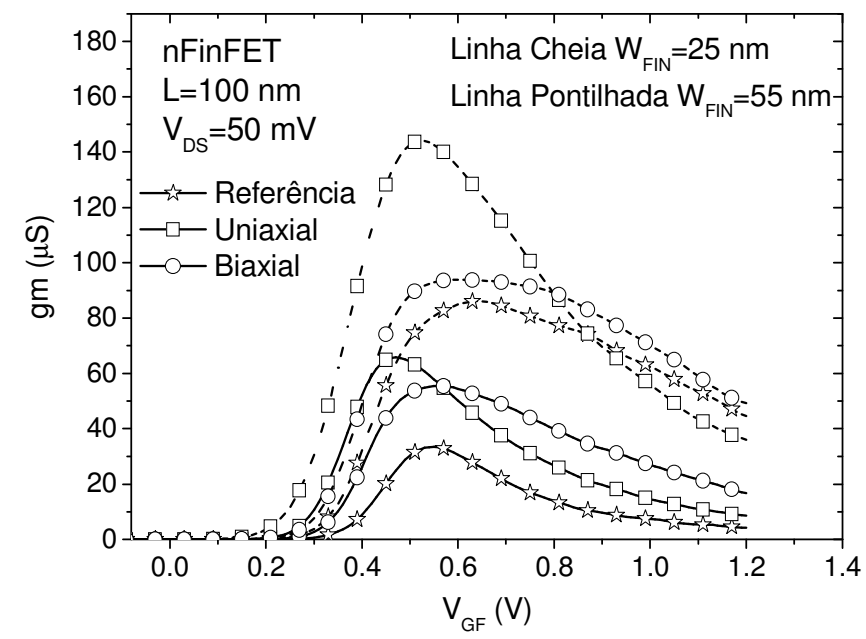

(c)

Figura 5. 15. Análise da resistência total em função da largura do fin para comprimento de porta de $100 \mathrm{~nm}$ (a), curvas da condução de corrente (b) e transcondutância (c) para dispositivos com e sem deformação com $W_{\text {FIN }}$ de 25 e $55 \mathrm{~nm}$. 
Nos gráficos da figura 5.17, pode-se verificar que apesar do estreitamento da largura do fin, o melhor comportamento em relação à resistência total do dispositivo, ou seja, o menor valor da $\mathrm{R}_{\text {TOTAL }}$ e, como conseqüência, a menor influência da $R_{S D}$, é obtido quando a técnica uniaxial é usada. As figuras 17b e 17c apresentam as curvas da condução de corrente e da transcondutância em função da tensão aplicada na porta para os dispositivos mais estreitos com $\mathrm{W}_{\mathrm{FIN}}$ de 25 e $55 \mathrm{~nm}$ com o intuito de se verificar a degradação dessas características à medida que há o avanço da tecnologia. Nota-se, então que, apesar dos dispositivos com $W_{\text {FIN }}$ de $25 \mathrm{~nm}$ apresentarem um melhor controle do efeito de canal curto devido à aproximação de suas três portas, esses apresentam uma maior degradação da mobilidade devido ao aumento significativo da parcela da $R_{S D}$ na $R_{\text {TOTAL já }}$ que, como o canal é pequeno, a $R_{C H}$ torna-se desprezível em relação à $R_{S D}$. Para ambas as larguras do fin aqui analisadas, é possível verificar que a técnica de tensionamento uniaxial apresenta as melhores características. À medida que $\mathrm{W}_{\mathrm{FIN}}$ aumenta, mas com comprimento de canal ainda de $100 \mathrm{~nm}$, o efeito de canal curto torna-se mais efetivo, resultando na degradação das características dos dispositivos não havendo diferença significativa no valor da $\mathrm{R}_{\text {TOTAL }}$ para as três tecnologias estudadas.

A figura 5.18 e mostra a $R_{\text {TOTAL }}$ extraída em função da largura do fin para as três tecnologias com comprimento de canal de $920 \mathrm{~nm}$.

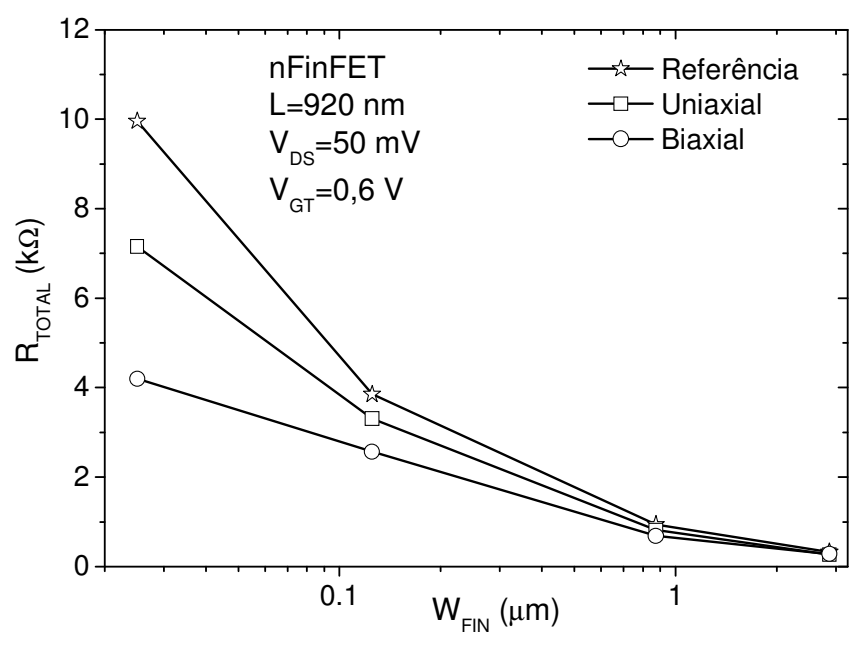

Figura 5. 16. Análise da resistência total em função da largura do fin para comprimento de porta de $920 \mathrm{~nm}$. 
Para os dispositivos medidos com comprimento de canal de $920 \mathrm{~nm}$, todas as cargas na região do canal são controladas pela porta superior e, por essa razão, esses dispositivos não estão sofrendo efeito de canal curto. Notase através da figura 5.18 que os dispositivos sob a técnica de tensão mecânica biaxial apresentam, dentre os outros mostrados graficamente, melhor comportamento em termos da $\mathrm{R}_{\text {TOTAL. }}$ Uma razão para o melhor comportamento do biaxial é devido ao aumento da densidade de corrente causada pelo aumento da mobilidade dos portadores que, por sua vez, está relacionado à mudança na rede cristalina que nesse caso ocorre nas duas direções.

\subsubsection{Resultados Experimentais com SEG}

Os mesmos dispositivos estudados até agora serão analisados com o uso do crescimento seletivo epitaxial com o intuito de se verificar a influência do SEG nas principais características elétricas dos dispositivos, através da comparação de seus resultados.

A figura 5.19 mostra as curvas da corrente de dreno em função da tensão aplicada na porta $\left(\mathrm{V}_{\mathrm{GF}}\right.$ de 0 a $\left.1,2 \mathrm{~V}\right)$, para polarização de dreno de 50 $\mathrm{mV}$, dos transistores de referência e sob influência de tensão mecânica com comprimento de canal de $100 \mathrm{~nm}$, com e sem o uso de SEG.

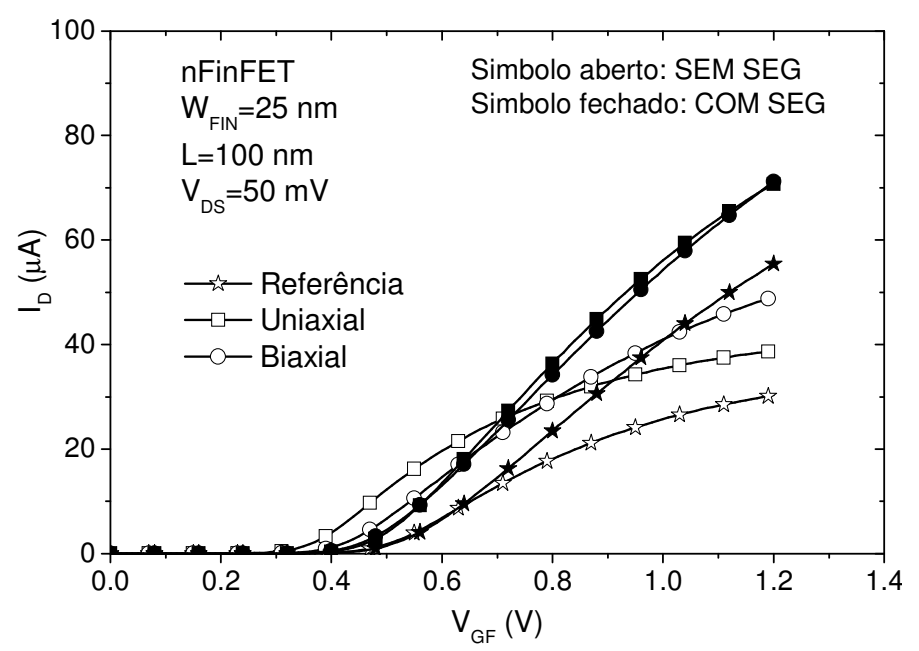

Figura 5. 17. Curvas características da corrente de dreno em função da tensão aplicada na porta para dispositivos com e sem deformação e com e sem SEG com comprimento de canal de $100 \mathrm{~nm}$ e largura do fin de $25 \mathrm{~nm}$. 
Nos gráficos da figura 5.19, pode-se observar que os dispositivos com crescimento seletivo epitaxial apresentam melhor comportamento da corrente de dreno em função da tensão aplicada na porta se comparado aos dispositivos sem SEG. Isso acontece não só com os dispositivos de canal tensionado, mas também com o dispositivo de referência. A maior condução de corrente ocorrerá quando a técnica de canal tensionado uniaxial for usada juntamente com o SEG mostrando uma melhora no desempenho do dispositivo.

A figura 5.20 apresenta as curvas da transcondutância em função da tensão aplicada na porta para os dispositivos de referência e sob influência de tensão mecânica com e sem o uso de SEG, para comprimento de canal de $100 \mathrm{~nm}$.

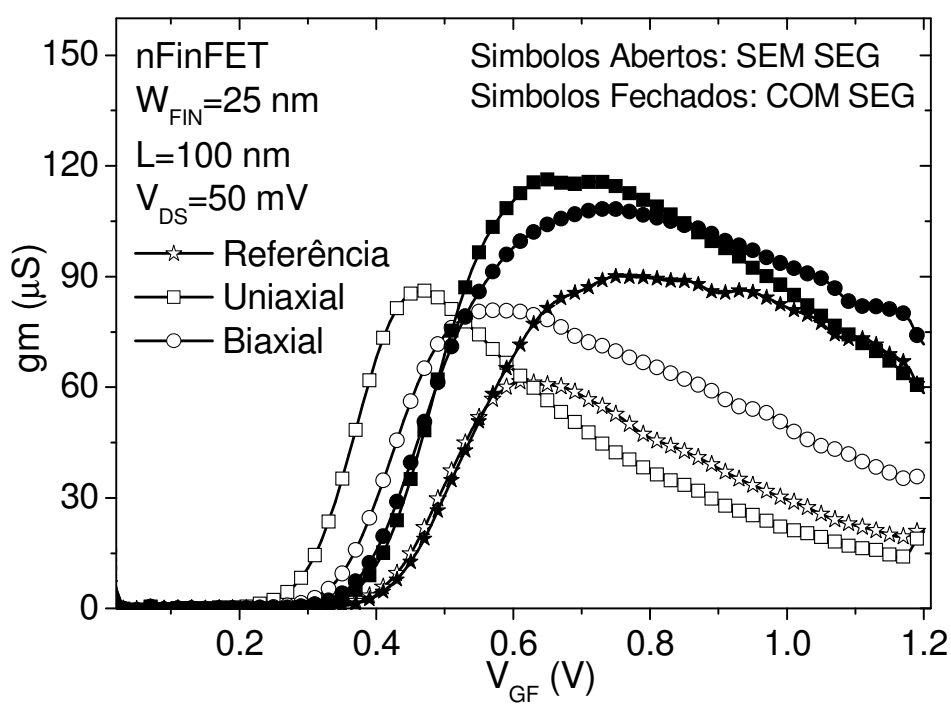

Figura 5. 18. Curvas da transcondutância em função da tensão aplicada à porta para dispositivos com e sem deformação e com e sem SEG com comprimento de canal de $100 \mathrm{~nm}$.

A partir dos gráficos da figura 5.20, torna-se possível observar que o crescimento seletivo provoca um aumento da transcondutância devido a diminuição da resistência série. A figura 5.20 mostra um aumento da transcondutância máxima até mesmo para o dispositivo de referência com SEG se comparado aos dispositivos sem SEG e sob influência de tensão mecânica. Para o comprimento de canal de $100 \mathrm{~nm}$, observa-se que os 
dispositivos com a técnica uniaxial apresentam o melhor desempenho em relação à mobilidade dos portadores sendo que um aumento de aproximadamente $35 \%$ é alcançado com essa técnica quando o SEG é usado.

A figura 5.21 apresenta as curvas da corrente de dreno em função da tensão aplicada na porta para os dispositivos de referência e sob influência de tensão mecânica com e sem o uso de SEG com comprimento de canal de 920 nm.

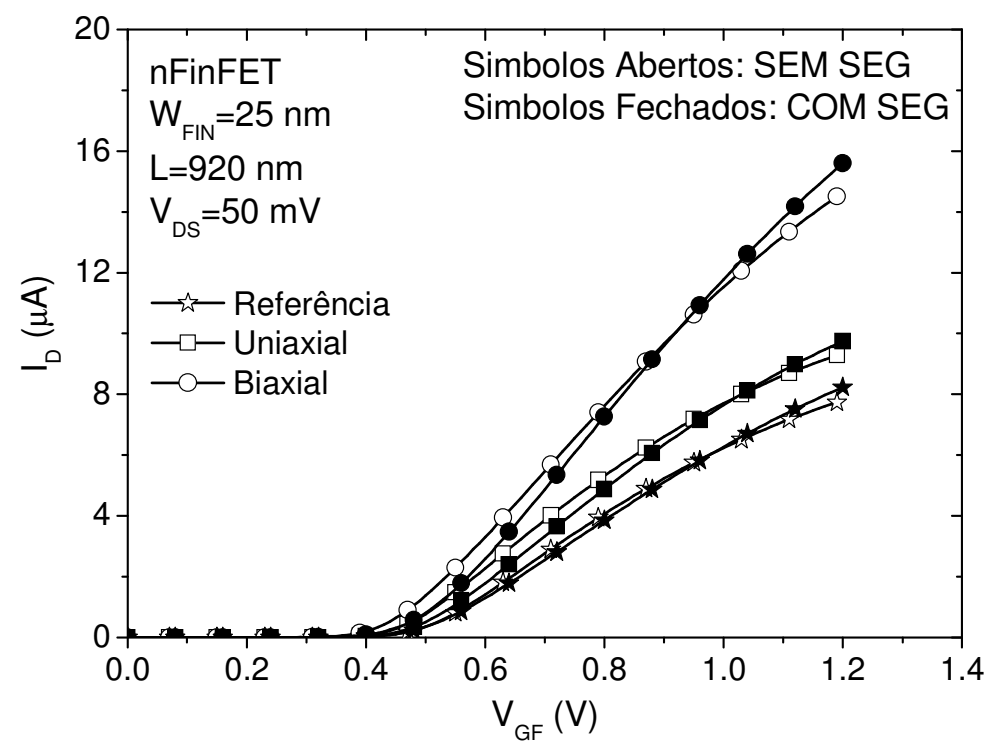

Figura 5. 19. Curvas características da corrente de dreno em função da tensão aplicada na porta para dispositivos com sem deformação e SEG com comprimentos de canal de $920 \mathrm{~nm}$ e largura do fin de $25 \mathrm{~nm}$.

Para comprimentos de canal de $920 \mathrm{~nm}$, constata-se através das curvas da corrente de dreno em função da tensão aplicada na porta que, como visto anteriormente, os dispositivos com deformação apresentam melhor comportamento da condução de corrente se comparado ao dispositivo de referência devido à alteração na rede cristalina causada pela tecnologia de canal tensionado, facilitando, assim, a condução dos portadores. Porém, o uso do SEG em dispositivos com comprimento de canal longo não se mostra muito vantajoso até mesmo nos transistores de referência, já que essa tecnologia foi desenvolvida principalmente para suprir a deficiência no aumento da $R_{S D}$ em dispositivos menores. 
As curvas da transcondutância em função da tensão aplicada na porta para os dispositivos de referência e sob influência das técnicas uniaxial e biaxial com e sem o uso de SEG e, com comprimento de canal de 920 nm é apresentada na figura 5.22 .

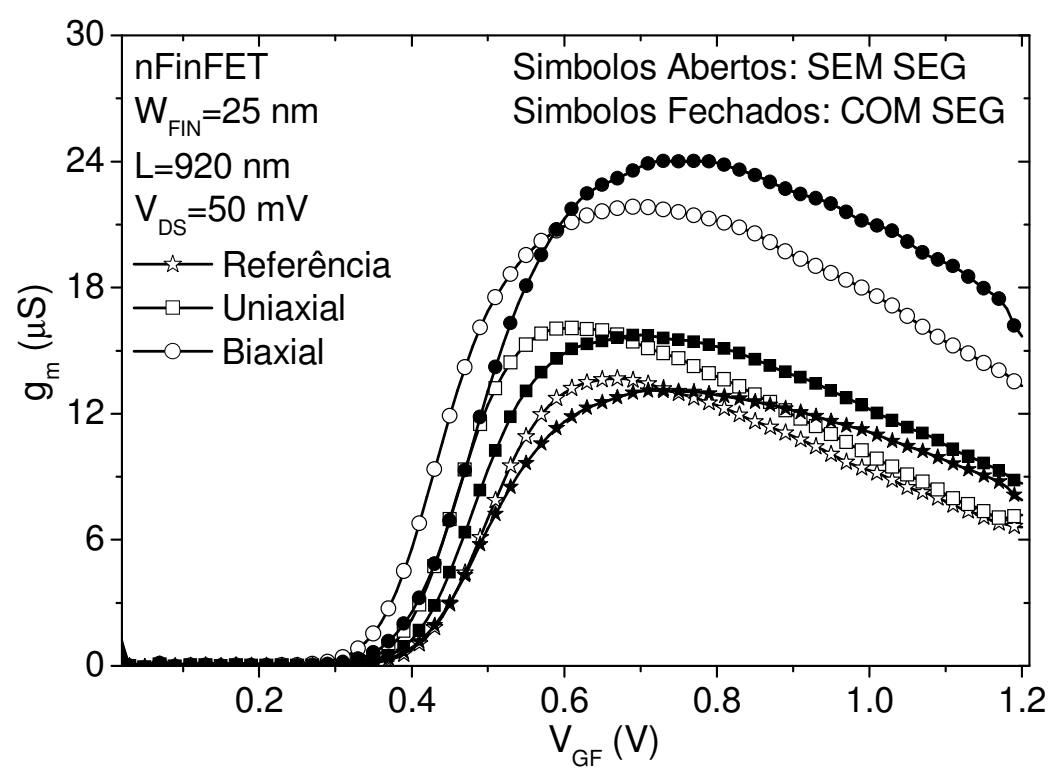

Figura 5. 20. Curvas da transcondutância em função da tensão aplicada à porta para dispositivos com e sem deformação e com e sem SEG com comprimento de canal de $920 \mathrm{~nm}$.

Através das curvas da figura 5.22, observa-se que há um aumento significativo da transcondutância máxima em função da tensão aplicada na porta devido ao aumento da mobilidade, para os dispositivos biaxial com e sem SEG se comparado aos outros dispositivos estudados. Entretanto, o uso de SEG nesses dispositivos, que podem ser classificados como dispositivos de canal longo, não se mostra muito vantajoso, pois há um aumento de apenas $10 \%$ na transcondutância máxima. Para os dispositivos de referência e sob a técnica uniaxial pode-se dizer que não há diferença significativa em relação à mobilidade, no uso ou não de SEG, para esse comprimento de canal.

A tabela 5.4 mostra o fator de degradação da mobilidade efetiva (MDF) para os dispositivos estudados com e sem o uso de SEG. Dessa tabela é possível notar que os dispositivos com SEG apresentam os menores valores de MDF devido à diminuição da $R_{S D}$ com o uso de SEG. 
Tabela 5. 4. Fator de degradação da Mobilidade efetiva [V-1] para $L=920$ nm

\begin{tabular}{|l|c|c|}
\hline \multicolumn{1}{|c|}{ TECNOLOGIA } & SEM SEG & COM SEG \\
\hline Referência & 1,95 & 1,17 \\
\hline Uniaxial & 2,57 & 1,66 \\
\hline Global & 1,31 & 0,91 \\
\hline
\end{tabular}

A partir do que foi estudado até agora será possível verificar e entender o comportamento da resistência total em função do comprimento de canal dos dispositivos de referência e aqueles sob influência de tensão mecânica, com e sem o uso de SEG, como pode ser visto na figura 5.23.

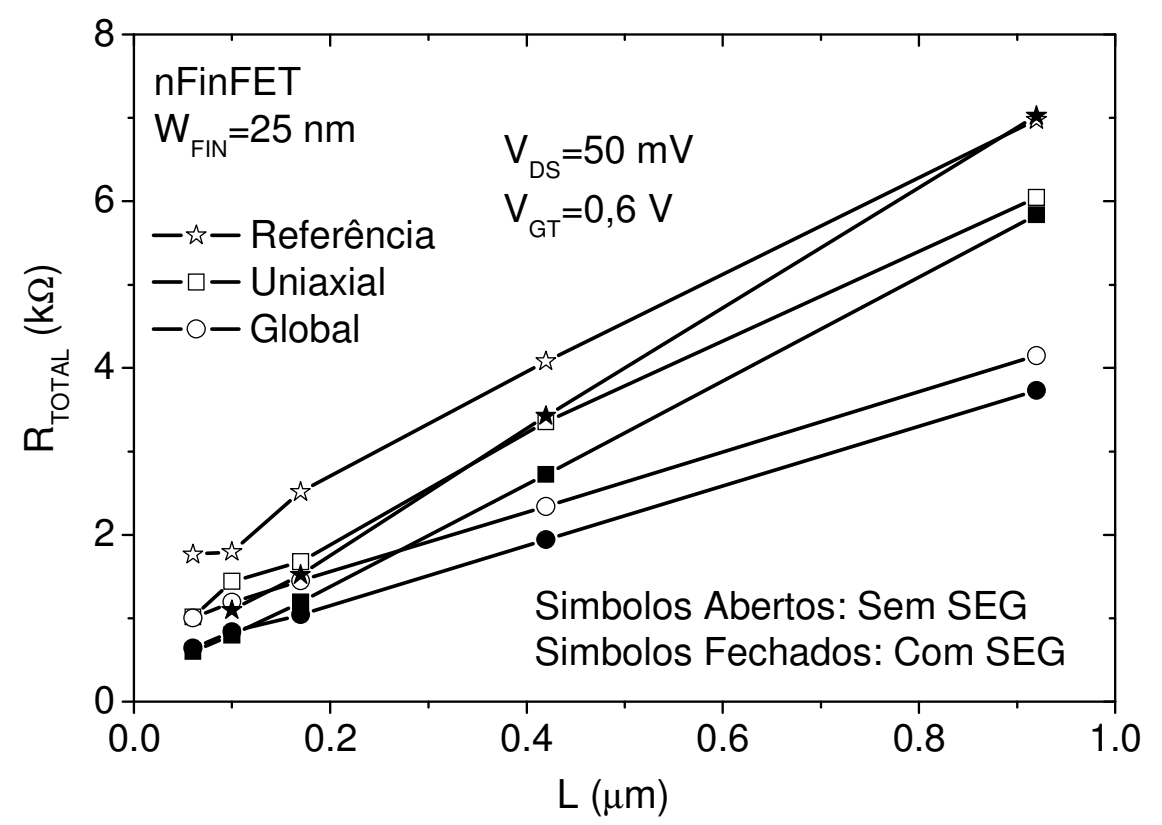

Figura 5. 21. Curvas da $R_{\text {TOTAL }}$ em função dos comprimentos de porta para dispositivos de referência e sob influência de deformação com e sem o uso de SEG

A partir da figura 5.23, observa-se que para os comprimentos de canal estudados, o uso de SEG em todos os dispositivos seja de referência ou tensionados, gera um menor valor da $\mathrm{R}_{\text {TOTAL }}$ se comparado aos dispositivos sem SEG. Para os dispositivos de canal longo com SEG, o melhor comportamento da $\mathrm{R}_{\text {TOTAL }}$ é adquirido quando a técnica biaxial é usada, sendo resultado do aumento da mobilidade de portadores e da condução de corrente devido à deformação biaxial. Nesse caso, como há o alinhamento entre os 
átomos da camada de silício com os da camada de SiGe, ocorre um aumento em espaçamento entre os átomos de silício mudando o formato das bandas de energia, aumentando a mobilidade e reduzindo assim a $\mathrm{R}_{\text {TOTAL. }}$.

Para os comprimentos de canal menores, apesar dos dispositivos tensionados sem SEG apresentarem como características o aumento da mobilidade e condução de corrente e, conseqüentemente, menor valor de $\mathrm{R}_{\text {TOTAL }}$ se comparado aos dispositivos de referência, quando se faz o uso de SEG nesses dispositivos menores, até mesmo os dispositivos de referência apresentam um melhor comportamento se comparado àqueles sem SEG, isso porque, elevando as regiões de fonte e dreno há uma diminuição em todas as resistências parasitas fornecendo mais silício para a formação do siliceto de fonte e dreno. Em outras palavras, pode-se dizer que, os dispositivos tensionados sem SEG perdem suas vantagens se comparados aos dispositivos com o uso de $S E G$ devido à redução da $R_{S D}$.

A tabela 5.5 mostra o valor da $R_{S D}$ estimada, como visto anteriormente, para os dispositivos estudados com e sem o uso de SEG. Como esperado, é possível notar que os dispositivos com SEG apresentam um menor valor da $R_{S D}$ sendo que o menor valor desta é obtido com a técnica uniaxial desde que a deformação uniaxial mostra-se maior nas extremidades do canal próximo as regiões de fonte e dreno.

Tabela 5. 5. $\mathbf{R}_{\mathrm{SD}}[\Omega]$ estimadas para as tecnologias estudadas obtidas através da regressão linear das curvas $\mathbf{R}_{\text {TOTAL }} \mathbf{X L}$

\begin{tabular}{|l|c|c|}
\hline \multicolumn{1}{|c|}{ TECNOLOGIA } & SEM SEG & COM SEG \\
\hline Referência & 1542 & 307 \\
\hline Uniaxial & 794 & 133 \\
\hline Biaxial & 836 & 432 \\
\hline
\end{tabular}

A figura 5.24 mostra a resistência total extraída em função da largura do fin comparando as três tecnologias com e sem o uso de SEG para comprimento de canal de $100 \mathrm{~nm}$. 


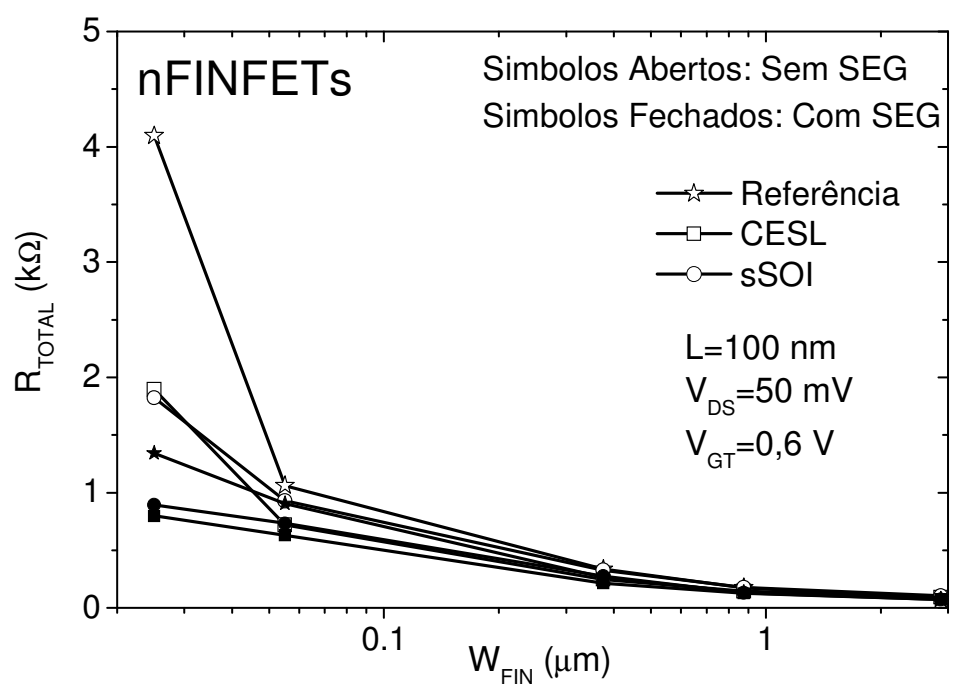

Figura 5. 22. Resistência total em função da largura do fin com comprimento de canal de 100 $\mathrm{nm}$ para as três diferentes tecnologias de dispositivos com e sem o uso de SEG e com polarização de porta de $50 \mathrm{mV}$.

$\mathrm{Na}$ figura 5.24, nota-se que para dispositivos mais estreitos com $W_{\text {FIN }}<100 \mathrm{~mm}$, aqueles que fazem o uso de SEG apresentam os menores

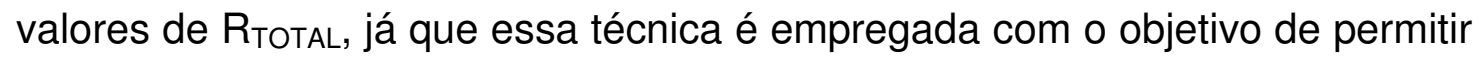
o estreitamento da largura do fin sem degradar a transcondutância e a condução de corrente. À medida que a largura do fin aumenta enquanto o comprimento do canal mantém-se constante em $100 \mathrm{~nm}$, os efeitos de canal curto tornam-se mais efetivos resultando na degradação das características dos transistores. O pior comportamento observado a partir da figura 5.24 acontece para o dispositivo de referência com $W_{\mathrm{FIN}}$ de $25 \mathrm{~nm}$ sem o uso de SEG. Com o uso de SEG nesse mesmo dispositivo, que não apresenta como característica aumento adicional da mobilidade e, conseqüentemente, diminuição da resistência total, como os dispositivos com deformação, há uma melhora de aproximadamente $67 \%$ no valor final da $\mathrm{R}_{\text {TOTAL. Para }}$ as outras tecnologias como uniaxial e biaxial observa-se através do gráfico, que o uso

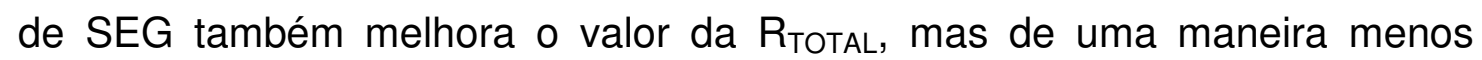
significativa como no dispositivo de referência, pois os dispositivos com canal tensionado já apresentam como característica a melhora no comportamento da $R_{\text {TOtAL. }}$

A análise acima também foi feita para dispositivos com comprimento de canal de $920 \mathrm{~nm}$, como pode ser visto na figura 5.25 abaixo: 


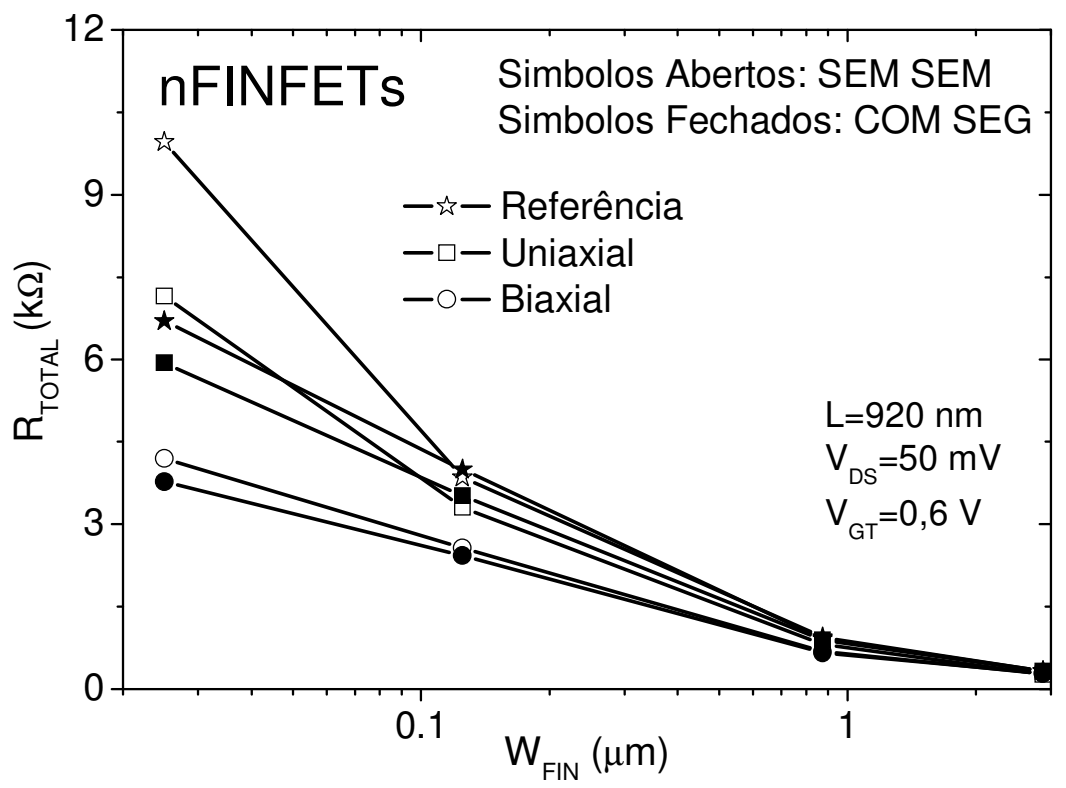

Figura 5. 23. Resistência total em função da largura do fin com comprimento de canal de 920 $\mathrm{nm}$ para as três diferentes tecnologias de dispositivos com e sem o uso de SEG e com polarização de porta de $50 \mathrm{mV}$.

Para os transistores com comprimento de canal de $920 \mathrm{~nm}$, todas as cargas na região do canal são controladas pela porta superior e, sendo assim, esses dispositivos não estão sob efeito de canal curto. Para o comprimento de canal aqui estudado, os dispositivos sob a técnica biaxial apresentam um melhor comportamento da RTOTAL com e sem o uso de SEG para todas as larguras de fin estudadas, não havendo diferença significativa entre esses

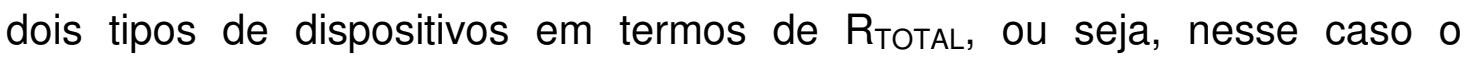
crescimento da camada de silício nas regiões de fonte e dreno não apresenta muita influência na $R_{S D}$. Outra razão para o melhor desempenho da técnica biaxial é o aumento da densidade de corrente causada pelo aumento da mobilidade dos portadores, que, por sua vez, está relacionada à mudança da rede cristalina que, nesse caso, ocorre nas duas direções.

Os dispositivos que apresentam o melhor comportamento no controle das cargas na região do canal são àqueles sob a técnica uniaxial com e sem o uso de SEG, como pode ser visto na figura 5.26, a qual mostra a tensão de limiar em função da largura do fin para comprimento de canal de $100 \mathrm{~nm}$. 


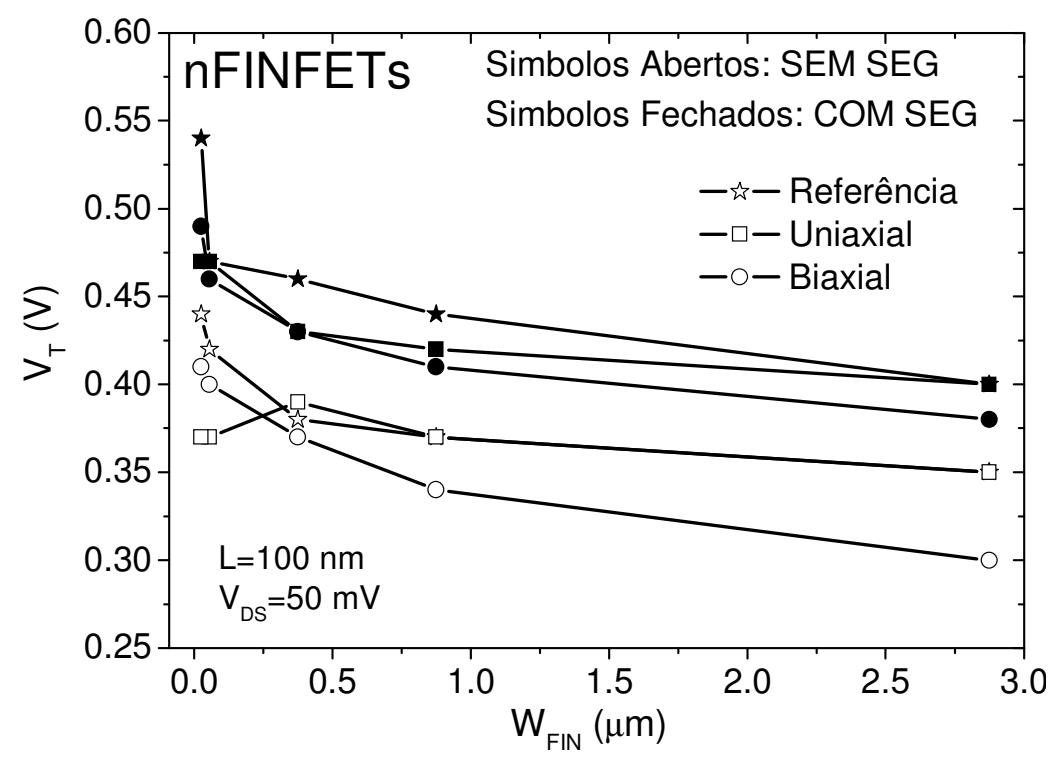

Figura 5. 24. Tensão de limiar em função da largura do fin para as três diferentes tecnologias de dispositivos com e sem SEG para comprimento de canal de $100 \mathrm{~nm}$ com V de $50 \mathrm{mV}$.

A tensão de limiar foi extraída através do método da observação do pico máximo da derivada da transcondutância, como visto anteriormente, a partir da segunda derivada da curva $\mathrm{I}_{\mathrm{D}} \mathrm{x} \mathrm{V}_{\mathrm{GF}}$ para baixos valores de $\mathrm{V}_{\mathrm{DS}}$. Nesse caso, nota-se que a menor variação da tensão de limiar é obtida nos dispositivos sob a técnica uniaxial podendo ser associada à mudança na rede cristalina causada pelo stress uniaxial. Também é impossível observar que uma característica não desejada do SEG é o aumento de $\mathrm{V}_{\mathrm{T}}$.

Analisando a tabela 5.6, que mostra a tensão de limiar em função da largura do fin para dispositivos com comprimento de canal de $920 \mathrm{~nm}$, podese observar que para dispositivos com $W_{F I N} \leqslant 100 \mathrm{~nm}$, àqueles com SEG apresentam um aumento da tensão de limiar que pode ser entendido como resultado das características do processo da elevação das regiões de fonte e dreno. Para os dispositivos com $W_{F I N}>100 \mathrm{~mm}$ esse comportamento não é óbvio, mas ainda acontece. 
Tabela 5. 6. Tensão de limiar para as três tecnologias estudadas com e sem o uso de SEG para comprimento de canal de $920 \mathrm{~nm}$

\begin{tabular}{|c|c|c|c|c|c|c|}
\hline \multicolumn{3}{|c|}{ SEM SEG } & \multicolumn{3}{c|}{ COM SEG } \\
\hline $\mathbf{W}_{\text {FIN }}(\boldsymbol{\mu m})$ & Referência & Uniaxial & Biaxial & Referência & Uniaxial & Biaxial \\
\hline 2,875 & 0,41 & 0,39 & 0,32 & 0,41 & 0,41 & 0,31 \\
\hline 0,875 & 0,41 & 0,37 & 0,36 & 0,41 & 0,41 & 0,33 \\
\hline 0,125 & 0,42 & 0,42 & 0,39 & 0,42 & 0,42 & 0,41 \\
\hline 0,055 & 0,42 & 0,43 & 0,40 & 0,47 & 0,45 & 0,44 \\
\hline 0,025 & 0,47 & 0,44 & 0,44 & 0,50 & 0,48 & 0,47 \\
\hline
\end{tabular}

Uma característica observada nos dispositivos sob a técnica biaxial é que esses apresentam os menores valores de $\mathrm{V}_{\mathrm{T}}$ devido ao stress biaxial que influencia diretamente na faixa proibida do material, diminuindo assim esse parâmetro. 


\section{SIMULAÇÕES TRIDIMENSIONAIS}

\subsection{O Simulador ATLAS}

As simulações dos dispositivos estudados nesse trabalho foram feitas através do simulador ATLAS. O ATLAS é um simulador de dispositivos semicondutores tanto bidimensional como tridimensional produzido pela Silvaco $^{76} \mathrm{e}$, normalmente é executável conjuntamente com o ambiente DECKBUILD.

Esse simulador de dispositivos é baseado em equações físicas que permitem obter características elétricas associadas às estruturas físicas e às condições de polarização. Essas características são obtidas pela aproximação da operação do dispositivo em grades bi ou tridimensionais já definidas, consistindo de um número de pontos de grades chamados de nó, sendo o nó resultado do cruzamento entre linhas e colunas. Através da aplicação de um conjunto de equações diferenciais nessas grades, originárias da lei de Maxwell, o transporte de portadores ao longo da estrutura pode ser simulado. Isso significa que o desempenho elétrico de um dispositivo poderá ser modelado em modos de operação cc, ca e no domínio do tempo.

Com o simulador ATLAS é possível obter características elétricas, ópticas e de ruído dos dispositivos, através de curvas que demonstram seus comportamentos, assim como extrair parâmetros como, tensão de limiar, tensão de ruptura, transcondutância, inclinação de sublimiar, tensão Early, etc.

A primeira etapa ao se criar um arquivo de simulação, é a determinação de uma grade de pontos que seja adequada à estrutura a ser simulada. Para que a construção das grades seja feita de maneira correta, as linhas e colunas não precisam, necessariamente, cruzar toda a estrutura; os pontos devem se concentrar na transição de materiais e dopantes; as regiões com concentração de dopantes constante podem possuir um menor número de pontos e, se durante a construção das grades forem observados triângulos obtusos, as 
grades deverão ser refeitas, pois do contrário haverá problemas de convergência.

Em seguida, devem ser definidas as diferentes regiões a serem estudadas, assim como os eletrodos, as dopagens das regiões, os modelos físicos que melhor se aplicam e, finalmente, as condições de polarização para obtenção das curvas características.

Os modelos físicos podem ser específicos de mobilidade de portadores, de ionização por impacto, recombinação de portadores, temperatura de operação dos dispositivos, etc

Uma breve descrição dos modelos utilizados nas simulações realizadas na primeira parte desse trabalho será apresentada a seguir.

\subsection{Modelos Utilizados}

Foram utilizados os seguintes modelos para o desenvolvimento desse trabalho $^{76}$ :

- BGN (Bandgap Narrowing)

Modelo importante para regiões altamente dopadas. Esse modelo diz respeito ao estreitamento da faixa de energia e é necessário para a correta modelagem do ganho do transistor bipolar parasitário intrínseco ao transistor SOI. Deve ser usado junto com o modelo KLAASSEN.

- KLA (Klaaseen Model)

Modelo de mobilidade proposto por Klaassen que inclui dependência de concentração de portadores, temperatura e concentração intrínseca de portadores. Aplica separadamente 
mobilidades para portadores majoritários e minoritários. Recomendado para transistores da tecnologia SOI.

- SHI (Shirahata Model)

Modelo de mobilidade que leva em consideração a degradação da mobilidade dentro das camadas de inversão, causada pelo campo elétrico vertical, sendo ideal para transistores com óxido de porta fino.

\section{- SHAPEOX}

Esse modelo especifica qual algorítimo será usado para o cálculo da corrente de tunelamento quântico em uma grade não retangular. Se esse modelo não for especificado, então a corrente é calculada na direção normal de cada segmento da interface óxido-semicondutor. Se esse modelo é especificado, então a mínima distância é encontrada entre cada segmento ou em um contato ou em uma região de polisilício. A corrente de tunelamento quântico é calculada ao longo da direção que fornece a menor distância.

- PRINT

Permite a impressão de tensões dos nós do circuito após o cálculo de cada ponto (análise cc) ou etapa de tempo (análise do transitório).

- TEMP

Temperatura do dispositivo a ser usado durante a simulação. O presente trabalho foi estudado em temperatura ambiente. 


\subsection{Simulação}

Nesse trabalho foi desenvolvido, no simulador ATLAS, um arquivo para a simulação das características elétricas do dispositivo. A estrutura presente nesse arquivo foi desenhada no DevEdit3 $D^{76}$ sendo dividida por regiões, que por sua vez são divididas em polígonos e representadas por uma grade de pontos nas direções $x, y$ e $z$. O DevEdit3D é um editor da estrutura do dispositivo que pode ser usado para gerar uma nova grade em uma estrutura existente com o intuito de modificá-la, ou criar um dispositivo a partir do zero.

A figura 6.1 mostra um exemplo de FinFET de porta tripla em forma de polígonos, em função dos eixos x e z, figura $6.1 \mathrm{a}$ e 6.1 b, respectivamente.

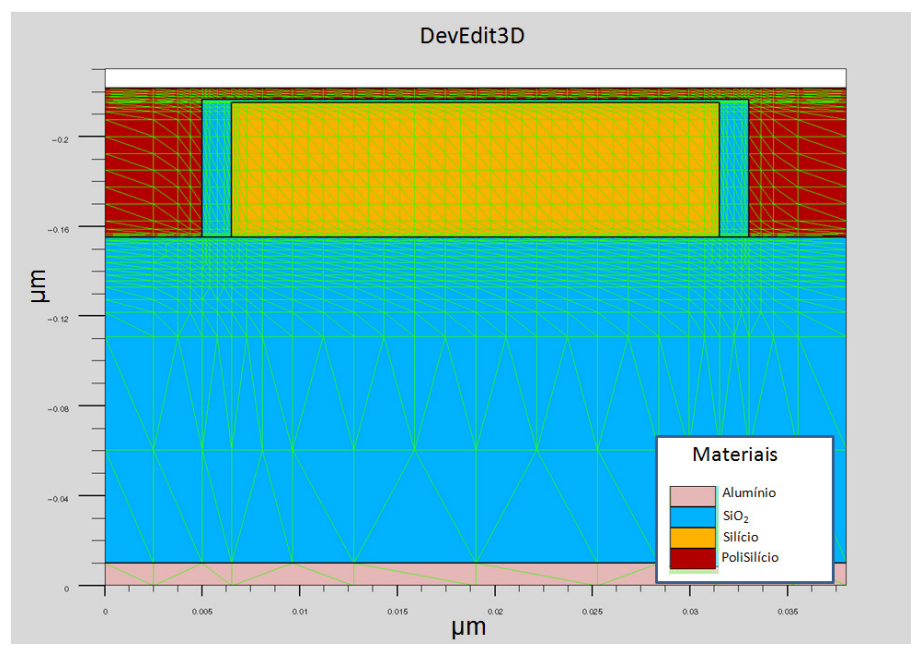

(a)

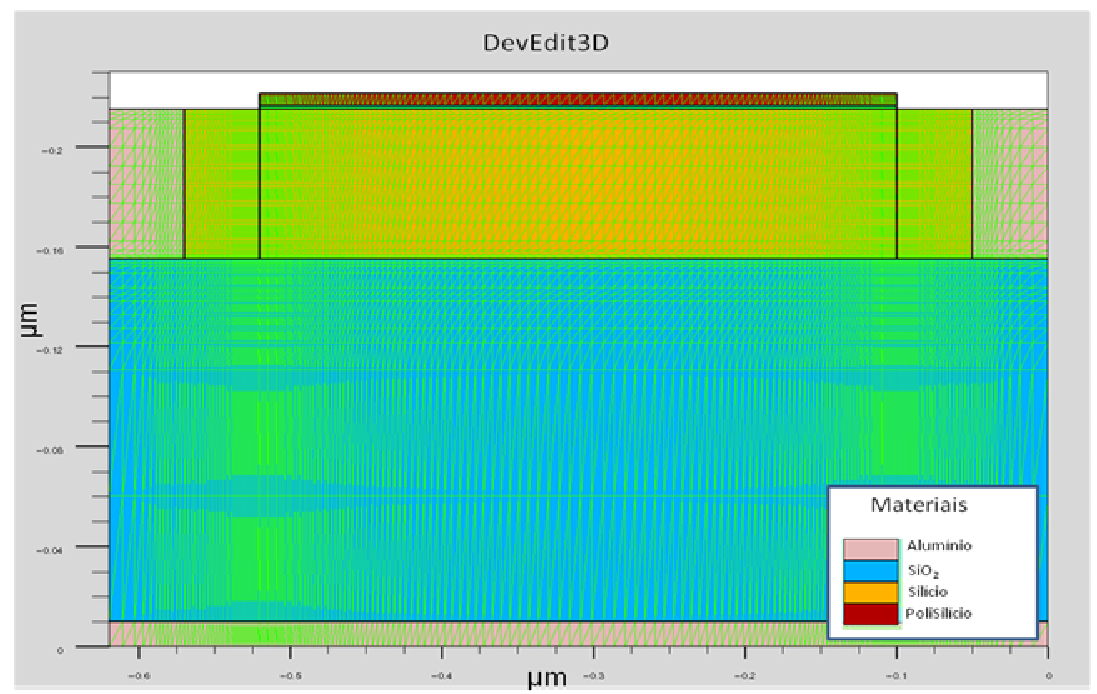

(b)

Figura 6. 1. Estrutura de um FinFET de porta tripla construída no DevEdit3d, em função dos eixos $x(a)$ e $y(b)$. 
Através da ferramenta TonyPlot3D ${ }^{76}$ é possível visualizar graficamente as características das estruturas como regiões de diferentes materiais; contornos; vetores; grades; etc, que foram geradas no DevEdit3D. A figura 6.2 mostra como um FinFET de porta tripla gerada no DevEdit3D é visualizada no TonyPlot3D.

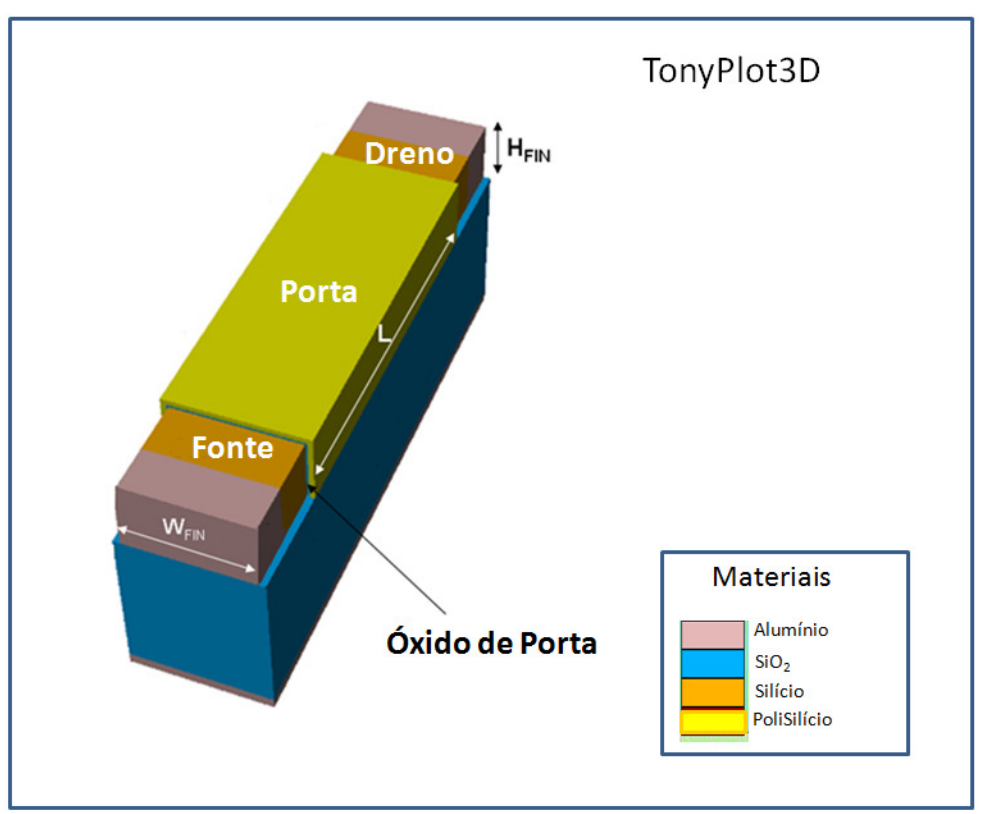

Figura 6. 2. Estrutura de um FinFET de porta tripla gerada no TonyPlot3D.

As estruturas simuladas representam transistores FinFETs de porta tripla com as seguintes características: comprimento das regiões de fonte e dreno e, das regiões $L D D$ s iguais a $50 \mathrm{~nm}$, espessura do óxido enterrado igual a $145 \mathrm{~nm}$ e, espessura do óxido de porta igual a $2 \mathrm{~nm}$, altura de $60 \mathrm{~nm}$.

A região do canal é constituída de silício tipo $P$ e as regiões de fonte e dreno de silício tipo $\mathrm{N}$ sendo os contatos dessas regiões, feitos de alumínio. $\mathrm{A}$ função trabalho dos contatos do material de porta é 4,57 eV representando Nitreto de Titânio (TiN). Para o óxido de porta e óxido enterrado foi utilizado óxido de silício $\left(\mathrm{SiO}_{2}\right)$. A concentração de dopantes na região do canal $\left(\mathrm{N}_{\mathrm{A}}\right)$ é de $1 \times 10^{15} \mathrm{~cm}^{-3}$ e nas regiões LDDs $\left(N_{D}\right)$ é de $1 \times 10^{20} \mathrm{~cm}^{-3}$.

Os transistores FinFETs de porta tripla foram simulados para três diferentes larguras de fin $\left(\mathrm{W}_{\mathrm{FIN}}\right)$ de 60, 120 e $500 \mathrm{~nm}$, com comprimento de canal $(L)$ variando de 0,1 a $0,5 \mu \mathrm{m}$ e altura $\left(H_{\mathrm{FIN}}\right)$ de $60 \mathrm{~nm}$. A temperatura utilizada foi de $300 \mathrm{~K}$. 


\subsection{Resultados e Discussões da Simulação}

\subsubsection{Curvas características $\mathrm{I}_{\mathrm{D}}-\mathrm{V}_{\mathrm{GF}}$}

Para estudar a resistência série de fonte e dreno nesse presente trabalho, foram simulados dispositivos com larguras de fin $\left(\mathrm{W}_{\mathrm{FIN}}\right)$ de 60, $120 \mathrm{e}$ $500 \mathrm{~nm}$ e comprimentos de canal (L) de 100, 200, 300, 350, 400, 450 e 500 $\mathrm{nm}$, com o intuito de verificar quais desses dispositivos estariam sob o efeito de canal curto.

A verificação da existência do efeito de canal curto foi possível através da análise do comportamento da curva característica $\mathrm{I}_{D} \times V_{G F}$ e, conseqüentemente de $\mathrm{V}_{\mathrm{T}} \mathrm{xL}$ e $\mathrm{S} \times \mathrm{L}$ desses dispositivos, como também visto anteriormente no capítulo 5 de caracterização elétrica, e é mostrada através das figuras 6.3 e 6.4 .

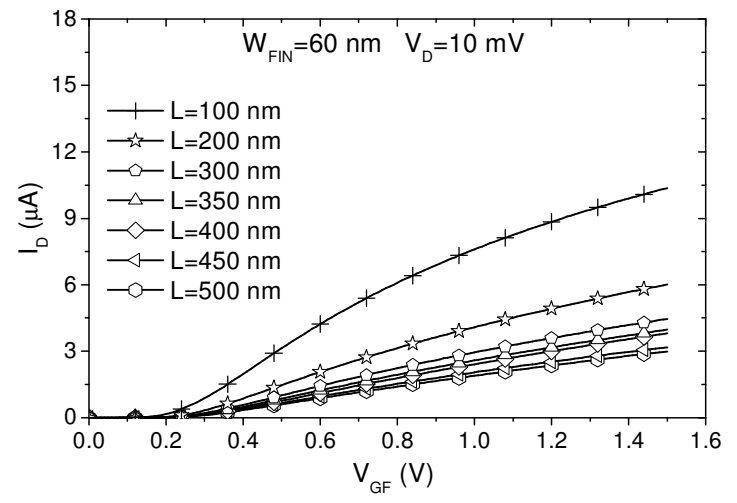

(a)

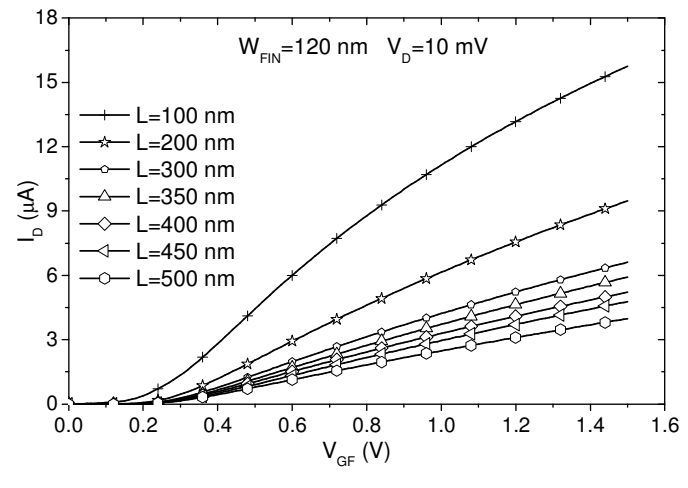

(b)

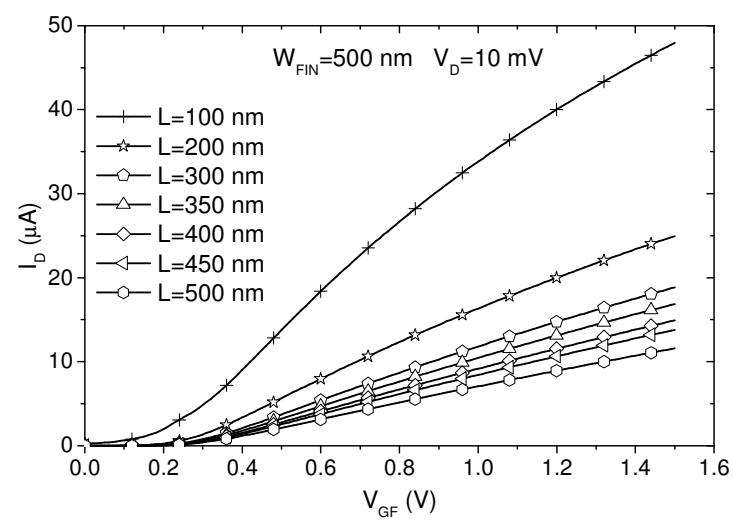

(c)

Figura 6. 3. Curvas características da corrente de dreno $\left(I_{D}\right)$ em função da tensão aplicada na porta $\left(\mathrm{V}_{\mathrm{GF}}\right)$ para os FinFETs de porta tripla com $\mathrm{V}_{\mathrm{DS}}=10 \mathrm{mV}$ para $\mathrm{W}_{\mathrm{FIN}}$ de (a) $60 \mathrm{~nm}$, (b) $120 \mathrm{~nm}$ e (c) $500 \mathrm{~nm}$. 


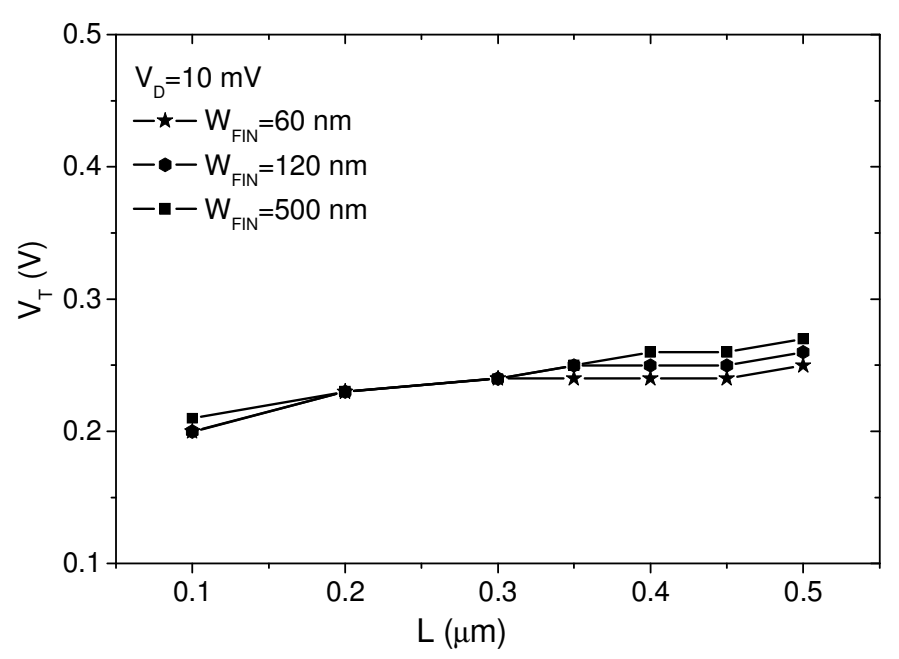

(a)

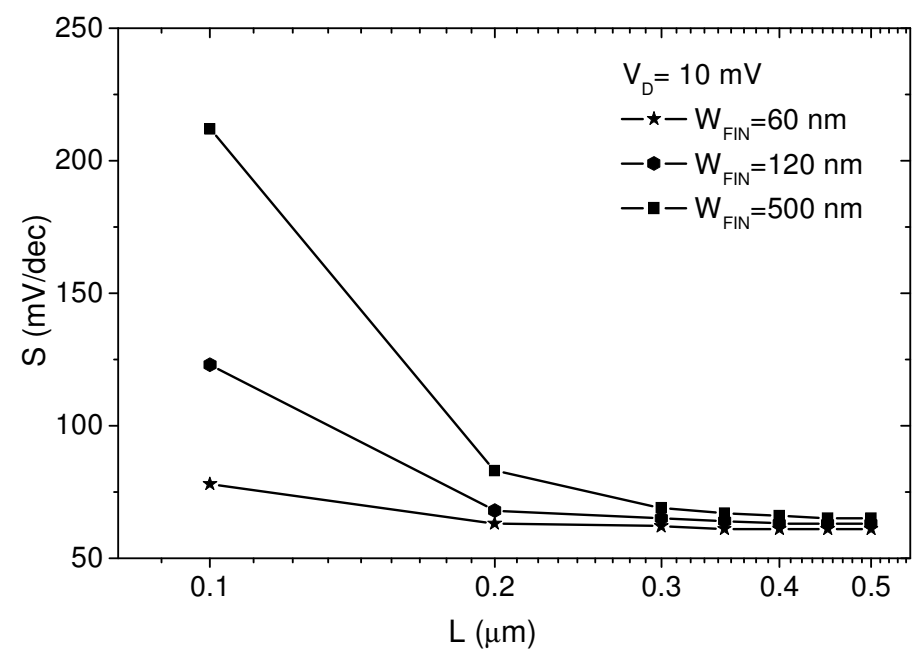

(b)

Figura 6. 4. Curvas da (a) tensão de limiar $\bigvee_{T}$ e (b) inclinação de sublimiar (S) em função do comprimento de canal com $\mathrm{V}_{\mathrm{DS}}=10 \mathrm{mV}$ para dispositivos com diferentes larguras de fins $\left(\mathrm{W}_{\mathrm{FIN}}\right)$.

Analisando conjuntamente as curvas das figuras 6.3 e 6.4 , observa-se que o efeito de canal curto está presente à medida que ocorre a diminuição do comprimento de canal dos dispositivos e que este também é dependente de $\mathrm{W}_{\mathrm{FIN}}$. Uma conseqüência direta da redução do canal dos transistores, e que pode ser observada nessas figuras, é a diminuição da tensão de limiar e aumento da inclinação de sublimiar.

À medida que as dimensões dos dispositivos vão ficando menores, as cargas da região de depleção sob o canal, que normalmente são controladas 
pela tensão na porta, passam a ser parcialmente controladas pelas regiões de depleção de fonte e dreno em decorrência da aproximação dessas regiões. Como a tensão de limiar do transistor é proporcional à quantidade de cargas controladas pela porta, se houver uma redução nesse controle, haverá uma diminuição na tensão.

A tensão de limiar foi extraída através do método da observação do pico máximo da derivada da transcondutância, ou seja, da segunda derivada da curva $I_{D}$ em função de $V_{G F}$ para baixos valores de $V_{D}{ }^{77}$.

Outro efeito causado pela diminuição do comprimento de canal dos dispositivos é o aumento da inclinação de sublimiar. A inclinação de sublimiar foi extraída através da curva monologarítmica de $I_{D}$ em função de $V_{G F}$ e obtida no ponto mínimo do inverso do coeficiente angular da curva resultante.

Observa-se ainda que os dispositivos com menor largura de fin $\left(\mathrm{W}_{\mathrm{FIN}}=60\right.$ $\mathrm{nm}$ ) foram os que apresentaram melhores características de inclinação de sublimiar mesmo para os menores comprimentos de canal, isso devido ao melhor acoplamento de cargas na região do canal pela aproximação das três portas do transistor. Isso implica que quanto menor for o valor da inclinação de sublimiar, mais eficiente e rápido será o chaveamento do dispositivo do estado desligado para o estado ligado.

Através das curvas obtidas, observa-se também que a intensidade da corrente de dreno aumenta devido ao aumento da largura do fin $\left(\mathrm{W}_{\mathrm{FIN}}\right)$, pois a corrente é diretamente proporcional a $W$, sendo assim, se há um aumento da corrente, haverá uma diminuição da resistência total.

O comprimento do canal (L) dos dispositivos ficou limitado em $300 \mathrm{~nm}$, pois para $\mathrm{L}=200 \mathrm{~nm}$ e $\mathrm{W}_{\mathrm{FIN}}=500 \mathrm{~nm}$, passa a existir uma degradação da inclinação de sublimiar desse dispositivo, ficando esse valor distante do ideal de $60 \mathrm{mV} / \mathrm{dec}$. 
Comparando esses resultados com os obtidos por caracterização elétrica de resultados experimentais, verifica-se que como a largura de fin dos FinFETs de porta tripla medidos é de $20 \mathrm{~nm}$, há um maior acoplamento das cargas na região do canal devido à maior proximidade das três portas do transistor, permitindo assim que o comprimento de canal desses dispositivos sem que haja o efeito de canal curto, seja maior, nesse caso $910 \mathrm{~nm}$.

\subsubsection{Extração da Resistência Série de Fonte e Dreno}

A extração da resistência série de fonte e dreno nesses dispositivos foi feita através da aplicação do método da extrapolação exponencial de primeira ordem $^{49}$ e da junção dos métodos de extrapolação linear ${ }^{47,50}$, já que esses dois métodos apresentam o mesmo princípio diferindo no tipo de estrutura.

\subsubsection{Método de Dixit, A. et al. ${ }^{49}$}

Como visto anteriormente, para extrair a resistência série através do método da extrapolação exponencial, a curva característica da corrente de dreno em função da tensão aplicada na porta deve ser obtida para baixo valor de $V_{D S}$, para que resistência do canal $\left(R_{C H}\right)$ diminua de tal forma que a resistência total ( $\mathrm{R}_{\text {TOTAL }}$ ) fique próxima ao valor da resistência série de fonte e dreno.

Para os dispositivos simulados, o dreno foi polarizado com tensão de 10 $\mathrm{mV}$ e, o valor da resistência série foi extraído quando a tensão de porta atingiu $5 \mathrm{~V}$. Com essa tensão aplicada na porta, os portadores da região do canal já estão invertidos fazendo com que a resistência nessa região seja desprezada e que resistência total tenha somente a parcela da resistência das regiões de fonte e dreno.

A figura 6.5 mostra as curvas da resistência total em função da tensão aplicada na porta para os diferentes valores de comprimentos de canal. 


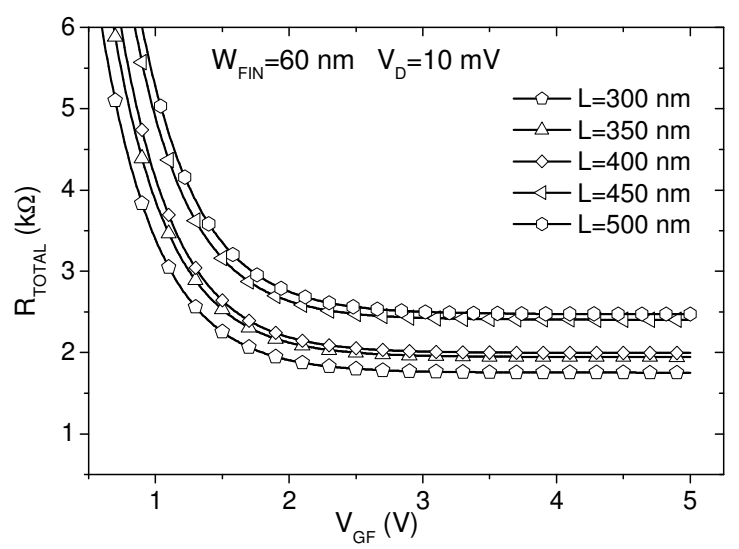

(a)

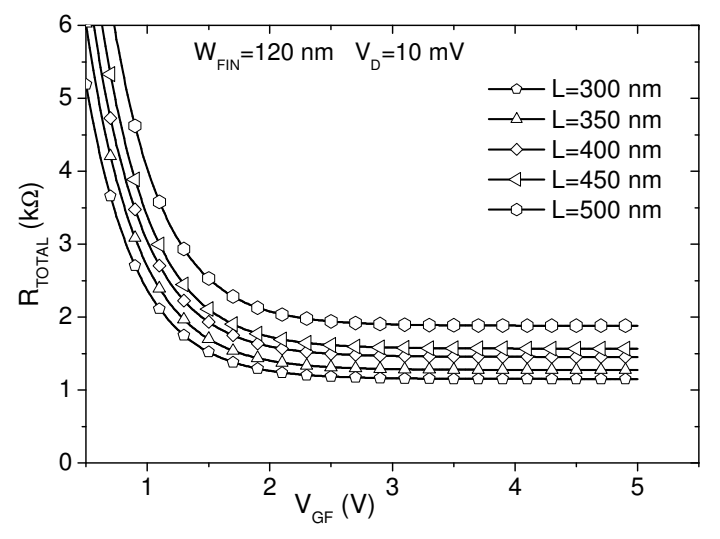

(b)

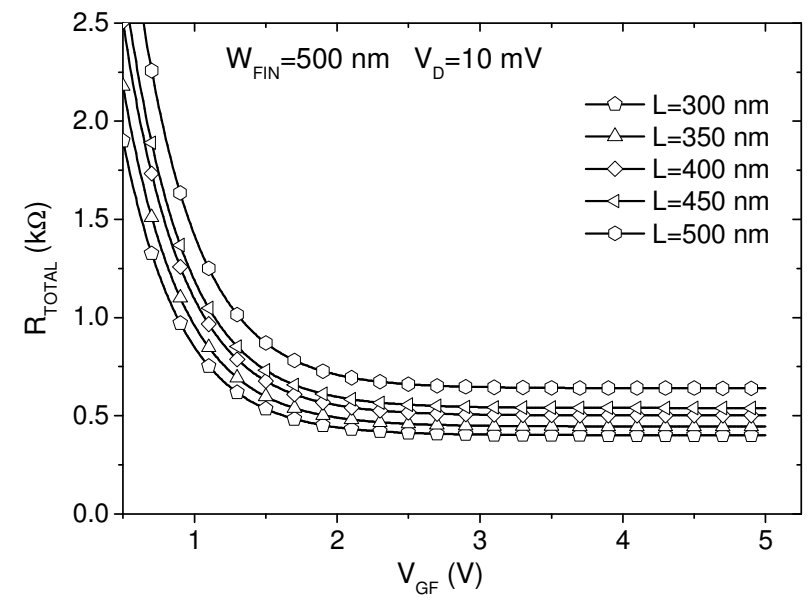

(c)

Figura 6. 5. Resistência Total ( $\left.\mathrm{R}_{\mathrm{TOTAL}}\right)$ em função da tensão aplicada na porta ( $\left.\mathrm{V}_{\mathrm{GF}}\right)$ para (a) $\mathrm{W}_{\mathrm{FIN}}=60 \mathrm{~nm}$, (b) $\mathrm{W}_{\mathrm{FIN}}=120 \mathrm{~nm}$ e (c) $\mathrm{W}_{\mathrm{FIN}}=500 \mathrm{~nm}$ para diferentes comprimentos de canal (L), com $V_{D S}=10 \mathrm{mV}$.

Analisando as curvas da figura 6.5, verifica-se que para o dispositivo com largura de fin mais estreita $\left(\mathrm{W}_{\mathrm{FIN}}=60 \mathrm{~nm}\right)$, o valor da resistência total é maior em relação à resistência total dos outros dispositivos independente da dimensão do comprimento do canal, isso porque com o estreitamento das regiões de fonte e dreno, há um aumento de todas as componentes da resistência série de fonte e dreno, tornando esse parâmetro mais significativo.

Em um dispositivo, o valor da resistência série não deve ser alterado com o comprimento do canal, o que na observação dos gráficos da figura 6.5, não ocorre. De acordo com esse método, quando $\mathrm{V}_{\mathrm{GF}}$ é igual a $5 \mathrm{~V}$, a $R_{\text {TOTAL }} \cong R_{S D}$, sendo assim, pode ser visto na figura 6.5 , que há um aumento da $R_{S D}$ à medida que aumenta o valor do comprimento de canal (L). 
O aumento da resistência total de um dispositivo deve-se ao aumento da resistência de canal à medida que o comprimento dessa região aumenta, ou seja, a resistência do canal não mais pode ser desprezada para comprimentos de canal elevados e o método utilizado não funciona adequadamente.

$\mathrm{Na}$ figura 6.6 são apresentadas as curvas $R_{S D}$ em função do comprimento do canal para os diferentes dispositivos simulados.

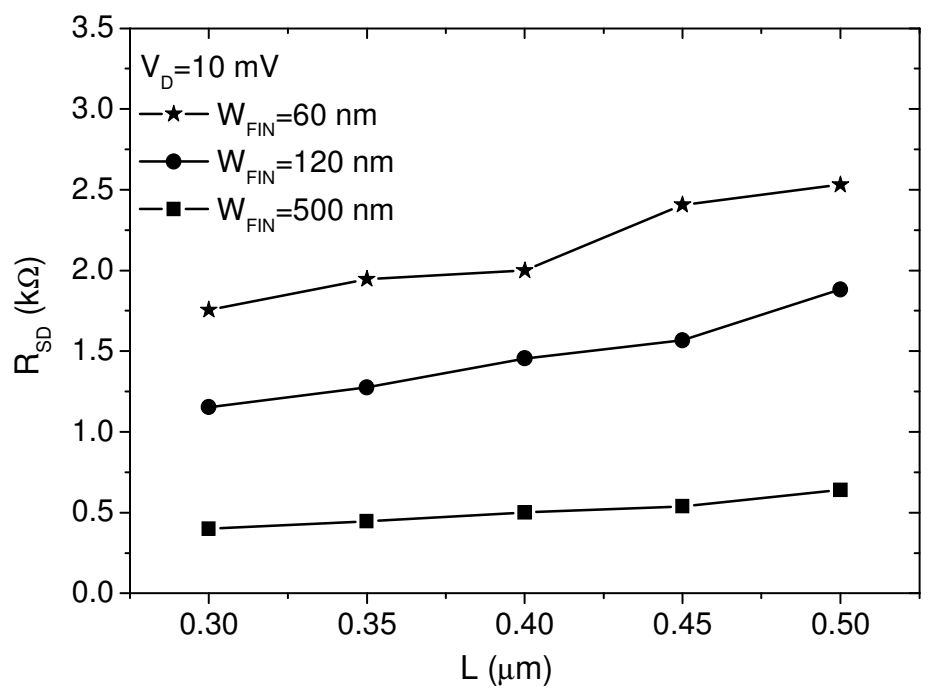

Figura 6. 6. Resistência Série de fonte e dreno em função do comprimento de canal com $V_{D S}$ de $10 \mathrm{mV}$ para diferentes larguras de fin $\left(\mathrm{W}_{\mathrm{FIN}}\right)$.

A partir dos resultados apresentados na tabela 6.1, pode-se observar a variação da resistência série de fonte e dreno em função do comprimento de canal para $\mathrm{V}_{\mathrm{GF}}$ de $5 \mathrm{~V}$.

Tabela 6. 1. Valores obtidos por simulação da extração da $R_{S D}$ para $V_{G F}$ de $5 \mathrm{~V}$, com $V_{D}=10 \mathrm{mV}$ para diferentes larguras de fins $\left(\mathrm{W}_{\mathrm{FIN}}\right)$ e comprimento de canal $(\mathrm{L})$.

\begin{tabular}{|c|c|c|c|}
\cline { 2 - 4 } \multicolumn{1}{c|}{} & \multicolumn{3}{c|}{$R_{\mathrm{SD}}(\Omega)\left(\mathrm{V}_{\mathrm{GF}}=5 \mathrm{~V}\right)$} \\
\hline $\mathrm{L}(\mu \mathrm{m})$ & $\mathrm{W}_{\mathrm{FIN}}=60 \mathrm{~nm}$ & $\mathrm{~W}_{\mathrm{FIN}}=120 \mathrm{~nm}$ & $\mathrm{~W}_{\mathrm{FIN}}=500 \mathrm{~nm}$ \\
\hline 0,3 & 1755 & 1153 & 400 \\
\hline 0,35 & 1946 & 1276 & 445 \\
\hline 0,4 & 2000 & 1455 & 501 \\
\hline 0,45 & 2406 & 1568 & 539 \\
\hline 0,5 & 2531 & 1881 & 640 \\
\hline
\end{tabular}


Os resultados da tabela acima mostram que quanto mais estreito o fin, maior a resistência série de fonte e dreno e que aumentando o comprimento de canal, aumenta o valor da resistência série, onde o ideal seria que o valor da resistência do canal fosse desprezível. A figura 6.7 mostra a resistência série extraída em função da largura do fin para os diferentes comprimentos de canal.

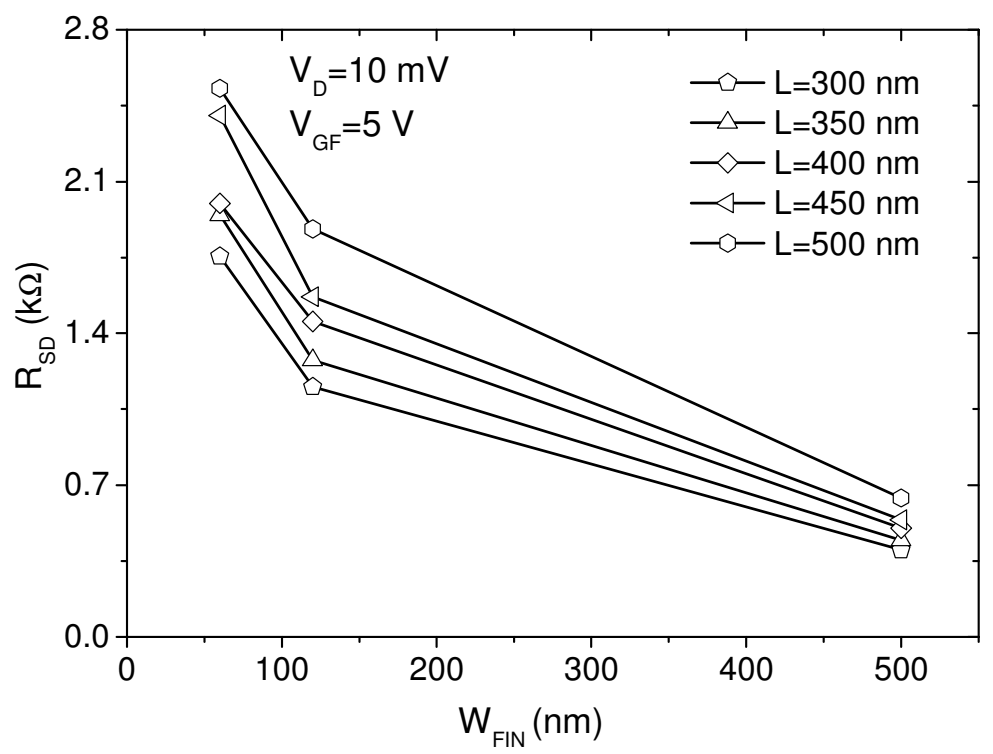

Figura 6. 7. Resistência série de fonte e dreno extraída para $V_{G F}$ igual a $5 \mathrm{~V}$ em função da largura do fin.

Através do gráfico da figura 6.7, observa-se que dispositivos não planares como os FinFETs de porta tripla, sofrem de elevada resistência parasita de fonte e dreno devido ao estreitamento de suas regiões de fonte e dreno, ou seja, aumentando a largura do fin a resistência parasitária diminui.

Um teste foi realizado a fim de se verificar o comportamento do método descrito acima para transistores com comprimentos de canais menores, sendo $\mathrm{L}=100$ e $200 \mathrm{~nm}$, figura 6.8 . 


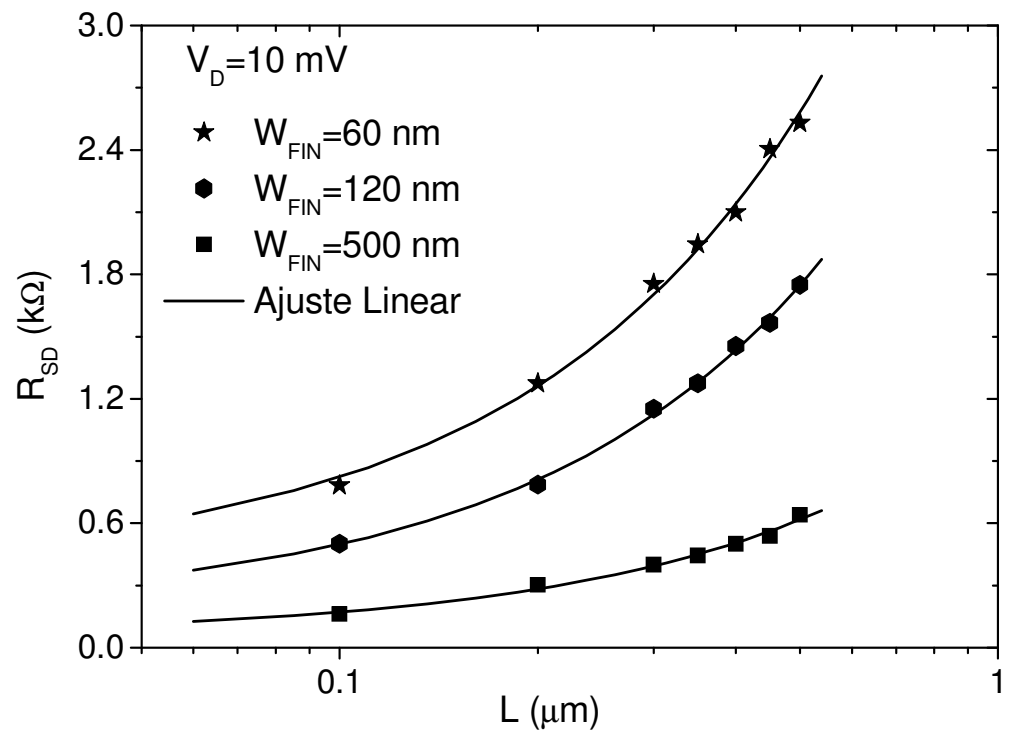

Figura 6. 8. Resistência Série de fonte e dreno em função do comprimento de canal com $V_{D}$ de $10 \mathrm{mV}$ para diferentes larguras de fin $\left(\mathrm{W}_{\mathrm{FIN}}\right)$, com comprimentos de canal menores $(\mathrm{L}=100 \mathrm{e}$ $200 \mathrm{~nm})$.

A figura 6.8 apresenta a mesma tendência observada nos resultados experimentais onde $\mathrm{o}$ valor da resistência série se tornará constante à medida que o comprimento de canal dos transistores for reduzido. Então, novamente conclui-se que 0 método da exponencial de primeira ordem ${ }^{49}$ ajusta-se bem para transistores com comprimento de canal menores.

\subsubsection{Métodos de Terada e Muta ${ }^{50}$ e de J. Hu, et al. ${ }^{47}$}

Para extrair a resistência série de fonte e dreno pelos métodos de extrapolação linear ${ }^{47,50}$, deve-se obter as curvas características $I_{D} \times V_{G F}$ para baixos valores de $V_{D}$, para pelo menos dois dispositivos com diferentes comprimentos de canal. Uma melhor exatidão nos resultados será alcançada se mais dispositivos foram usados.

Com base na curva $I_{D} \times V_{G F}$ é possível calcular a resistência total dos dispositivos dividindo $V_{D}$ por $I_{D}$, plotando a curva $R_{\text {TOTAL }} x L$ para um valor fixo de $V_{G F}$, figura 6.9. A resistência série de fonte e dreno é obtida quando 0 comprimento de canal for igual a zero, ou seja, dada a equação da reta: 


$$
y=A+B x
$$

Substituindo os termos com relação à resistência total e ao comprimento de canal:

$$
R_{T O T A L}=R_{S D}+L x
$$

Através da equação 6.2, conclui-se que quando o comprimento de canal for igual a zero, a resistência total do dispositivo será igual à resistência série de fonte e dreno.

A figura 6.9 mostra a resistência total em função do comprimento de porta para diferentes larguras de fin.

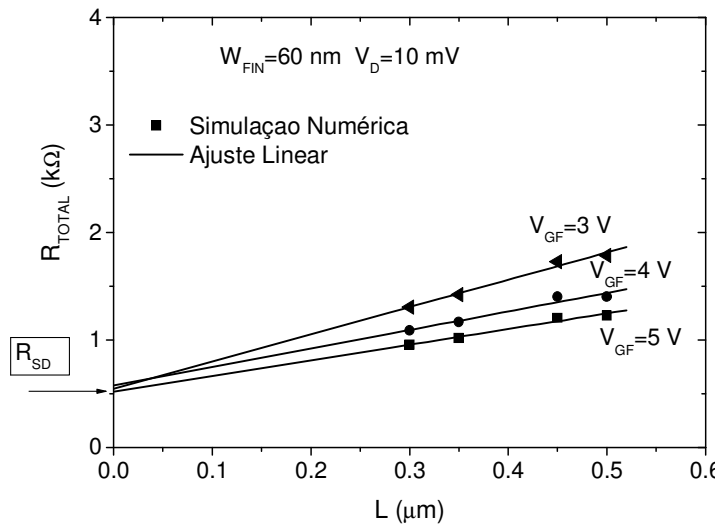

(a)

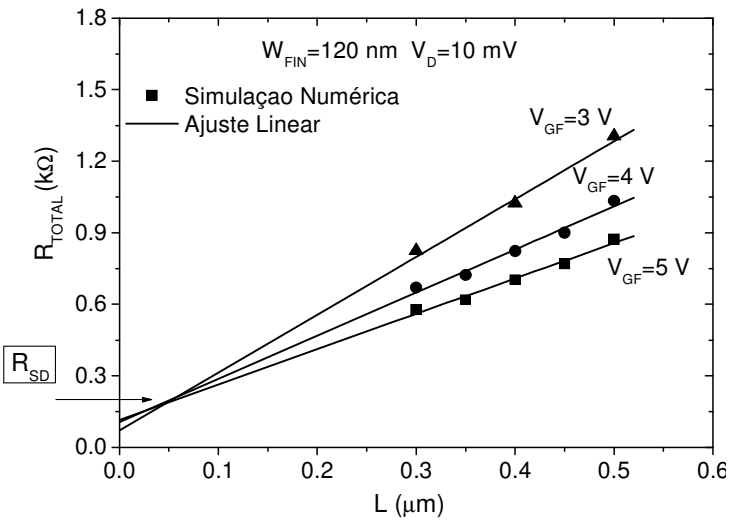

(b)

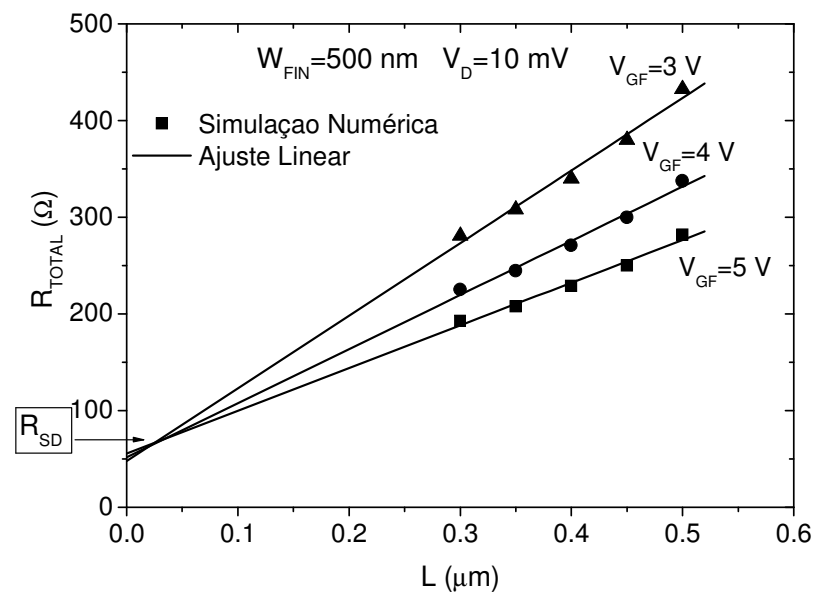

(c)

Figura 6. 9. Resistência Total em função do comprimento do canal para diferentes polarizações de porta obtidas por simulações numéricas para (a) $W_{\mathrm{FIN}}=60 \mathrm{~nm}$, (b) $\mathrm{W}_{\mathrm{FIN}}=120 \mathrm{~nm}$, (c) $\mathrm{W}_{\mathrm{FIN}}=500 \mathrm{~nm}$. 
A partir da figura 6.9 observa-se que aumentando o comprimento do canal, a resistência total também aumenta como esperado. Isso significa que a resistência do canal não pode ser desprezada e conseqüentemente seu valor é incorporado no valor da resistência total. Todos os valores da resistência total extraídos, para cada polarização de porta considerada, podem ser ajustados linearmente, com coeficiente de ajuste em torno de $98 \%$.

Tabela 6. 2. Valores obtidos por simulação da extração da $R_{S D}$ por extrapolação linear, com para diferentes larguras de fin ( $\left.\mathrm{W}_{\mathrm{FIN}}\right)$ e comprimento de canal $(\mathrm{L})$.

\begin{tabular}{|c|c|}
\hline \multicolumn{2}{|c|}{$\mathrm{V}_{\mathrm{GF}}=5 \mathrm{~V}$} \\
\hline $\mathrm{W}_{\mathrm{FIN}}(\mathrm{nm})$ & $\mathrm{R}_{\mathrm{SD}}(\Omega)$ \\
\hline 60 & 520 \\
\hline 120 & 187 \\
\hline 500 & 56 \\
\hline
\end{tabular}

Nota-se pela observação dos gráficos obtidos até agora, que os valores da resistência série de fonte e dreno obtidos pelo método da extrapolação linear apresentaram-se mais baixos, isso pode ser resultado de um erro de ajuste na extrapolação exponencial. O mesmo método foi aplicado em dispositivos com comprimento de canal maiores como $L=1,2,3,4,5 \mu \mathrm{m}$. Nesses dispositivos, a extrapolação linear deu-se de forma mais correta, como coeficiente de ajuste em torno de 99,99\%. A figura 6.10 mostra um exemplo desse resultado.

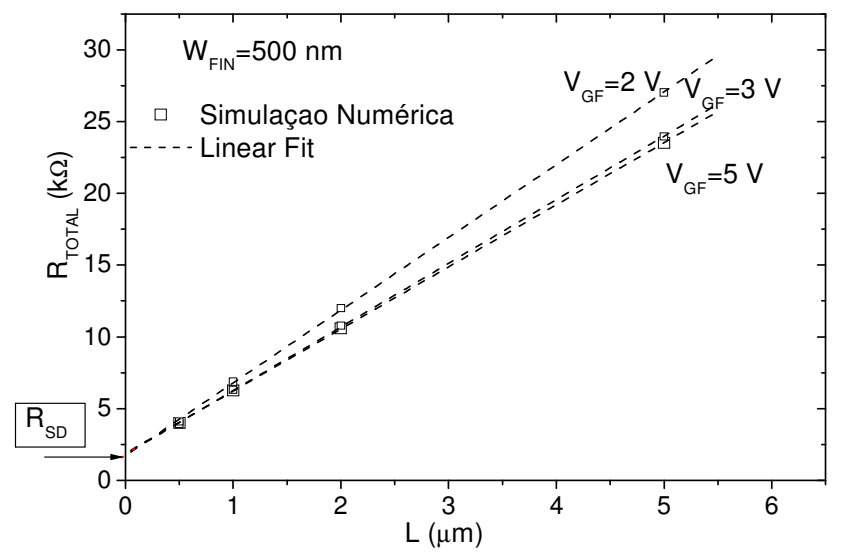

Figura 6. 10. Resistência Total em função de comprimento de canal para dispositivos com comprimento de canal maiores para diferentes polarizações de porta. 


\subsection{Resultados e Discussões da Simulação com deformação}

\subsubsection{O modelo CVT}

Uma série de simulações tridimensionais foi gerada para os FinFETs de porta tripla com e sem deformação, considerando as mesmas dimensões $\left(\mathrm{W}_{\mathrm{FIN}}=25 \mathrm{~nm}, \mathrm{~L}\right.$ de 100 a $920 \mathrm{~nm}$, número de fins igual a 5) e características dos dispositivos medidos, com o intuito de obter a mesma tendência dos resultados experimentais em simulação. Devido à incapacidade do simulador ATLAS de simular dispositivos de canal tensionado, houve a necessidade de ajustar as curvas simuladas às experimentais através da melhor aproximação das componentes dos modelos usados. Nesse caso, foi necessário ajustar as componentes do modelo de mobilidade completo de Lombardi (CVT), já que a característica da tecnologia de canal tensionado é a alteração no parâmetro da mobilidade, além disso, esse modelo é considerado muito bom para dispositivos não-planares e incorpora todos os efeitos necessários para a simulação da mobilidade dos portadores.

O modelo CVT inclui efeitos relativos à concentração de dopantes, temperatura, campo elétrico transversal e paralelo. Nesse modelo, as componentes da mobilidade referentes a esses efeitos são combinadas através da regra de Matthiessen's ${ }^{76}$, como seguem:

$$
\mu_{T}^{-1}=\mu_{A C}^{-1}+\mu_{s r}^{-1}+\mu_{b}^{-1}
$$

A primeira componente $\mu_{A C}$ refere-se à limitação da mobilidade de superfície por espalhamento com fônons acústicos, ou seja, pela iteração dos portadores de carga com as vibrações da rede cristalina. Essa componente é dada por:

$$
\mu_{A C}=\left(\frac{B N . C V T}{E_{\perp}^{E N . C V T}}+\frac{C N \cdot C V T N^{T A U N} \cdot C V T}{E_{\perp}^{D N . C V T}}\right) \frac{1}{T_{L}}
$$

Onde $\mathrm{T}_{\mathrm{L}}$ é a temperatura, $E_{\perp}$ é o campo elétrico perpendicular e $\mathrm{N}$ é a concentração de dopantes. 
A segunda componente $\mu_{\mathrm{sr}}$ refere-se ao fator de rugosidade da superfície, quando campo elétrico vertical, controlado pela tensão aplicada à porta, atrai os portadores para a superfície de condução reduzindo a mobilidade devido a rugosidade da superfície, sendo dada por:

$$
\mu_{s r}=\left(\frac{D E L N \cdot C V T}{E_{\perp}^{K N . C V T}}+\frac{F E L N \cdot C V T}{E_{\perp}^{3}}\right)
$$

O valor default de FELN.CVT é definido com um valor alto, fazendo com que o segundo termo do fator de rugosidade da superfície seja desprezível.

A terceira componente da mobilidade, $\mu_{\mathrm{b}}$, refere-se à mobilidade limitada pelo espalhamento com fônons de intervales ópticos.

$$
\begin{aligned}
\mu_{b}=\text { MUON. } & \text { CVTexp }\left(\frac{-P C N . C V T}{N}\right) \\
& +\frac{\left[M U M A X N \cdot C V T\left(\frac{T_{L}}{300}\right)^{-G A M N . C V T}-\text { MUON.CVT }\right]}{1+\left(\frac{N}{C R N . C V T}\right)^{\text {ALPHN.CVT }}} \\
& -\frac{M U 1 N \cdot C V T}{1+\left(\frac{C S N \cdot C V T}{N}\right)^{\text {EETAN.CVT }}}
\end{aligned}
$$

Onde $\mathrm{N}$ é a densidade total de impurezas e TL é a temperatura, sendo que todos os demais parâmetros podem ser ajustados.

Analisando os parâmetros das componentes do modelo CVT na simulação, observou-se que os parâmetros BN.CVT, CN.CVT, EN.CVT, DN.CVT e MUMAXN.CVT seriam os responsáveis pelos melhores ajustes das curvas experimentais às simuladas, sendo que o MUMAXN.CVT influenciaria no aumento ou diminuição da mobilidade máxima e os restantes, em sua degradação. 
Outro parâmetro que foi alterado durante as simulações foi a work function $\left(\mathrm{w}_{\mathrm{f}}\right)$ do material de porta, para ajuste da tensão de limiar.

Os dispositivos sob influência da tensão biaxial global não obtiveram na simulação um ajuste adequado, em relação às medidas experimentais, devido à ineficiência do simulador em efetuar o efeito do stress biaxial, desta maneira ficam aqui omitidos nos resultados e discussões do tópico das simulações.

\subsubsection{Curvas Características $\mathrm{I}_{\mathrm{D}} \times \mathrm{V}_{\mathrm{GF}}$}

As figuras 6.11 e 6.12 apresentam as curvas características $I_{D} X V_{G F}$ obtidas nas simulações tridimensionais, ajustadas às curvas experimentais, para os dispositivos de referência e sob a técnica uniaxial, respectivamente, com comprimentos de canal de 100, 170, 420 e $920 \mathrm{~nm}$.

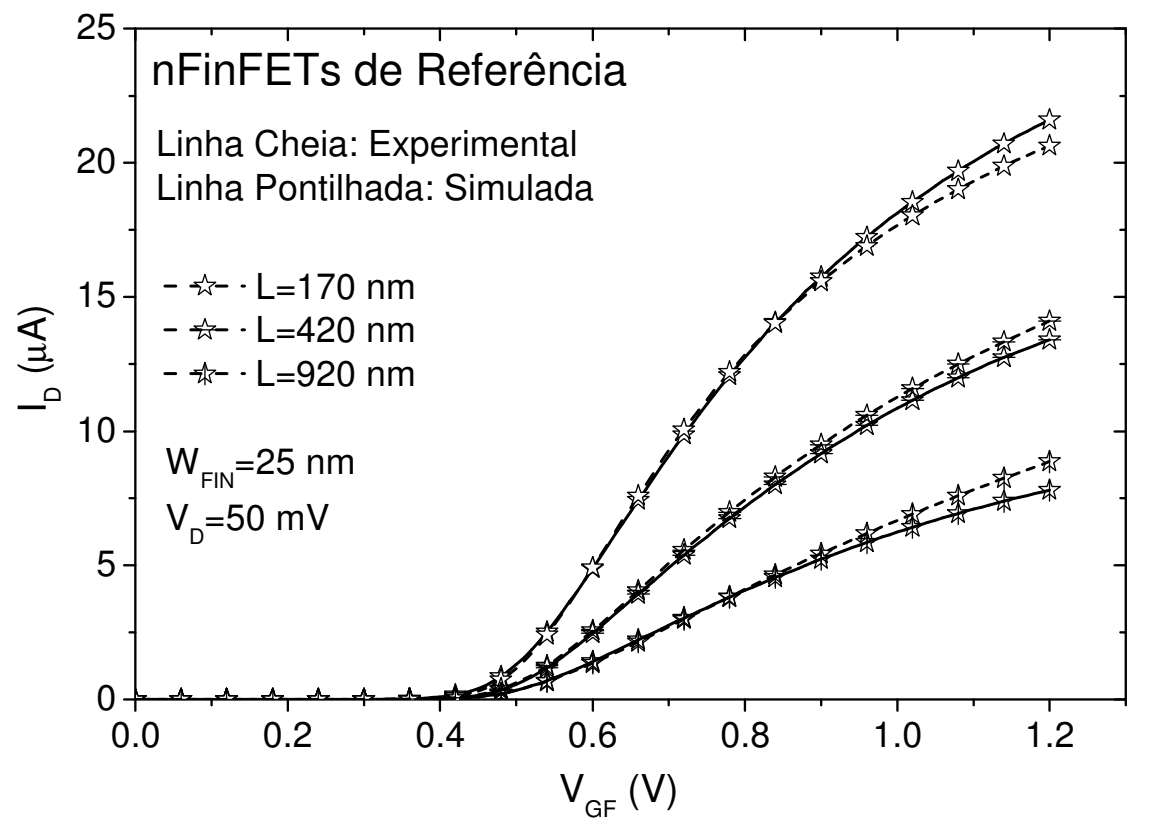

Figura 6. 11. Curvas características $I_{D} \times V_{G F}$ obtidas através de simulações tridimensionais, ajustadas às curvas experimentais, para os dispositivos de (a) referência e com comprimentos de canal de 170, 420 e $920 \mathrm{~nm}$ para largura de fin de $25 \mathrm{~nm}$. 


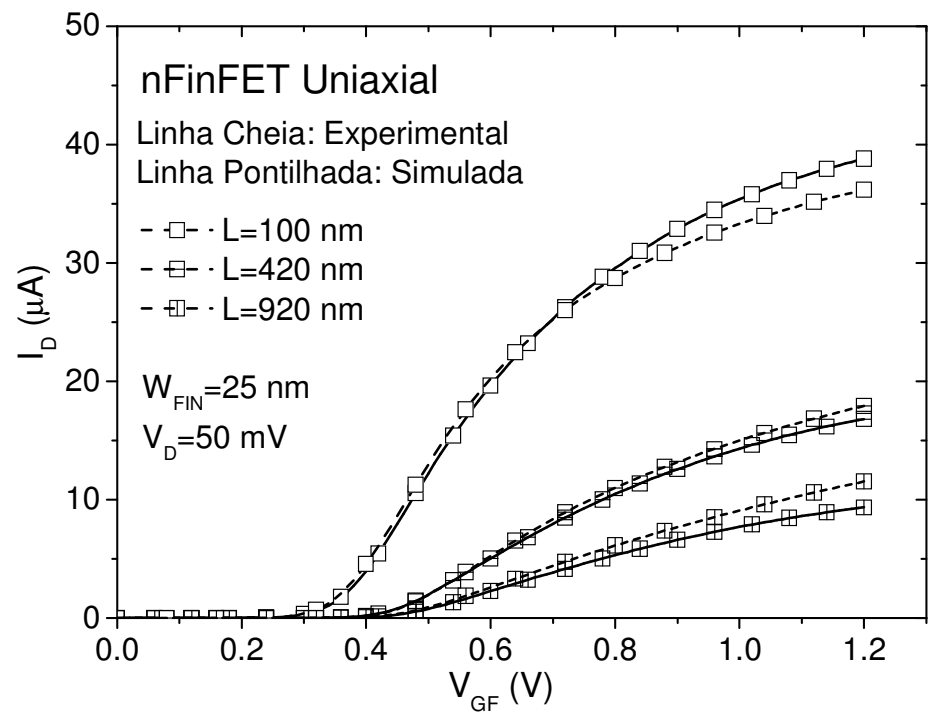

Figura 6. 12. Curvas características $\mathrm{I}_{\mathrm{D}} \mathrm{x} \mathrm{V}_{\mathrm{GF}}$ obtidas através de simulações tridimensionais, ajustadas às curvas experimentais, para os dispositivos sob a técnica uniaxial com comprimentos de canal de 100, 420 e $920 \mathrm{~nm}$ para largura de fin de $25 \mathrm{~nm}$.

A partir da dos gráficos das figuras 6.11 e 6.12, nota-se que as curvas $I_{D} X V_{G}$ obtidas por simulação apresentam uma aproximação aceitável às curvas obtidas experimentalmente. Os melhores resultados obtidos por simulação para os dispositivos de referência foram para os comprimentos de canal de 170, 420 e $920 \mathrm{~nm}$. Observa-se, também, que a maior corrente de dreno em função da tensão aplicada na porta encontra-se para o comprimento de canal de $170 \mathrm{~nm}$. Isso acontece, pois para comprimentos de canal menores há uma maior influência das três portas no canal do dispositivo, podendo-se dizer então que a corrente de dreno será multiplicada pelo seu número de portas e, ainda devido a menor resistência na região do canal, já que este é um dispositivo de canal curto. Em compensação para esse dispositivo há um aumento da degradação da corrente, como pode ser observado, devido ao aumento da resistência série.

A menor corrente de dreno é obtida para o dispositivo com comprimento de canal de $920 \mathrm{~nm}$, pois nesse caso não há influência das portas laterais da região do canal, podendo-se dizer que para esse comprimento de canal, o FinFET de porta tripla comporta-se como um dispositivo de porta única e há um aumento significativo da resistência total devido ao comprimento do canal, resultando em um menor valor da corrente 
de dreno. Observando as curvas características dos dispositivos de referência como um todo, não há diferença significativa entre as curvas da corrente de dreno para os comprimentos de canal estudados. Para os dispositivos sob influência da tensão uniaxial local (CESL), os melhores ajustes da corrente de dreno em função da tensão aplicada na porta ocorreram para os comprimentos de canal de 100, 420 e $920 \mathrm{~nm}$. Observa-se que os dispositivos com comprimento de canal de $100 \mathrm{~nm}$ apresentam um aumento de corrente de dreno muito significativo se comparado aos comprimentos de canal restantes. Isso acontece devido à característica da técnica uniaxial de melhorar a condução de corrente em comprimentos de canal menores devido à maior intensidade do stress uniaxial nesses dispositivos. Comparando os gráficos da figura 6.11 e 6.12 nota-se que os dispositivos sob influência da técnica de canal tensionado apresentam maior condução de corrente em relação aos dispositivos de referência.

\subsubsection{Curvas de $\mathrm{gmxV}_{\mathrm{GF}}$}

A figura 6.13 apresenta as curvas simuladas e experimentais da transcondutância em função da tensão aplicada na porta para os dispositivos de referência (a) e sob a técnica de deformação uniaxial (b).

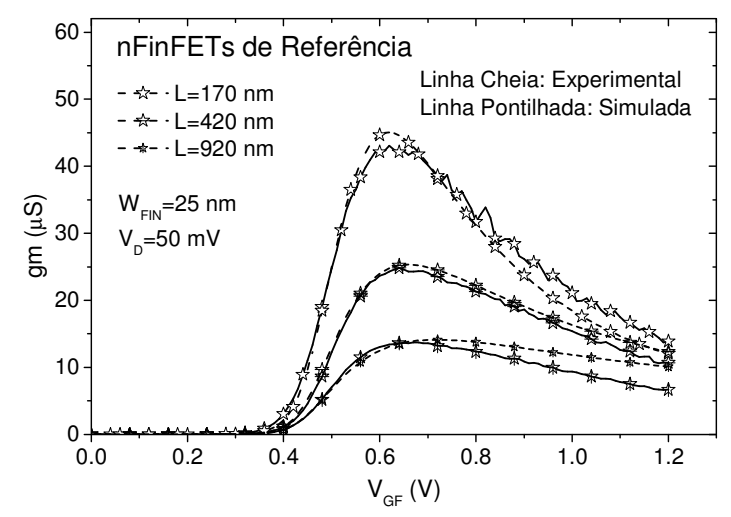

(a)

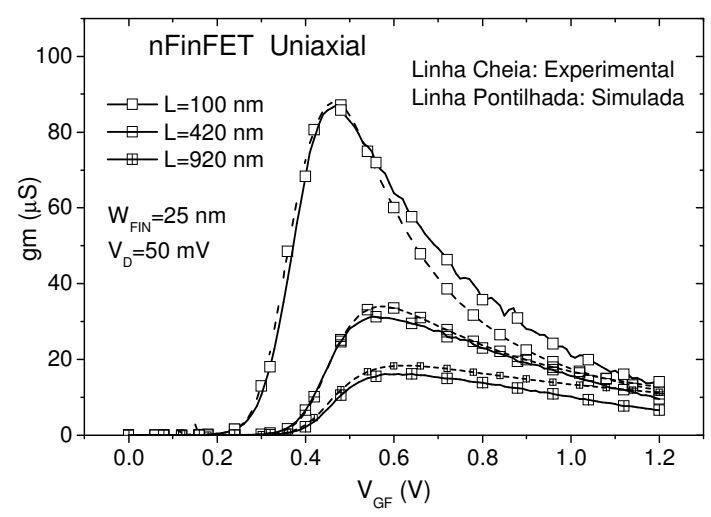

(b)

Figura 6. 13. Curvas da transcondutância em função da tensão aplicada na porta obtidas através de medidas experimentais e simulações dos dispositivos de referência (a) e sob influência da deformação uniaxial (b) com comprimentos de canal de 100, 170, 420 e $920 \mathrm{~nm}$, largura do fin de $25 \mathrm{~nm}$ e $V_{D S}$ igual a $50 \mathrm{mV}$. 
Através das figuras $6.13 \mathrm{a}$ e $6.13 \mathrm{~b}$, verifica-se que as curvas simuladas apresentam boa aproximação em relação às curvas de referência até o valor máximo da transcondutância. Após atingir-se o valor máximo da transcondutância e, por conseqüência, da mobilidade, a transcondutância começa a sofrer uma degradação e, devido à degradação nos dispositivos simulados serem ajustados pela alteração dos valores default dos parâmetros das componentes do modelo CVT, observa-se um distanciamento no ajuste da degradação principalmente nos dispositivos de canal tensionado com comprimento de canal de $100 \mathrm{~nm}$, isso ocorre, pois os valores alterados dos parâmetros default chegaram ao limite físico aceitável já que o simulador não modela o efeito do stress uniaxial.

\subsubsection{Comparação das curvas características dos dispositivos simulados}

A figura 6.14 apresenta as curvas características $\mathrm{I}_{\mathrm{D}} \times \mathrm{V}_{\mathrm{GF}}$ dos dispositivos de referência e sob influência da técnica uniaxial com o intuito de se verificar o comportamento da corrente de dreno em função da tensão aplicada na porta para os diferentes comprimentos de canal simulados.

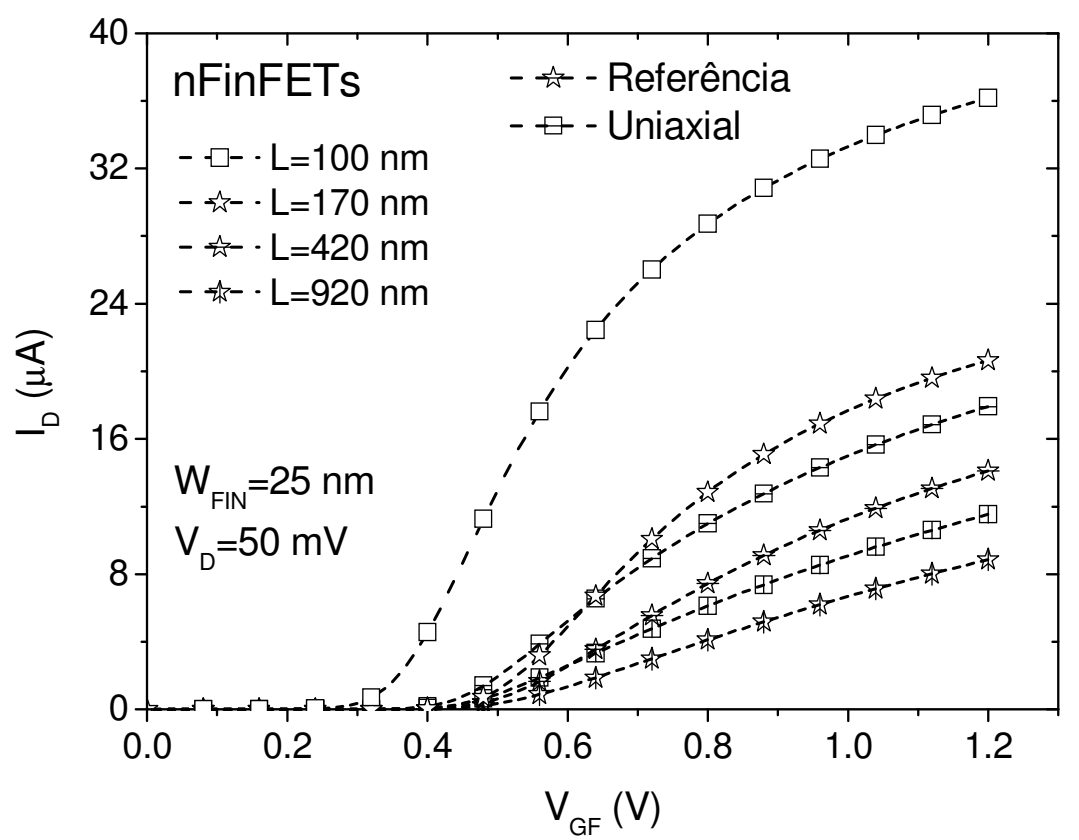

Figura 6. 14. Curvas características $I_{D} x V_{G F}$ obtidas por simulação dos dispositivos de referência e sob influência da deformação uniaxial com comprimentos de canal de 100, 170, 420, 920 e largura do fin de $25 \mathrm{~nm}$. 
A partir da figura 6.14, é possível verificar que a maior corrente de dreno, ou seja, a maior condução de corrente é obtida quando a técnica uniaxial é usada no dispositivo com comprimento de canal de $100 \mathrm{~nm}$, mostrando a mesma tendência obtida nos resultados experimentais que, para comprimentos de canais menores, o efeito do stress uniaxial mostra-se mais efetivo devido à alteração da estrutura cristalina dos dispositivos, facilitando assim a condução de corrente. Observa-se também que, à medida que o comprimento de canal dos dispositivos torna-se maior, a diferença do uso de canal tensionado em relação ao dispositivo de referência mostra-se menos significativa, ou seja, para comprimentos de canal de $920 \mathrm{~nm}$, o stress uniaxial não apresenta o mesmo efeito visto em dispositivos de canal menores, perdendo então seu efeito tensor ao longo do canal. Analisando todas as curvas características para os diferentes comprimentos de canal acima, conclui-se que mesmo para dispositivos maiores com L de 420 e 920 nm, embora o efeito da deformação seja menos eficiente, o uso da técnica de canal tensionado mostra-se vantajosa em relação à condução de corrente dos dispositivos.

A figura 6.15 mostra as curvas da transcondutância em função da tensão aplicada na porta para os dispositivos de referência e sob influência da técnica uniaxial para os diferentes comprimentos de canal estudados.

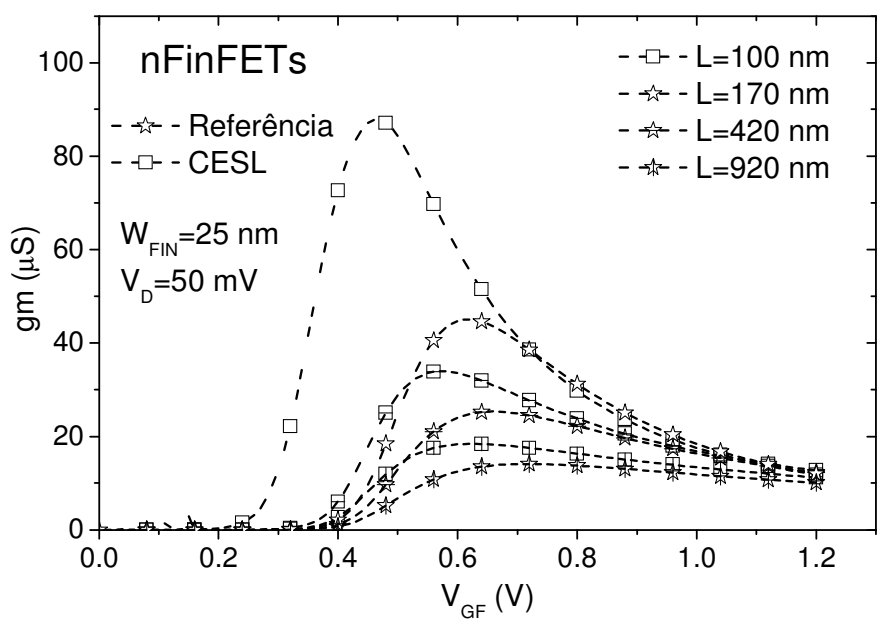

Figura 6. 15. Curvas da transcondutância em função da tensão aplicada na porta obtidas através de simulação para os dispositivos de referência e com tensão uniaxial local com comprimentos de canal de 100, 170, 420 e $920 \mathrm{~nm}$ e largura de fin de $25 \mathrm{~nm}$. 
Na figura 6.15, nota-se que o máximo valor da transcondutância e, por conseqüência, da mobilidade, para os diferentes comprimentos de canal estudados, é obtido com o comprimento de canal de $100 \mathrm{~nm}$ sob influência da técnica uniaixal. O uso da técnica uniaixal em dispositivos com comprimento de canal curto aumenta significativamente a mobilidade dos portadores devido à diminuição da massa efetiva e da taxa de espalhamento. Portanto, a conseqüência de se tensionar o silício é o aumento da distância média que um elétron pode percorrer antes de se chocar com a rede cristalina, reduzindo sua massa efetiva, facilitando assim, a mobilidade para um dado campo elétrico. Para todos os comprimentos de canal acima, a mobilidade é sempre maior quando se faz o uso da técnica uniaxial.

A figura 6.16 apresenta as curvas $\mathrm{R}_{\text {TOTAL }} \mathrm{XL}$ para os dispositivos de referência e sob influência da técnica uniaxial, obtidas através de resultados simulados.

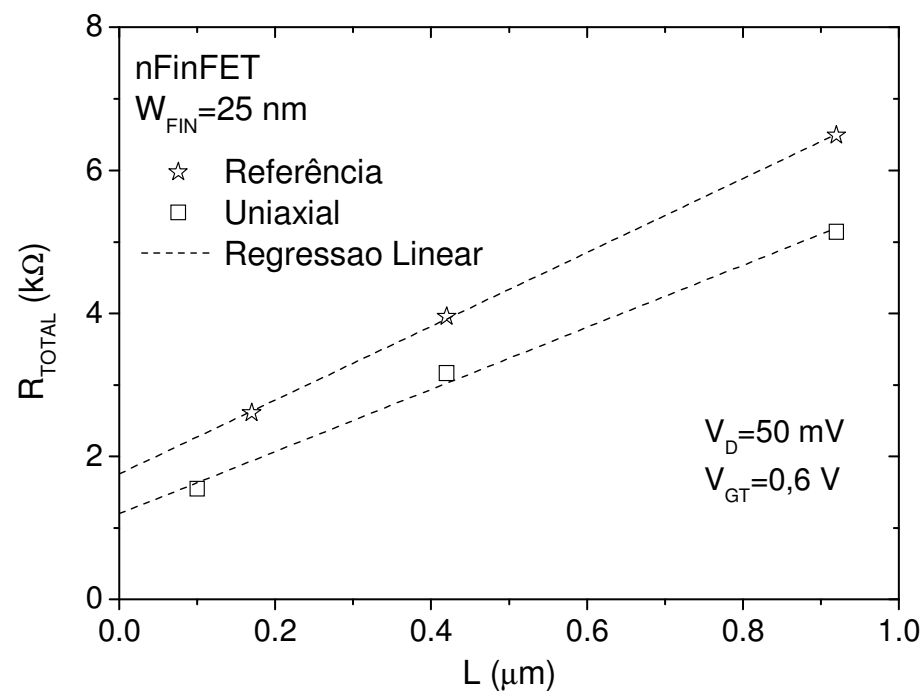

Figura 6. 16. Curvas da $R_{\text {TOTAL }}$ em função dos comprimentos de canal para estimar a $R_{S D}$ através da regressão linear dessas curvas para os dispositivos de referência e sob influência da técnica de deformação uniaxial.

A partir das curvas da figura 6.16, apresentando a $\mathrm{R}_{\text {TOTAL }}$ em função dos comprimentos de canal, obtidas através de simulações tridimensionais, nota-se que os dispositivos de canal tensionado apresentam menor resistência total em relação aos dispositivos de referência para todos os comprimentos de canal estudados, ou seja, um melhor comportamento da

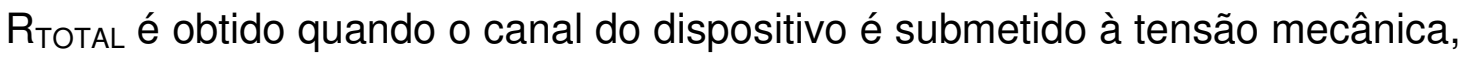


resultado do aumento da mobilidade e da condução de corrente devido à deformação uniaxial, diminuindo assim, a resistência da região do canal que para dispositivos com comprimento de canal longo representa uma parcela significativa dentro da $\mathrm{R}_{\text {TOTAL. }}$.

Para os resultados simulados, o uso da tecnologia de canal tensionado, apresenta uma redução de aproximadamente $32 \%$ no valor da resistência série estimada, enquanto que experimentalmente essa redução é de aproximadamente $48 \%$. Essa diferença pode estar relacionada a imprecisão nos ajustes dos parâmetros das componentes do modelo de mobilidade CVT, assim como, a diferença no processo de construção dos dispositivos simulados e reais.

Pode-se concluir então que os resultados simulados apresentam a mesma tendência obtida nos resultados experimentais, estando em concordância com o que foi estudado. 


\section{CONCLUSÕES DO TRABALHO}

Nesse trabalho, o estudo do comportamento da resistência série de fonte e dreno em transistores da tecnologia SOI nFinFETs de porta tripla foi apresentado. Transistores nFinFETs de porta tripla convencionais (de referência), transistores de canal tensionado (técnicas uniaxial e biaxial) e, com o uso de crescimento seletivo epitaxial (SEG) foram estudados.

Inicialmente, foi realizado o estudo de métodos de extração da resistência série de fonte e dreno, com o intuito de entendê-los e verificar quais deles poderiam ser aplicados em dispositivos avançados. Esses métodos primeiramente, foram aplicados em transistores nFinFETs de porta tripla convencionais. Através da aplicação desses métodos, em resultados obtidos por medidas experimentais e simulações numéricas tridimensionais desses dispositivos, observou-se que o método de Terada e Muta (método da extrapolação linear), foi que apresentou os valores mais confiáveis de resistência série de fonte e dreno. O método desenvolvido por Dixit, A. et, (método da exponencial de primeira ordem) para transistores de múltiplas portas, mostrou que há uma limitação desse método quando aplicado em transistores com comprimento de canal maiores. A partir de simulações, foi possível obter uma melhor compreensão do método da exponencial de primeira ordem, onde este se mostra mais confiável se aplicado em transistores com comprimento de canal menores.

Devido à limitação do método da exponencial de primeira ordem, foi definido que as análises posteriores da resistência série de fonte e dreno seriam feitas através da aplicação do método da extrapolação linear.

A partir da análise das principais características dos transistores sob influência da tensão mecânica na região do canal, verificou-se que o melhor comportamento da resistência total dos dispositivos com comprimento de canal longo foi obtido quando a técnica de deformação biaxial foi usada. Como resultado da redução do comprimento do canal nesses dispositivos, a técnica de tensionamento uniaxial mostrou-se mais eficiente, pois o tensionamento pôde ser transmitido de melhor maneira em dispositivos de canal curto.

Foi realizado, um estudo da resistência total em transistores com tensão mecânica na região do canal com e sem o uso da técnica de crescimento 
seletivo epitaxial. A partir desse estudo, resultados experimentais mostraram que transistores $\mathrm{nFinFETs}$ de porta tripla com SEG, apresentaram os menores valores da resistência total se comparado aos valores obtidos nos transistores sem SEG, devido à elevação das regiões de fonte e dreno diminuindo todas as resistências parasitas e, fornecendo assim, mais silício para a formação de silicetos de fonte e dreno. Quando SEG é usado, até mesmo dispositivos de referência apresentam um melhor comportamento da resistência total se comparado com transistores sob influência de tensão mecânica na região do canal sem SEG. Conseqüentemente, dispositivos com canal tensionado sem SEG, perdem suas vantagens como aumento da condução de corrente e da mobilidade dos portadores, resultando em um aumento da resistência total.

O comportamento da transcondutância também foi analisado e mostrou que os transistores sob a influência de tensão mecânica, apresentaram um aumento da transcondutância máxima devido ao aumento da mobilidade de baixo campo e, àqueles com SEG esse aumento foi obtido devido à diminuição da resistência total. Em transistores com comprimento de canal longo, analisando o comportamento da mobilidade através das curvas da transcondutância, o uso de SEG em transistores de referência e sob influência de tensão uniaxial, não apresenta muita vantagem, sendo que na técnica biaxial há um aumento de aproximadamente $10 \%$ na mobilidade dos portadores.

Dentre todos os dispositivos estudados, àqueles de referência (sem tensionamento e sem SEG) apresentaram o pior comportamento em todas as características estudadas.

Como sugestão de conseqüência deste trabalho, uma análise mais profunda da resistência série de fonte e dreno em estruturas com crescimento seletivo epitaxial e com canal tensionado poderia ser realizada, para análise desse importante parâmetro em dispositivos mais avançados, como por exemplo, o Bulk FinFET. 


\section{PUBLICAÇÕES GERADAS DURANTE O PERÍODO DE MESTRADO}

\subsection{Artigo em Congresso}

1 Analysis of the Total Resistance in Standard and Strained FinFETs Devices With and Without the Use of SEG. Talitha Nicoletti, João Antonio Martino, Eddy Simoen, Cor Clayes, In: Microelectronics Technology and Devices SBMicro - 2009 - Chip in the Dunes.

\subsection{Forum de Estudantes}

1 Improved Method to Extract the Parasitic S/D Resistance in Multiple-Gate FETs. Talitha Nicoletti, Salvador Pinillos Gimenez, João Antonio Martino, In: $8^{\text {th }}$ Microelectronic Students Forum - Sforum - 2008. 


\section{REFERÊNCIAS}

${ }^{1}$ MOORE, G. IEDM Tech. Digest, 1975. p. 11-13.

2 CHANG, L., et al. Moores's law lives on [CMOS transistor], IEEE Circuits and Devices Magazine, 2003. v. 19, n. 1.

${ }^{3}$ SEKIGAWA, T. HAYASHI, Y., Solid-State Electronics, v. 27, p. 827, 1984.

${ }^{4}$ HISAMOTO, D.; KAGA, T.; TAKEDA, E. IEEE Transactions on Electron Devices, 1991.

${ }^{5}$ HUANG, X., et al. Technical Digest of IEDM, p. 67, 1999.

${ }^{6}$ DOYLE, B. S., et al. IEEE Electron Device Letters, v. 24, n. 4, p. 263, 2003.

7 MAGNONE, P. in Microelectronic Engeneering, v. 85, p. 1728, 2008.

${ }^{8}$ COLINGE, J.P. Thin-Film SOI Technology: The Solution to Many Submicron CMOS Problems. Electron Devices Meeting, 1989.

9 STANLEY, T. D. The State-of-the-art in SOI Technology. IEEE Trans. On Nuclear Science, 1988. v. 35, p.1346-1349,

${ }^{10}$ KRULL, W. A.; LEE, J. C. Proceeding SOS/SOI Technology Workshop, 1989. p. 69.

${ }^{11}$ LIM, H. K.; FOSSUM, J. G. Threshold voltage of thin-film Silicon-on Insulator (SOI) MOSFETs. IEEE Transactions on Electron Devices, 1983. v. 30, n.10, p.1244-1451.

12 YOUNG, K. K. Short-channel effect in fully depleted SOI MOSFETs. IEEE Transactions on Electron Devices, 1989. v. 36, n. 2, p. 399-402.

${ }^{13}$ COLINGE, J. P. Subthreshold slope of Thin- Film SOI MOSFETs. IEEE Electron Device Letters, 1986. v. edl-7, n. 4.

${ }^{14}$ SHERONY, M. J., et al. SOI MOSFET Effective Channel Mobility. IEEE Transactions on Electron Devices, 1994. v. 41, n. 2.

${ }^{15} \mathrm{CAO}, \mathrm{M}$., et al. 0.18- $\mu \mathrm{m}$ Fully Depleted Silicon-On-Insulator MOSFETs. IEEE Electron Device Letters, 1997. v. 18, n. 6.

${ }^{16}$ COLINGE, J. P. Silicon-On-Insulator Technology. Materials to VLSI, 3 ed., Boston (MS): Kluwer Academic Publishers, 2004.

17 VEERARAGHAVAN, S.; FOSSUM J.G. Short-Channel Effects in SOI MOSFETs. IEEE Transactions on Electron Devices, 1989. v. 36, n. 3. 
18 SZE, S. M., Physics of Semiconductor Devices. New York, Wiley, 1981. $447 \mathrm{p}$.

${ }^{19}$ MANASEVIT, H. M.; SIMPSON, W. I. Journal of Applied Physics. v. 35, p. 1349, 1988.

${ }^{20}$ CHANG, L., et al. Moores's law lives on [CMOS transistor], IEEE Circuits and Devices Magazine, 2003. v. 19, n. 1.

${ }^{21}$ International Technology Roadmap for Semiconductors, SIA, 2001.

22 CHOI, Y. -K., et al. Sub $20 \mathrm{~nm}$ CMOS FinFET Technologies. IEEE Transactions on Electron Devices, v. 49, n. 3, p. 436-441, 1989.

${ }^{23}$ YANG, F. -L., et al. 35nm CMOS FinFETs, IEEE Transactions on Electron Devices, 2002.

24 MAGNONE, P. Gate Voltage Geometry Dependence of Series Resistance and of the Carrier Mobility in FinFET devices, Microelectronic Engeneering, 2008.

${ }^{25}$ COLINGE, J. P. Multiple-Gate SOI MOSFETs. Solid-State Electronic, 2004. v. 48 , n. 6 , p. $897-905$.

${ }^{26}$ FRANCK, D., et al. IEDM Tech Dig, 1992.

${ }^{27}$ HISAMOTO, D., et al. IEEE Transactions on Electron Devices, 1991.

${ }^{28}$ HISAMOTO, D., et al. IEDM Tech. Digest, 1998.

29 CRISTALOVEANU, S. Silicon-on-Insulator Technology, 2006.

30 CHAU, R., et al. Advanced depleted-substrate transistors: single-gate, double-gate and tri-gate. Int. Conf. on Solid State Dev. and Mat, 2002.

${ }^{31} \mathrm{YU}, \mathrm{B}$., et al. FinFET scaling to $10 \mathrm{~nm}$ gate length. IEDM, 2002.

${ }^{32}$ WANG, H., et al. The behavior of narrow-width SOI MOSFETs with MESA isolation. IEEE Trans Electron Dev, 2000.

33 XIONG, W., et. al.. Corner Effect in Multiple-Gate SOI MOSFETs. In: SOI Conference IEEE International. p. 111-113, 2003.

34 RODRIGUEZ, M., et. al.. Corner Effect on Capacitance-Voltage Curves in Triple-Gate FinFET, in press: SBMicro 2008.

${ }^{35}$ COLINGE, J. P., Microelectronic Engineering, v. 84, p. 2071, 2007. 
${ }^{36}$ COLINGE, J. P., FinFETs and Other Multi-Gate Transistors, 1 ed., 2008.

37 COLINGE, J. P., Novel Gate Concepts for MOS Devices. Proceedings of ESSDERC, v. 45, 2004.

38 YAN, R. H., et al. IEEE Transactions on Electron Devices, v. 39, p. 1704, 1992.

${ }^{39}$ CONDE, O.A., et al. A review of recent MOSFET threshold voltage extraction methods. Microelectronics Reliability, v. 42, p. 583-596, 2002.

40 TERAO, A. et al. IEEE Electron Devices Letters, v. 12, p. 682, 1991.

41 ANDRADE, M. G. C.; MARTINO, J. A., Threshold Voltages of Double and Triple Gate SOI FinFETs. EUROSOI 2008 - Conference Proceedings, 2008.

${ }^{42}$ XIONG, W., et al. Proceedings of the IEEE International SOI Conference, p. $111,2003$.

${ }^{43}$ COLINGE, J. P., et al. IEEE Electron Device Letters, v. 28, n. 8, p. 515, 2003.

${ }^{44}$ NICOLETT, A. S., et al. Extraction of the lightly doped drain concentration of fully depleted SOI nMOSFETs using the back gate bias effect. Solid-State Electronics, v. 44, p. 677-684, 2000.

${ }^{45}$ SHEU, B. J., et al. Source and Drain series resistance of LDD MOSFET's. IEEE Electron Device Letter, v. EDL-5, p. 365, 1984.

46 SEAVEY, M. H. Source and drain resistance determination for MOSFET's. IEEE Device Letters, v. EDL-5, p. 479, 1984.

${ }^{47} \mathrm{HU}, \mathrm{G}$. J., et al. Gate-Voltage-Dependent Effective Channel Length and Series Resistance of LDD MOSFET's. IEEE Transactions on Electron Devices, v. ED-34, 1987.

${ }^{48}$ ANTONIADIS, D. A. MOSFET scalability limits and 'new frontier' devices. VLSI Tech. Dig., p. 2-5, 2002.

49 DIXIT, A. et al. Analysis of the Parasitic S/D Resistance in Multiple-Gate FETs. IEEE Transactions on Electron Devices, v. 52, n. 6, 2005.

50 TERADA, K., MUTA, H. A New Method to Deternine Effective MOSFET Channel Length. JAPANESE JOURNAL OF APPLIED PHYSICS, v. 18, n. 05, p. 953-959, 1979.

${ }^{51}$ SUN, J. Y.-C., et al. On the accuracy of channel Length characterization of LDD MOSFET's, IEEE Transactions on Electron Devices, v. ED-33, n. 10, 1986. 
52 DIXIT, A. FEOL CMOS Process- and Device-Parasitics in SOI-MuGFETs. Tese (Doutorado) - Universidade Católica de Leuven. Leuven - Bélgica, 2007.

53 ISE-TCAD, User's Manual, 2004.

54 WELSER, J. J.; HOYT, J. L.; GIBBONS, J. F. Electron Mobility enhancement in strained-Si n-type metal-oxide-semiconductor field-effect-transistor. IEEE Electron Device Letters, v. 15, n. 3, 1994.

55 RIM, K.; et al. Enhanced Hole Mobilities in Surface-channel Strained-Si pMOSFETs. International Electron Devices Meeting, p. 517,1995.

56 SVERDLOV, V. et al. Impact of Confinement of Semiconductor and Band Engineering on Future Device Performance. ECS Transaction, v. 19 n. 4, 2009

57 PARTON, E.; VERHEYEN, P. Strained Silicon - the key to sub-45 $\mathrm{nm}$ CMOS. III-Vs review. Adv Semiconductor Magazine, v. 19, n. 3, 2006

58 ITRS roadmap: http://public.itrs.net

${ }^{59}$ MAITI, C. K.; MAITI, T. K..; MAHATO, S. S. Strained engineered MOSFETs. Semiconductor India.

${ }^{60}$ GALLON, C. et al. Mechanical and electrical analysis of strained liner effect in $35 \mathrm{~nm}$ fully depleted silicon-on-insulator devices with ultra thin silicon channels. Japanese Journal Applied Physics, v. 45, 2006.

${ }^{61}$ MIZUNO, T. et al. High performance strained-SOI CMOS devices using thin film SiGe-on-insulator technology. IEEE Transaction Electron Devices, v. 50, n. 4, 2003.

62 MISTRY, K. et al. Delaying Forever: Uniaxial Strained Silicon Transistors in a $90 \mathrm{~nm}$ CMOS Technology. Symposium On VLSI Technology Digest of Technical Papers, p. 50, 2004.

63 THOMPSON, S. E. et al. A Logic Nanotechnology Featuring Strained-Silicon. IEEE Electron Device Letters, v. 25, n. 4, 2004.

64 ANDRIEU, F. et al. In-Depth Study of Strained SGOI nMOSFETs down to 30nm Gate Length. Proc. de ESSDERC, p. 297, 2005.

${ }^{65}$ RIM, K. et al. Characteristics and Device Design of Sub-100 nm Strained Si $\mathrm{N}$ - and PMOSFETs. Symposium On VLSI Technology Digest of Technical Papers, p. 98, 2002.

66 AUGENDRE, E. et al. On the Scalability of Source/Drain Current Enhancement in Thin Film sSOI. Proc. de ESSDERC, p. 301, 2005. 
${ }^{67}$ MOHTA, N., THOMPSON S. E. Strained Si-The Next Vector to Extend Moore's Law. IEEE Circuits and Devices Magazine, v. 21, n. 5, 2005.

${ }^{68}$ KAVALIEROS, J. et al. Tri-Gate Transistor Architecture with High-k Gate Dielectrics, Metal Gates and Strain Engineering. Symposium On VLSI Technology Digest of Technical Papers, p. 50, 2006.

69 KEDZIERSKI, J. et al. Extension and Source/Drain Design for HighPerformance FinFET Devices. IEEE Transactions on Electron Devices, v. 50, n. 4, 2003.

${ }^{70}$ OHGURO, T. et al. $0.12 \mu \mathrm{m}$ raised gate/source/drain epitaxial channel NMOS technology. International Electron Devices Meeting, p. 927,1998.

${ }^{71}$ HOKAZONO, A. et al. Souce/Drain engineering for sub-100 nm CMOS using selective epitaxial growth technique. International Electron Devices Meeting, p. 243,2000 .

${ }^{72}$ COLLAERT, N. et al. Multi-Gate Devices for the $32 \mathrm{~nm}$ Technology Node and Beyond: Challenges for Selective Epitaxial Growth. Solid-States Electronics, v. 52, n. 9, 2008.

${ }^{73}$ REN, $Z$ et al. An experimental study on transport issues and electrostatics of ultrathin body SOI pMOSFETs. IEEE Electron Device Letter, v. 23, p. 609, 2002.

${ }^{74}$ HUANG, X. et al. Sub 50-nm FinFET: PMOS. International Electron Devices Meeting, p. 67, 1999.

75 -YUAN, C. Z. et al. Electron mobility enhancement in strained-Si n-MOSFETs fabricated on SiGe-on-insulator (SGOI) substrates. IEEE Electron Device Letter, v. 22, p. 321, 2001.

${ }^{76}$ ATLAS, Device Simulation User's Manual, Silvaco International

77 TERAO, A. et al. Measurement of threshold voltages of Thin-Film Accumulation-Mode SOI MOSFETs. IEEE Electron Device Letters, v. 12 p. 682, 1991. 